\author{
Marquette University \\ e-Publications@Marquette
}

\title{
Pediatric Oncology Nurses' Experiences with Prognosis-Related Communication
}

Amy Rose Newman

Marquette University

Follow this and additional works at: https://epublications.marquette.edu/dissertations_mu

Part of the Health Communication Commons, Oncology Commons, and the Pediatrics Commons

\section{Recommended Citation}

Newman, Amy Rose, "Pediatric Oncology Nurses' Experiences with Prognosis-Related Communication" (2017). Dissertations (1934 -). 699.

https://epublications.marquette.edu/dissertations_mu/699 


\section{PEDIATRIC ONCOLOGY NURSES' EXPERIENCES WITH PROGNOSIS-RELATED COMMUNICATION}

by

Amy R. Newman, MSN, RN, CPNP-PC, CPHON®

A Dissertation submitted to the Faculty of the Graduate School, Marquette University, in Partial Fulfillment of the Requirements for the Degree of Doctor of Philosophy

Milwaukee, Wisconsin

May 2017 


\title{
ABSTRACT \\ PEDIATRIC ONCOLOGY NURSES' EXPERIENCES WITH PROGNOSIS-RELATED COMMUNICATION
}

\author{
Amy R. Newman, MSN, RN, CPNP-PC, CPHON® \\ Marquette University, 2017
}

Health care providers (HCPs) in pediatric oncology are faced with the challenge of communicating the devastating news of a cancer diagnosis and prognosis. This type of communication can be referred to as prognosis-related communication (PRC). While the initial conversation with the patient and family regarding prognosis is generally considered the responsibility of the physician, patients and family members will subsequently turn to nurses for clarification of the information presented. If nurses are excluded from initial conversations, they may feel as though they are "working in the dark," trying to answer questions while not contradicting what the physician said. This strained communication limits the nurse's ability to fully advocate and care for patients. Little has been reported regarding pediatric oncology nurses' experiences with PRC.

A cross-sectional survey design framed by the Quality Care Model $\odot$ was used to examine 1) nurses' experiences with PRC with parents of children with cancer; 2) factors associated with experiences; and 3) associations with interprofessional collaboration, quality of care, and moral distress. Three hundred and sixteen members of the Association of Pediatric Hematology/Oncology Nurses completed an online survey containing measures of study variables. Correlation and regression were used to explore relationships among variables. Findings demonstrated that nurses strongly agreed that prognostic disclosure is critical for decision making, but are challenged in determining their role. Nurses who had more years of experience, more training in PRC, worked outpatient or inpatient/outpatient, and indicated higher levels of collaboration reported more positive experiences with PRC. A significant correlation was identified between experiences with PRC and collaboration, and both were significantly associated with measures of quality of care and moral distress.

Implications for nursing practice, education and research are identified. Nurses should work to be active participants in PRC. When nurses sense that prognostic discussions have not occurred or if clarity is needed, nurses should feel confident in approaching physician colleagues to ensure parent understanding and satisfaction around communication. Future research and education should aim to develop interprofessional training to enhance communication and collaboration among nurses and physicians to ensure the highest quality of communication and care to patients and families. 


\title{
ACKNOWLEDGEMENTS
}

\author{
Amy R. Newman, MSN, RN, CPNP-PC, CPHON®
}

I have been incredibly blessed in that God has placed so many supportive and influential family members, friends and mentors in my life. It is with their ongoing strength and unwavering support that I have achieved what, at times, seemed impossible. I would like to thank Mark for the never-ending support that he has provided to me as my husband, best friend, and co-parent. I could not have accomplished this goal without his love, strength, and supportive nature. He has always believed in me, even when I have not believed in myself, and this has propelled me forward. I would like to thank Isaac for inspiring me and always making me smile. His never-ending energy and love of life are infectious.

I would like to thank my parents, Wayne and Marilyn, for always encouraging me and challenging me to do my best and achieve more. Both are students of life, and have served as exemplary role models of how to try and make the world a better place. In addition, they have instilled in me and nurtured my faith in God, which provides the foundation for all that I do.

I would also like to thank my sister, Ann, and her husband, Ryan, as well as their sons, Tyler, Aiden, and Harrison. As a family, they have supported me every step of this journey, always encouraging me, believing in me, and listening to me whenever I needed them to. The boys served as an ongoing source of laughter, joy, and love, which feeds the soul.

I would like to thank my dear friend, Christine, for always listening, advising, and cheering me onward. Her insights and support have been invaluable.

I am thankful to have started my nursing career at Texas Children's Hospital, where I had the opportunity to work with Dr. Marilyn Hockenberry, the late Dr. Nancy Kline, and Dr. Cheryl Rodgers. Each of them have inspired me in different ways, but each made me realize the significant contributions that nurse scientists can make in the field of pediatric oncology. Further, they helped me believe in myself and my potential.

I would like to thank Dr. Marianne Weiss for her relentless support and encouragement. Her dedication to nursing and research are glaringly obvious in everything she does, and her knowledge is vast! I credit her with moving me forward by leaps and bounds during my program. She too helped me to believe in myself, and never doubt my potential. She has been an amazing source of support, is always available, and has helped me develop into a budding nurse scientist.

I would also like to thank Dr. Callahan for being an inspiration and role model. Her accomplishments and achievements are vast, and she is an incredible advocate for nursing. Her leadership and support have been instrumental in my development. I would also like to acknowledge the other members of my dissertation committee, Dr. Stacee Lerret and Dr. Debra Oswald, for their commitment to my success.

Finally, I am thankful for all of the pediatric oncology nurses who participated in my study, and all of the patients and families who have inspired me over the course of my career. 


\section{TABLE OF CONTENTS}

ACKNOWLEDGEMENTS. ..i

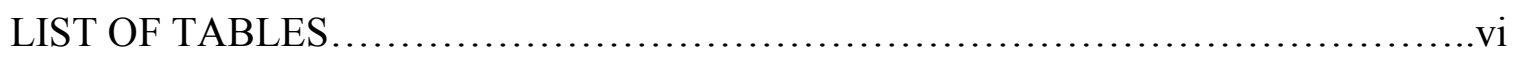

LIST OF FIGURES.....................................................vii CHAPTER

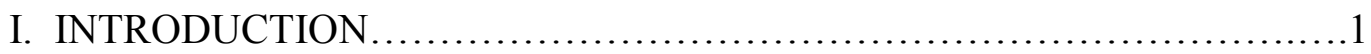

Problem Statement \& Purpose....................................... 3

Significance to Nursing........................................

Significance to Nursing Education.................................4

Significance to Nursing Research.................................5

Significance to Vulnerable Populations................................5

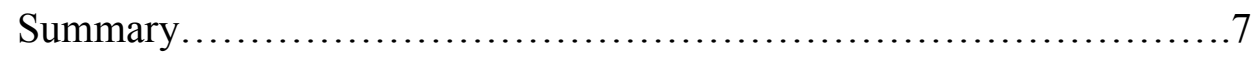

II. REVIEW OF THE LITERATURE.....................................9

Conceptual \& Philosophical Underpinnings........................9

Philosophical Underpinnings............................ 9

Conceptual-Theoretical-Empirical Structure...................16

Review of the Literature......................................22

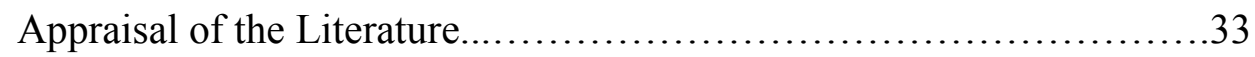

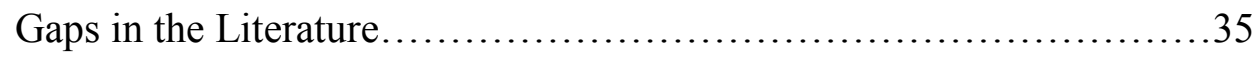

Assumptions................................................ 37

Purpose $\&$ Specific Aims......................................... 38

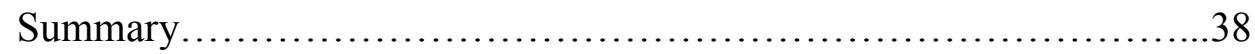

III. RESEARCH DESIGN AND METHODS ..............................40

Research Design...........................................40

Specific Aims with Research Questions \& Hypotheses..........41 
Specific Aim 1

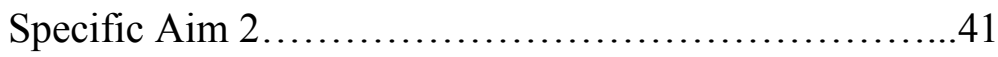

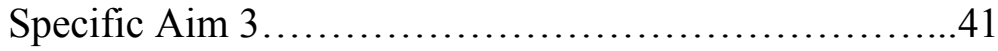

Sample \& Setting...........................................43

Study Variables \& Instruments ..........................46

Prognosis-Related Communication in

Oncology Nursing.................................46

Collaborative Behavior Scale.......................48

Nurses' Assessment of Quality Scale..................49

Moral Distress Scale - Revised......................51

Demographic Questionnaire..........................53

Data Collection Methods.............................................53

Methodological Rigor..........................................55

Statistical Procedures \& Rationale.................................61

Human Subjects Protection......................................63

Limitations..................................................64

Summary.................................................65

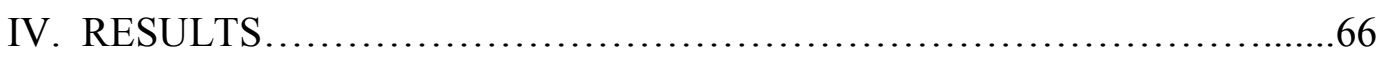

Demographics..............................................66

Scale Characteristics...........................................70

Preliminary Screening of Data............................. 70

Scale Statistics..............................................73

Additional Details on Findings for Hypotheses........................76

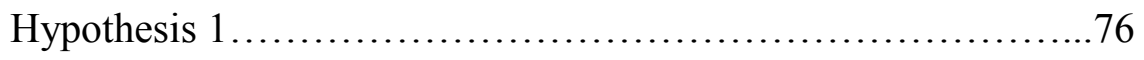




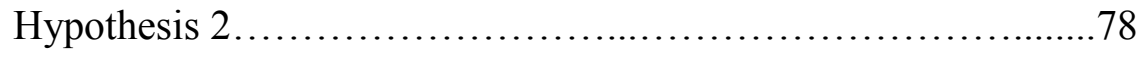

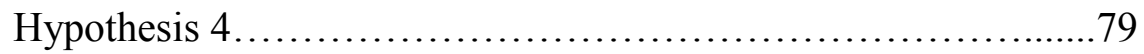

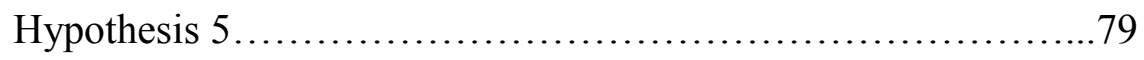

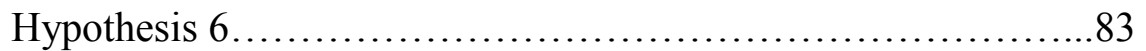

Additional Analyses..............................................83

Psychometric Evaluation of PRCON......................83

Psychometric Evaluation of NAQS-ACV ........................86

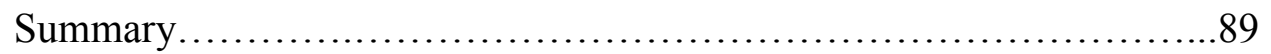

V. DISCUSSION ................................................ 90

Interpretation of Findings.................................... 90

Demographics......................................... 90

Scale Statistics.........................................91

High \& Low Scoring Items.........................91

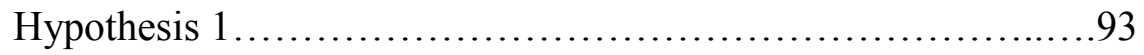

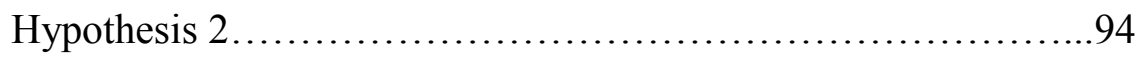

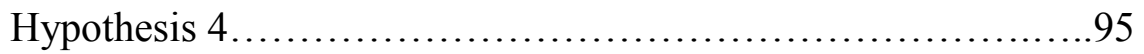

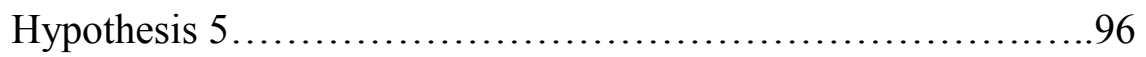

Additional Analyses......................................97

Psychometric Evaluation of PRCON..................97

Psychometric Evaluation of NAQS-ACV ..............98

Theoretical Implications of Findings.................................98

Methodological, Theoretical, and/or Statistical Implications

of Findings......................................................... 100 
Relationship between Findings, Previous Research, and the Theoretical/Conceptual Framework/Model.........................101

Implications for Nursing Practice.............................101

Implications for Vulnerable Populations.......................102

Implications for Nursing Education..............................104

Implications for Nursing Research............................107

Strengths and Limitations..................................... 108

Conclusion................................................... 108

REFERENCES.........................................................110

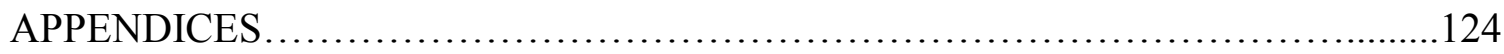

A. Manuscript I................................................. 124

B. Manuscript II..................................................... 125

C. Prognosis-Related Communication in Oncology Nursing.................126

D. Collaborative Behavior Scale - Part A............................... 128

E. Assessment of Nursing Care Scale................................... 130

F. Moral Distress Scale - Revised, Pediatric Version.......................131

G. Demographic Questionnaire..................................... 132

H. Manuscript III............................................... 134 


\section{LIST OF TABLES}

1. Conceptual-Theoretical-Empirical Structure................................22

2. Sample Size Estimates...............................................44

3. "Other" Race Category..................................................67

4. Comparison of Sample \& National APHON Member Characteristics...............69

5. Top \& Low Scoring Items on Each Instrument.................................. 74

6. PRCON Scores \& Individual Nurse Factors...................................76

7. PRCON RN Role Subscale \& Individual Nurse Factors...........................77

8. Comparison of CBS Scores by Race...................................... 79

9. Categories of Morally Distressing Situations ................................ 81

10. Correlation between MDS-R \& NAQS-ACV Subscales.............................83

11. PRCON Inter-Item \& Inter-Scale Correlations...............................85

12. NAQS-ACV Inter-Item \& Inter-Scale Correlations............................ 88 


\section{LIST OF FIGURES}

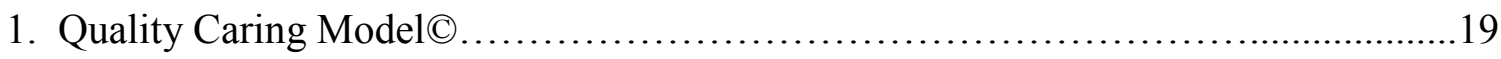

2. Theoretical Model.........................................................21

3. Analytic Model............................................................. 42 


\section{Chapter 1: Introduction}

Approximately 10,380 children were diagnosed with cancer in the United States in 2015 (American Cancer Society, 2016). Health care providers (HCPs) specializing in pediatric oncology are faced with the challenge of communicating with children and their parents the devastating news of the diagnosis. HCPs including nurses are charged with not only communicating with parents and children about the disease and its treatment, but also the prognosis associated with the cancer and cancer treatment (Mack, Wolfe, Grier, Cleary, \& Weeks, 2006). This type of communication can be referred to as prognosisrelated communication. Such information often incorporates the revelation of likelihood of cure, how long the child is anticipated to live, and the kind of life the child is expected to have (Mack et al., 2006). While the initial conversation with the patient and family regarding prognosis is generally considered the purview of the physician (Dewar, 2000), patients and family members will subsequently turn to the nursing staff for clarification of the information that was presented (Rassin, Levy, Schwartz, \& Silner, 2006).

Prognosis-related communication has been found to enhance decision-making by patients and parents, reduce uncertainty, engender hope, and empower patients to live their lives (Butow, Dowsett, Hagerty, \& Tattersall, 2002; Lamont \& Christakis, 2003; Mack \& Joffe, 2014). Conversely, lack of prognostic disclosure can result in more stress, frustration, and uncertainty among patients and families (Innes \& Payne, 2009). Not knowing the prognosis can often be more difficult than knowing, as uncertainty allows one's worst fears to take precedence (Mack \& Joffe, 2014). Foregoing prognosis-related discussions can lead to false optimism and significant discrepancies between patient and physician estimates of survival. Such discrepancies can lead patients and families to 
pursue futile care that may impact quality of life, delay referral for palliative care services, and limit end-of-life care planning (Hancock et al., 2007; Innes \& Payne, 2009). Finally, lack of disclosure can leave patients and families feeling abandoned by their care providers, mistrustful of their healthcare team, and less hopeful (Innes \& Payne, 2009; Mack et al., 2007).

Lack of communication between the physician and nurse regarding prognosis can have a negative impact on the nurse. If nurses are excluded from the initial conversation that occurs between the physician and the patient regarding diagnosis and prognosis, they may feel as though they are "working in the dark" (McLennon, Uhrich, Lasiter, Chamness, \& Helft, 2013, p. 119), trying to answer patient and family questions while not contradicting what the physician said. This strained communication limits the nurse's ability to fully advocate and care for patients (Tobin, 2012). Lack of interprofessional communication surrounding prognosis also requires the nurse to exert an incredible amount of effort gathering and clarifying information for patients and families rather than addressing patient care and other psychosocial needs (Wittenberg-Lyles, Goldsmith, \& Ferrell, 2013). Nurses also report anger and frustration when such delicate information is presented by the physician without compassion or in a location that did not allow for privacy (Dunniece \& Slevin, 2000; Griffiths, Ewing, Wilson, Connolly, \& Grande, 2015).

In order to fully engage and support parents and provide a consistent message, nurses must be included in key discussions regarding a patient's diagnosis and prognosis. Without communication and collaboration with physician colleagues and clear direction regarding their role in the process of prognosis-related communication, nurses may experience moral distress, which can constrain their ability to effectively communicate 
with parents of children with cancer (Tobin, 2012). This lack of open communication can negatively impact parental decision making and the maintenance of hope, which parents have identified as being critical to coping with the diagnosis and its treatment (Mack et al., 2007). Explicating the role of the pediatric oncology nurse in the process of prognosis-related communication is essential to ensuring excellence in nursing care within an interprofessional care model and a quality health care experience for patients with cancer and their families.

\section{Problem Statement and Purpose}

Limited research has been performed exploring the concept of prognosis-related communication in the pediatric oncology population. Nurses are believed to play a critical role in this process, but this remains unexplored in the pediatric oncology population. Further, the pediatric oncology nurse's experience with this process has not been reported. The purpose of this research was to examine nurses' perceptions of their experiences with prognosis-related communication with parents of children with cancer, factors associated with their perceptions and experiences, and the associations with interprofessional collaboration, nurse moral distress, and quality of care. The long-term goal is to apply this knowledge to improving the care of children and families during the process of prognosis-related communication.

\section{Significance to Nursing}

The information gleaned from this research has the potential to impact nursing practice, education, and research in a meaningful way. From a practice perspective, the perceived role of the nurse in the process of prognosis-related communication will be 
described. This understanding along with determination of collaborative behaviors that exist between physicians and nurses will provide the foundation to better clarify the roles of different members of the healthcare team in the process of prognosis-related communication. Better clarity regarding the nurse's role in the process along with an understanding of factors that may improve the nurse's experience will guide the development of individual and interprofessional interventions to empower nurses in this process with the ultimate goal of improving patient and family care. In addition, revelations about the nurse's role in prognosis-related communication and interprofessional collaboration will empower nurses to more actively participate in interprofessional care processes, which may reduce the distress they experience in this process, and improve the general care of children with cancer and their families.

\section{Significance to Nursing Education}

Most nurses indicate that they have never received education or training on the delivery of prognostic information or what is often referred to as the "breaking of bad news." This concept of breaking bad news is used throughout the literature, and has been defined by Buckman (1992) as "any news that drastically and negatively alters the patient's view of his or her future" (p. 15). Data collected from this study specifically documented pediatric oncology nurses' education surrounding the topic of prognosisrelated communication. Assessment of knowledge deficits will guide the development of educational interventions to ensure that nurses have the requisite knowledge to engage and feel empowered to participate in the process of prognosis-related communication. As potential barriers to nurse participation in prognosis-related communication are identified, education can be focused on providing nurses with the knowledge and 
expertise they need to overcome barriers to ensure that patients and families receive the highest quality of care. Armed with such knowledge, nurses can educate their physician colleagues regarding the nurse's role in the process, working to explore interventions to ensure that collaborative methods are used to provide patients and families with essential information in a manner that is empathetic and supportive. Finally, this knowledge can be transmitted to schools of nursing to ensure faculty are preparing nurses to participate in such critical and sometimes difficult conversations in an interprofessional manner.

\section{Significance to Nursing Research}

The results of this study provide the impetus for further research in this area. The nurse's perceived role in the process must first be reconciled with the expectations and needs of other members of the healthcare team along with those of patients and families. Once roles have been better established, intervention work utilizing different educational approaches for nurses and strategies for developing interprofessional team practices can be explored along with different methods of sharing prognosis-related information with patients and families. Identifying the methods that best support the process of prognosisrelated communication is essential to ensuring high quality care and support to patients and families throughout their illness experience. Ultimately, the impact of such interventions on patient, family, and health care outcomes can be measured.

\section{Significance to Vulnerable Populations}

In the context of nursing, the term "vulnerable populations" refers to groups of people who are at risk of adverse health outcomes. All human beings are considered to be vulnerable; what Sellman (2005) refers to as "ordinary vulnerability" (p. 3). When a 
person requires the services of health care providers and systems, the person is considered to be "more than ordinarily vulnerable" (p. 4) due to his or her increased exposure to potential harm and reduced capacity for self-protection. In caring for patients, the nurse is positioned to provide protection against patient vulnerabilities, and consequently also promote human flourishing.

Parents of children with cancer are extremely vulnerable to a number of physical, psychosocial, emotional and spiritual harms particularly at the time of a new diagnosis or recurrence. A child's cancer diagnosis can be overwhelming and devastating for parents. Most parents have little to no experience or knowledge regarding childhood cancer and its treatment. Upon hearing that their child has cancer, parents fear the worst, that is, that their child will die (Compas et al., 2015). Their lives become filled with uncertainty as they venture into unknown territory. Consequently, a proportion of parents of children with newly diagnosed cancer have been found to have generalized emotional distress including symptoms consistent with post-traumatic stress, anxiety, and depression (Dunn et al., 2012; Muscara et al., 2015). This distress can impair parents' abilities to listen and receive critical information regarding a child's diagnosis, prognosis, and treatment. Findings suggest that parental subjective appraisal of their child's illness including understanding of the diagnosis and its impact on the child's life has more of an impact on long-term parental outcomes than objective factors of the child's illness (Muscara et al., 2015). Therefore, how diagnostic and prognostic information are presented to parents is critical. Information must be presented accurately and consistently by all members of the healthcare team in a family-centered fashion. The results of this study provide the foundation to understand how nurses can work collaboratively to ensure that parents get 
the information they need to develop an accurate understanding of their child's diagnosis and prognosis. Accurate understanding is critical for parents to make informed decisions regarding their child's care, to come to some resolution regarding their child's diagnosis, and to have hope (Popp, Conway, \& Pantaleao, 2015).

Interestingly, at times, nurses also become vulnerable in a variety of different ways. Unfortunately because of the many hierarchical structures within health care, the role of the nurse in the process of prognosis-related communication often goes unnoticed. Warnock et al. (2010) warn that the role of the nurse risks being overlooked if his or her contribution is not identified, recognized, or valued. Dewar (2000) adds that because the nurse's role in this setting is often played out in an ad hoc manner, it risks being invisible, and therefore not valued. This invisibility places the nurse in a vulnerable position; one in which he or she is often subservient to the actions and decisions of the physician. Without better clarification and illumination of the nurse's role in this process and what the nurse can contribute to positive patient outcomes, the role of nursing is marginalized. Results of this study will clarify and highlight the role of the nurse in this process as well as modifiable factors and barriers that may contribute to nurse participation in prognosisrelated communication.

\section{Summary}

Research targeting prognosis-related communication in the pediatric oncology population and the perceptions of these experiences by pediatric oncology nurses are glaringly absent. The proposed study served to address this gap by describing nurses' perceptions of their experiences with prognosis-related communication with parents of 
children with cancer and the potential impact of such experiences. The goal was to also identify the interplay between these perceptions and nurses' experiences with interprofessional collaboration, moral distress, and quality patient care. Backed with this knowledge, changes in practice can be made to enhance interprofessional collaboration with the goal of improved provider communication and optimal patient care. Further it is hypothesized that if nurses are better prepared and empowered to communicate with parents throughout this process, they will describe an increased ability to provide quality care to patients and their families. 


\section{Chapter 2: Review of the Literature}

Chapter Two, "Review of the Literature," includes a description of the theoretical framework and a review of the literature on nurses' experiences with prognosis-related communication. This review is divided into the following sections: a) Conceptual and philosophical underpinnings, b) review of the literature with definitions of concepts, c) appraisal of the current literature, d) summary of gaps in the literature, e) assumptions, and f) purpose and specific aims.

\section{Conceptual and Philosophical Underpinnings}

\section{Philosophical Underpinnings}

Nursing is both a discipline and a professional practice (Parse, 1999; Reed, 1997).

"The goal of the discipline is to expand knowledge about human experiences through creative conceptualization and research" (Parse, 1999, p. 275). This knowledge then functions as the scientific guide to the art of nursing practice (Parse, 1999). Carper's (1978) seminal work described four different patterns of knowing in nursing: empirics (the science of nursing), esthetics (the art of nursing), ethics (the component of moral knowledge in nursing), and the component of a personal knowledge in nursing. White (1995) expanded this list to include sociopolitical knowing, which incorporates the context of persons (the nurse and patient) and the context of nursing as a practice profession. Knowledge is therefore generated by an interaction of each of these ways of knowing; each informing the other (Monti \& Tingen, 1999). Empirical knowing is concerned with describing, explaining, and predicting phenomena, in the case of nursing, as it relates to human beings. 
In approaching empirical knowing, one must examine his or her own thoughts about how knowledge is generated. Paradigms provide a worldview or philosophy of science that set the stage for how one views the nature of reality (ontology) and what constitutes knowledge and ways of knowing (epistemology) (Racher \& Robinson, 2003). Subsequently, paradigms determine how one approaches research, and from these philosophical underpinnings, specific research methodologies flow. A number of different paradigms exist to guide nursing research.

This study was grounded in the post-positivist paradigm, but was also influenced by critical theory. A review of the post-positivist paradigm is presented along with rationale for why this paradigm supported the exploration of nurses' experiences with prognosis-related communication. Critical theory is also reviewed. The ontology, epistemology, and methodology associated with each will also be described.

Post-positivism was generated in response to critical appraisal of the positivist paradigm. Within the positivist paradigm, the aim of science is to identify the true nature of reality, and further to predict and control natural phenomena (Guba, 1990). The researcher maintains an objective position, adopting a distant, non-interactive approach, thus eliminating potential bias and value judgments when evaluating outcomes. Empirical experimentalism is the methodology relevant to positivism, aiming to control any potential confounding variables. Questions or hypotheses are stated in advance in propositional form, and are subjected to empirical tests (Guba, 1990). Methods aim to verify hypotheses, and replication studies are encouraged.

Post-positivism is described as a modified version of positivism. Prediction and control remain the aim. Although realism remains the central concept, post-positivism 
recognizes that it is impossible for humans to truly perceive natural cause and effect with their imperfect senses and intellect. Thus, recognizing these limitations, post-positivists are critical of their work, acknowledging that "one can never be sure that ultimate truth has been uncovered" (Guba, 1990, p. 20). Further post-positivists recognize complete objectivity on the part of the researcher is impossible, and therefore, espouse a modified objectivity. Post-positivists also reject the assumption that an absolute source of knowledge exists and that findings can be proven to be true, rather they are falsified. Finally, the concept of discovery is permitted within the post-positivist paradigm, inviting insider viewpoints to enhance understanding of meanings and purposes that people ascribe to actions (Racher \& Robinson, 2003).

Critical theory is inspired by the writings of Marx, Habermas, Freire, and Foucault, and is thought to be emancipatory in nature. Critical theorists contend that knowledge is generated within oppressive systems, and thus, has become so embedded in every day practice that knowledge has become a distortion and misrepresentation of true human experiences and desires (Freeman \& Vasconcelos, 2010). Thus, the aim of the critical paradigm is emancipation and the development of practical knowledge to help understand the world through the eyes of the oppressed. Critical theory contends that theory and practice are not separate entities, but rather are "embodied in praxis, in the way that humans act out their theoretical versions of the world" (Freeman \& Vasconcelos, 2010, p. 9).

Paradigms are characterized by their ontological, epistemological, and methodological assumptions (Guba, 1990). When exploring the ontological assumptions of a paradigm, one questions, "What is the nature of the 'knowable'? Or, what is the 
nature of 'reality'?" (Guba, 1990, p. 18). Post-positivists maintain a realist ontology, that is, the belief that there exists a true reality, which is independent of human perception of it (Weaver \& Olson, 2006). While absolute truth cannot be established, relationships among variables can be clarified and supported and generalizable patterns described (Jackson, 2015; Monti \& Tingen, 1999).

From an ontological perspective, critical theory also holds that a true reality exists, but that truth is deeply embedded within oppressive systems and therefore not known. Critical theorists contend that truth has been shaped by social, political, cultural, gender, and economic factors (Weaver \& Olson, 2006), and that inequalities have been accepted as natural occurrences (Freeman \& Vasconcelos, 2010).

Guided by the Quality-Caring Model@ (Duffy \& Hoskins, 2003) and a postpositivist paradigm, a priori hypotheses were established to explore relationships among individual nurse factors, prognosis-related communication, and outcome variables. Soliciting nurses' experiences with this process allowed for the clarification of the relationships and patterns among the variables including demographic factors, prognosisrelated communication, interprofessional collaboration, moral distress and perceived quality of care.

Obtaining the nurse's perspective of this process was further guided by critical theory. The hierarchies within medicine and healthcare can place nurses in positions which make them subservient to physicians in a medically driven culture. The role and the responsibility of the nurse, particularly as it relates to prognosis-related communication, may not always be appreciated or supported, and further may cause the nurse to doubt his or her actions, authority, and responsibility (Jameton, 1993). This 
oppression may cloud the real truth regarding the process of prognosis-related communication and the nurse's role and potential contributions to this process. Allowing nurses to reflect on the contributing factors, the process, and outcomes as guided by the Quality-Caring Model@ , will provide the first steps toward unveiling their truth. Further, the Quality-Caring Model $\odot$ merges an empirical perspective with a social-humanistic perspective, which is congruent with the philosophical underpinnings of the proposed research.

Epistemological assumptions of each paradigm answer the question of "What is the nature of the relationship between the knower (the inquirer) and the known or knowable)?" (Guba, 1990, p. 18). Post-positivists propose reality is always viewed and interpreted by a subjective receiver (Racher \& Robinson, 2003). Therefore, postpositivists espouse a modified objectivity. This modified objectivity is evidenced by the researcher attempting to remain as neutral as possible by identifying and disclosing any predispositions, examining results in the context of extant literature, and subjecting findings and results to peer review (Guba, 1990).

The epistemological stance of the critical paradigm is subjectivist, acknowledging that observations are all mediated by one's values (Guba, 1990; Weaver \& Olson, 2006). Critical theorists hold that rather than objective facts, knowledge is a product of societal values and influences (Jackson, 2015). Guba writes, "Nature cannot be seen as it 'really is' or 'really works' except through a value window" (Guba, 1990, p. 24). Critical theory asks, "What and whose values govern and influence knowledge and knowledge development?" 
The epistemology of this study fits most closely with the post-positivist paradigm, understanding that complete objectivity is not possible. The researcher acknowledges that a number of biases guided study development. First, the researcher contends that while not well-defined, the nurse plays an integral role in prognosis-related communication, and that further, this role is influenced by the hierarchical structures within medicine and nursing. This influence plays out in both positive and negative ways. In addition, the researcher is biased in believing that the nurse's perception of the process and the level of collaboration with physician colleagues impact the quality of patient care. Further, the interplay between these relations and outcomes can negatively impact the nurse, causing moral distress. These biases along with a critical appraisal of the existing literature led to the writing of the research questions for the proposed study.

Obtaining the pediatric oncology nurse's perspective on the process is also consistent with the post-positivist paradigm. Racher and Robinson (2003) write, "Lived reality serves as a focus of inquiry with subjective and objective realities merging in alliance between that reality and our knowledge of it" (p. 466). Understanding the perspective of those involved in the process and the subjective biases they have surrounding the concept expands understanding of the concept when it is critically examined within the context of the existing literature. Finally, to ensure more objective results, findings from the proposed research will be examined in the context of the extant literature surrounding this topic and subjected to peer review.

Subjective appraisal of the concept under study is also consistent with critical theory. The sometimes-silenced voice of the nurse will be obtained. Critical theorists hold that knowledge is value-laden, therefore, obtaining the subjective perspective of nurses 
regarding the process of prognosis-related communication and its relations to interprofessional collaboration, quality of patient care and moral distress, will expand our understanding and explanation of these processes.

The ontological and epistemological tenets of each paradigm help to answer the question of methodology or "How should the inquirer go about finding out knowledge?" (Guba, 1990, p. 18). Methodologically, post-positivists endorse empirical methods, but also accept and encourage other methods including qualitative inquiry. Context-stripping, which is prevalent and essential to the positivist paradigm, is rejected in the postpositivist paradigm, which encourages research to be carried out in more natural or less tightly controlled environments. Methods aim to falsify hypotheses and establish probable truths (Weaver \& Olson, 2006) via experiments, surveys, or evaluation of secondary sources of data (Jackson, 2015). Tools and instruments are used to measure concepts, assigning numerical values to each concept, in order to run statistical analyses (Monti \& Tingen, 1999). Within a critical paradigm, methodological approaches aim to reveal hidden power imbalances, learn how people subjectively experience problems, and make knowledge publicly available (Weaver \& Olson, 2006).

The methodological approach of the proposed study was consistent with the postpositivist paradigm. The process of prognosis-related communication, its contributing factors, and resulting outcomes will be explored via indirect observation. Instruments disseminated via surveys were used to measure the different variables, and generate numerical values for each in order to explore relationships and patterns among the variables via statistical analyses. While the quantitative methods described are not consistent with critical theory, critical theory still informs the methods. Nurses are one 
part of the process of prognosis-related communication in pediatric oncology. Physicians, parents, the patients, and other members of the healthcare team, all play important yet distinct roles in the process. Gaining insight into process from the nurse's perspective can lay the groundwork for further emancipatory work around prognosis-related communication that includes all members of the team. Thus, the aim of the proposed analyses of this study was to generalize the findings to the broader community of pediatric oncology, informing and encouraging further exploration and possibly practice change.

\section{Conceptual-Theoretical-Empirical Structure}

Nursing, as a discipline, exists to "generate, test, and apply theories that will improve the quality of people's lives" (Fawcett, 1999, p. 1). Conceptual models or frameworks provide the context or the frame of reference to guide theory generation and theory-testing research. Conceptual models, theories, and research are all part of a cycle aimed at describing, explaining and predicting human experiences (Fawcett, 1999). Research provides the data, and conceptual models and theory shape research questions, explain and give meaning to findings, and move inquiry forward through validation and refutation.

A conceptual model is defined as, "a set of relatively abstract and general concepts and the propositions that describe or link those concepts" (Fawcett, 1999, p. 3). Concepts are words or phrases that represent phenomena of interest. Propositions are statements about a concept or relations between concepts. The conceptual model guiding the proposed research is the Quality-Caring model(C developed by Duffy and Hoskins (2003). 
Grounded primarily in the work of Donabedian (1992) and Watson (1985), the Quality-Caring Model $\subset$ fuses the Structure-Process-Outcome model, which examines quality in health care, with the major constructs of the Human Caring Model, which espouses caring as the essence or core of nursing. The Quality-Caring Model(C aims to unveil the impact of caring nursing practices on outcomes within the complex health care environment. The three major components of the model are structure/causal past, process/caring relationships, and outcomes/future.

The first component structure/causal past includes the concept of participants (Duffy \& Hoskins, 2003). Participants are identified as patient/family, provider, and system. Each participant presents with a causal past, as described by Watson (1985), which incorporates the unique attributes and characteristics of participants. Each participant is also believed to have a phenomenal field, which is the unique frame of reference or context that is known only to that person or entity (Watson, 1985). Duffy and Hoskins indicate that each of the concepts and sub-concepts included in the structure component have the potential to impact the process of care. In addition, each may also either directly or indirectly influence outcomes of care.

In this study, the nurse presents with his/her own unique attributes or characteristics, which impact perceptions of prognosis-related communication and also perceptions regarding the process of interprofessional collaboration. Further nurse attributes, such as experience, level of education, practice setting, and extent of formal training in prognosis-related communication, have the potential to impact the outcomes of nurse perceived quality of care and nurse moral distress either directly or indirectly through perceptions of interprofessional collaboration. 
The second component includes the interventions or practices that health care providers perform. Such practices are represented by process. Duffy and Hoskins (2003) maintain that within nursing all of such practices are grounded in caring relationships as described by Watson (1985). Relationships are inclusive of both independent relationships and collaborative relationships. Independent relationships represent patient/family nurse interactions that are implemented by the nurse in an autonomous fashion. Such relationships incorporate discipline-specific interventions, which result in nurse-sensitive outcomes. Conversely collaborative relationships represent activities or responsibilities that the nurse engages in as a member of the health care team. Outcomes from these relationships are shared. Duffy and Hoskins (2003) highlight that in these situations the nurse is often the "glue" that holds such teams together. A major function of the nurse is balancing these complementary professional relationships while keeping patient/family needs as the central focus. This research focused on the collaborative relationships between physicians and nurses.

The third component represents the future or the outcomes of the structure/causal past and process/caring relationship components (Duffy \& Hoskins, 2003). Outcomes are intermediate and terminal. Intermediate outcomes represent a change in behavior, attitudes, or knowledge, which may impact terminal outcomes. Terminal outcomes are the major end results that impact the future. A potential reciprocal relationship exists between intermediate and terminal outcomes. The authors state, "Success in outcomes realization is heavily dependent on the dynamic and balanced independent and collaborative relationships that comprise professional encounters" (p. 83). Terminal outcomes in this research included nurse perceptions of quality of care and moral distress. 
The potential for a reciprocal relationship that may exist between nurse perceptions of quality of care and moral distress was explored as well. Figure 1 depicts the QualityCaring ModelC.

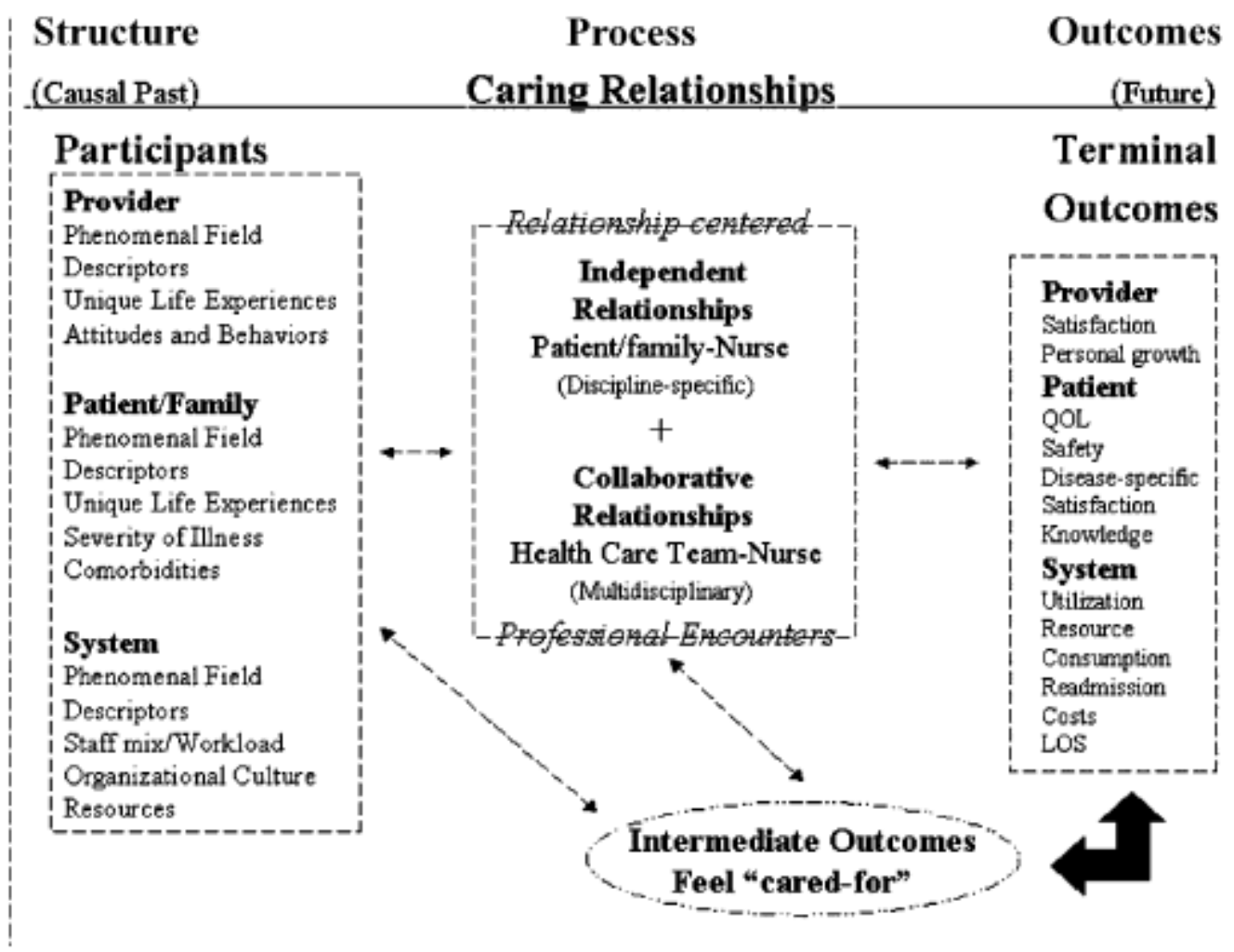

Figure 1. The Quality-Caring ModelC by Duffy and Hoskins (2003)

The Quality-Caring Model(C was selected as the guiding framework for this research as it closely aligned with the philosophical stance of the researcher. The QualityCaring Model $\mathbb{C}$ links together the post-positivist paradigm with the tenets of critical theory. Ontologically, the model aims to reveal the impact of caring nursing practices in the context of understanding the relationships between structure (causal past), process (caring relationships), and outcomes (future). The uncovering of caring practices that 
may not currently be acknowledged within health care systems is consistent with the ontology of critical theory. Truth exists, but it has been oppressed by different social, political and cultural factors. One must dig and put aside previously established hierarchies to discover truth. The structure (causal past) component of the model acknowledges the unique attributes, characteristics, and perspectives of participants, which is consistent with the epistemology of modified objectivity espoused by postpositivists and the value-laden, subjectivity described by critical theorists. Finally, the exploration of relationships between each component of the model is consistent with the post-positivist paradigm, which aims to investigate and clarify relationships and patterns among concepts.

Theories are more concrete and specific than conceptual models, but also exhibit a range of abstraction and specificity. Theory is defined as, "a set of relatively concrete and specific concepts and the propositions that describe or link those concepts" (Fawcett, 1999, p. 4). Theories are categorized as grand or middle-range. Grand theories are more abstract and broad, whereas middle-range theories are more concrete and narrow. The Quality-Caring Model(C provided the structure for the development of the theoretical framework (Figure 2) at the situation-specific level for this dissertation research. 


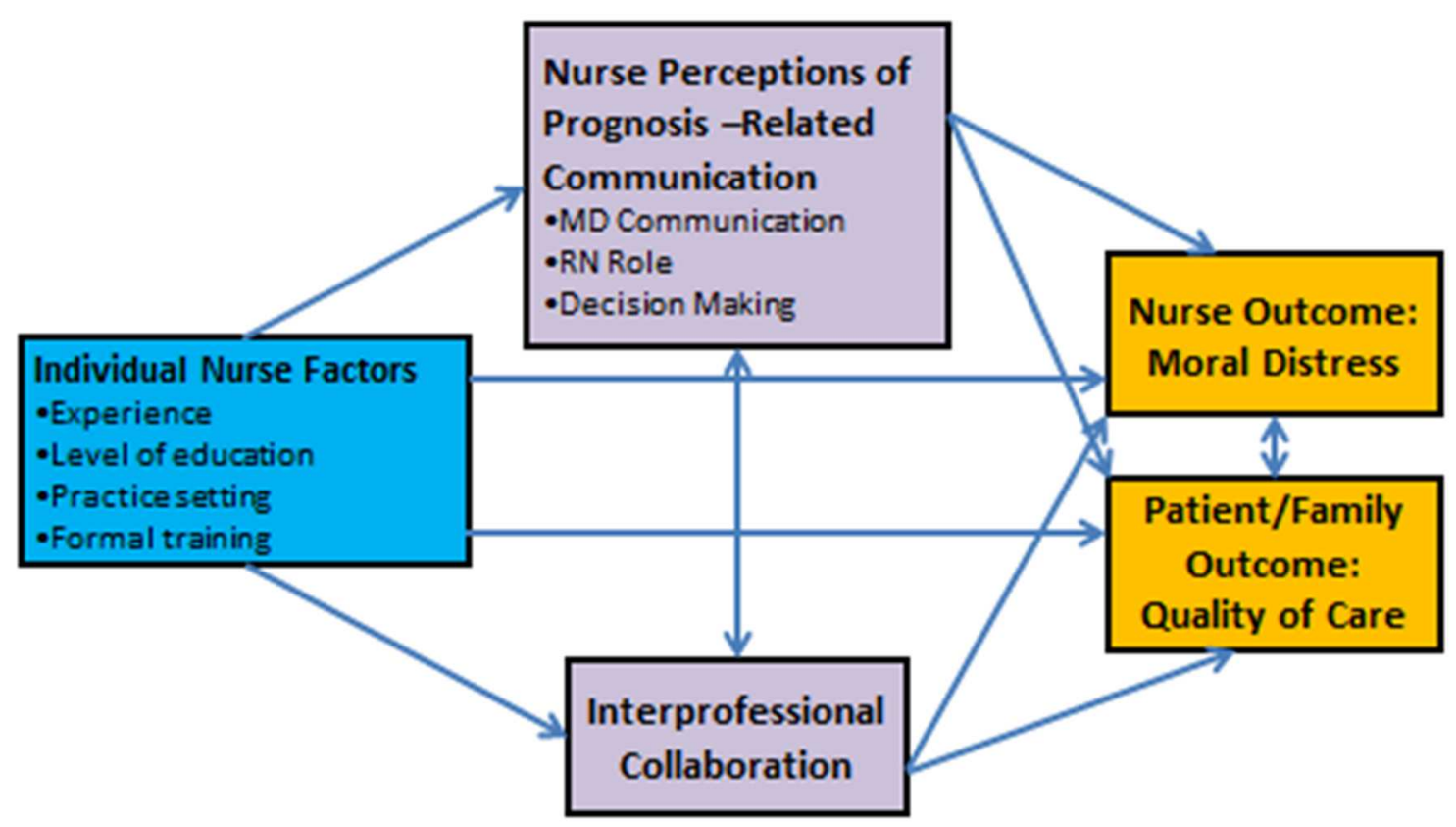

Figure 2. Theoretical Model

Research functions as the practical assessment of the propositions described by conceptual models and theories. Fawcett defines research as, "a formal, systematic, and rigorous process of inquiry used to generate and test the concepts and propositions that comprise middle-range theories, which are derived from or linked with a conceptual model" (Fawcett, 1999, p. 8). Theoretical substruction is performed to understand and outline the linkages between conceptual models, theories, and research (empirics). Each of these components is represented in the study and operationalized as study variables in Table 1. 
Table 1

Conceptual-Empirical-Theoretical Structure

\begin{tabular}{|l|l|l|l|}
\hline $\begin{array}{l}\text { Quality-Caring } \\
\text { Model }\end{array}$ & Structure/causal past & $\begin{array}{l}\text { Process/Caring } \\
\text { Relationships }\end{array}$ & Outcomes/future \\
\hline Study concepts & $\begin{array}{l}\text { Individual Nurse } \\
\text { Factors }\end{array}$ & $\begin{array}{l}\text { Nurse Perceptions of } \\
\text { Prognosis-Related } \\
\text { Communication } \\
\text { Interprofessional } \\
\text { Collaboration }\end{array}$ & $\begin{array}{l}\text { RN: Moral Distress } \\
\text { Patient/Family: } \\
\text { Patient Care }\end{array}$ \\
\hline $\begin{array}{l}\text { Study } \\
\text { variables }\end{array}$ & $\begin{array}{l}\text { Demographic } \\
\text { information } \\
\text { (experience, level of } \\
\text { education, practice } \\
\text { setting, formal } \\
\text { training) }\end{array}$ & PRCON & MDS-R \\
\hline
\end{tabular}

Note. $\mathrm{RN}=$ registered nurse; $\mathrm{PRCON}=$ Prognosis-Related Communication in Oncology Nursing; MDS-R = Moral Distress Scale - Revised; CBS = Collaborative Behavior Scale; NAQS-ACV = Nursing Assessment of Quality Scale - Acute Care Version.

\section{Review of the Literature}

A manuscript titled" "Nurses' Perceptions of Diagnosis and Prognosis-Related Communication: An Integrative Review" (Newman, 2016) located in Appendix A presents an exploration and critical appraisal of the relevant literature regarding nurses' experiences with diagnosis and prognosis-related communication. For the purposes of this study, prognosis-related communication was defined as the communication that occurs among health care providers (HCP), parents, and children with cancer including the revelation of whether or not the child will be cured of cancer, how long the child is expected to live, and the kind of life the child is expected to have (Mack et al., 2006). Other study concepts that are addressed only briefly in the manuscript are defined and reviewed in this section, specifically interprofessional collaboration, moral distress, and nurse perceived quality of care. 
Interprofessional collaboration (IPC) is a critical aspect of health care teams, and can have a significant impact on patients, families, and health care systems. Barr, Koppel, Reeves, Hammrick, and Freeth (2005) depict IPC as a relationship between two or more health or social care professionals, who work together to solve problems or provide services. IPC has also been identified as a complex process characterized by shared objectives, decision-making, responsibility, and power, aimed at solving patient care problems (Petri, 2010). Concepts inherent to collaboration including sharing, partnership, interdependence, and power (D'Amour, Ferrada-Videla, Rodriguez, \& Beaulieu, 2005). True ICP is enacted when the knowledge and experience of each professional is valued and integrated into developing solutions to complex problems (D'Amour et al., 2005). Well-executed IPC increases the quality of patient care, improves patient safety, and supports positive patient outcomes (Rose, 2011). Collaborative practice has been recognized by the World Health Organization (2010) as strengthening health systems and improving health outcomes by increasing access to health services, decreasing total patient complications and length of stay, and reducing hospital readmission rates and clinical error rates. In addition, collaborative practice has been found to reduce tension and conflict among caregivers and limit staff turnover.

Previous research (Baggs et al., 1999) in the intensive care unit (ICU) setting demonstrated that nurse perceptions of nurse-physician collaboration are associated with a reduced risk of negative patient outcomes (death or readmission to the ICU). Hamric and Blackhall (2007) surveyed both physicians and nurses in over 14 different ICUs in two separate institutions, and found that perceptions of nurse-physician collaboration 
were positively associated with physician and nurse satisfaction with patient care quality and negatively associated with levels of nurse moral distress.

Despite the documented benefits, numerous barriers to IPC exist within the complex healthcare environment. Barriers are systematic, organizational, and interactional in nature (Rose, 2011). First, the hierarchies established within the health care system can limit collaboration, particularly the philosophical and power differences between medicine and nursing. The medical model, which generally esteems objective, physical signs and minimizes the subjective responses to illness that nurses value, is given the most credence and priority in health care systems (Larson, 1999). These competing philosophies and foci can impede IPC. "Each discipline develops strong theoretical and discipline-based frameworks that give access to professional jurisdictions that are often rigidly circumscribed" (D’Amour et al., 2005, p. 117). Collaboration, therefore, requires that nurses and physicians transcend their own professional boundaries to acknowledge and value other professional paradigms. Such activity results in a "logic of collaboration rather than a logic of competition" (D'Amour et la., 2005, p. 117). Due to power dynamics, team members may not be willing to collaborate. Additional barriers to successful IPC include poor communication among team members, poor understanding of team members' roles and responsibilities, and conflict of opinion regarding patient care issues (Rose, 2011).

Nurses and physicians have different perceptions regarding the communication and collaboration that occurs between the two disciplines. Opinions differ on a) what constitutes good and desirable communication, b) whether communication and shared decision making are occurring, and 3) what it would take to improve care (Larson, 1999). 
Weaver, Callaghan, Brandman, and O'Leary (2015) surveyed nurses, residents, hospitalists, and oncology physicians to characterize the perceptions of teamwork in the inpatient oncology setting. They also explored barriers to establishing strong collaboration between nurses and physicians. Physicians and nurses differed significantly in their perceptions of teamwork and collaboration with nurses reporting less teamwork and collaboration and physicians reporting more. In addition, nurses identified "negative attitudes about the importance of communication" (p. 20) as a barrier to successful collaboration while physicians did not identify with any of the listed barriers to collaboration. The authors suggested that if nurses perceive poor collaboration with their physician colleagues, they may be reluctant to share patient concerns with the physician.

The work of nurses and physicians has a significant impact on the other. If nurses and physicians fail to collaborate, an unhealthy work environment can ensue, and patient needs may be neglected (Larson, 1999). At times, nurses caring for patients with lifelimiting illnesses report a lack of collaboration with their physician colleagues in regards to prognosis-related communication (Reinke, Shannon, Engelberg, Young, \& Curtis, 2010). Nurses may not be included in the initial discussion that occurs between the physician and the patient regarding prognosis. With limited knowledge regarding the content of these conversations, nurses are caught in the middle as they aim to advocate for their patients, but also support the medical team (McLennon, Uhrich, et al., 2013). If the nurse is unclear as to what has been communicated, the nurse will often limit communication with the patient, which can have negative implications. Nurses described this as "fractured trust" (Tobin, 2012, p. E27), which occurs when the nurse and/or the 
patient believes that the trust bond that had been established between the nurse and the patient is broken.

This fractured trust can then become an internal conviction that challenges the nurse's sense of professionalism and can lead to increased moral distress (Tobin, 2012). Hamric and Blackhall (2007) indicate that moral distress occurs when the nurse is clear about the ethically indicated course of action, but feels constrained in taking such action. If nurses perceive that physician collaboration is poor on their unit, they may not feel comfortable sharing such concerns with their physician colleagues and therefore are unable to fully advocate for their patients.

Moral distress has been identified as "the psychological disequilibrium, negative feeling state, and suffering experienced when nurses make a moral decision and then either do not or feel that they cannot follow through with their chosen action because of institutional constraints" (Corley, 2002, p. 643; Jameton, 1993; Wilkinson, 1987-1988). Such situations are inherently ethically challenging for those healthcare providers who are involved. By nature of the work they do, nurses are routinely put into situations that expose them to the development of moral distress. Corley (2002) emphasized that moral standards infuse nursing practice, and that, in fact, all nursing acts are fundamentally ethical in nature. Cavaliere, Daly, Dowling, and Montgomery (2010) echoed these sentiments, adding that nursing itself is a "moral endeavor" (p. 145), because of the unique nature of nurse-patient relationships and the role of the nurse. Nurses are challenged and can feel powerless when they are put into situations in which the values of and their responsibilities to patients, families, physicians, their institution, employers, self and profession are competing. How much input, authority, and responsibility the 
nurse has in any situation will determine whether or not distress is experienced.

Meaningful, ethical discussions that include all perspectives and all relevant stakeholders are essential to avoiding moral distress. Lack of inclusion may result in members of the team behaving in what they perceive as an ethically inappropriate manner, which violates one's core values and obligations. This can result in a powerfully negative phenomenon, eroding away one's moral integrity (Epstein \& Hamric, 2009).

Allen et al. (2013) explored moral distress among healthcare providers working with both adult and pediatric patients in community and rural hospitals within one large healthcare system. As a whole, healthcare providers were found to report moderate to high levels of moral distress. Levels of moral distress were found to be higher among professionals who had previously left or were considering leaving their current positions. Nurses reported the following situations as causing the most distress: carrying out physician orders for unnecessary tests, following family wishes for continuing life support when perceived to not be in the best interest of the patient, watching patients suffer due to lack of continuity, providing less than optimal care secondary to financial constraints, and initiating extensive lifesaving actions when perceived to prolong death.

Although the data are somewhat equivocal, several demographic factors seem to place certain groups of nurses at higher risk for developing moral distress. Older nurses (over the age of 33), nurses with more experience, and nurses working in the same position at the same institution for a number of years are more frequently confronted with distressing situations. As nurses get older and gain experience, the intensity of moral distress becomes less (Oh \& Gastmans, 2013; Pye, 2013). It is unclear if this is secondary to more experience coping with the causations of moral distress or desensitization. 
A number of sources of moral distress have been identified. Moral distress has been associated with a negative ethical climate within an institution (Oh \& Gastmans, 2013), which can arise out of poor interprofessional relationships or poor leadership. In addition, distress can arise when nurses are compelled to act in ways they do not believe are in the patient's best interest, such as providing futile care (Oh \& Gastmans, 2013). Further, family members can cause distress if they are uncooperative or display inappropriate behaviors with nurses and other staff (Oh \& Gastmans, 2013). Limited staffing can lead to moral distress as nurses struggle to provide the level of care they believe patients deserve in the setting of a nursing shortage (Oh \& Gastmans, 2013). Finally, the nurse's level of authority is often not commensurate with his or her level of responsibility. Therefore, at times, the nurse can feel incapable of or be blocked from pursuing what he or she determines to be the correct action for the patient (Cavaliere et al., 2010; Corley, 2002).

Pye (2013) explored the perceptions and experiences of moral distress among pediatric oncology nurses and physicians. Three main themes surfaced: 1) The importance of the decision-making process, 2) conflict over right to treatment and withholding treatment, and 3) the importance of communication within the team. Treatment-related decision making repeatedly evoked a sense of moral distress. Respondents identified feeling helpless, isolated, powerless, and devalued, when their role in the decision-making process was minimized or eliminated. As a result, the importance of the team, i.e., nurse-physician collaboration and communication, in the decision-making process was highlighted. The physicians confessed to leaving nurses caught in the middle between patients and the physician in the decision-making process. 
Physicians are identified as "bearing the burden" of decision making, but nurses "bear the burden" of decisions made (p. 250).

Moral distress can have a significant impact on nurses. More frequent exposure to distressing situations can result in emotional exhaustion and depersonalizing interactions with patients; both of which are components of burnout syndrome (Allen et al., 2013; Oh \& Gastmans, 2013). Further, moral distress can leave nurses feeling angry and frustrated, limiting their ability to cope with the challenges of nursing practice. This inability to cope leads some nurses to consider leaving their job or the nursing profession altogether. In an integrative review exploring moral distress, Oh \& Gastmans (2013) reported that approximately 10 to $45 \%$ of nurses and advanced practice nurses caring for adult patients reported leaving or consideration of leaving their current positions due to moral distress. In a study evaluating moral distress in neonatal intensive care unit nurses, four percent indicated they had left a position primarily due to moral distress, and approximately $40 \%$ reported that they had considered leaving a past position or were considering leaving their current positions (Cavaliere et al., 2010).

If not addressed, moral distress can lead to "moral residue" (Epstein \& Hamric, 2009, p. 330). Moral residue refers to the lingering negative feelings that persist after a morally problematic situation has passed. Moral residue challenges the nurses' moral identity, and can have a lasting and powerful impact on the nurse. Moral residue can be manifested by anxiety and depression, burnout, and the avoidance of patient interaction (Allen et al., 2013). Epstein and Hamric (2009) propose the "Crescendo Effect Model" (p. 3), which describes the interactions between moral distress and moral residue. As a morally distressing situation presents itself, the nurse's level of moral distress rises. As 
the situation concludes and if the nurse's distress remains unresolved, the nurse starts to develop moral residue. When a new situation presents itself, the baseline of moral residue leads to an increasingly higher crescendo of moral distress. Increasing crescendos and levels of moral residue evoke stronger reactions within the nurse as he or she is reminded of earlier distressing situations. Such reactions can significantly influence the quality, quantity, and cost of patient care (Cavaliere et al., 2010).

The provision of quality care is a critical aspect of nursing practice. Since 2001 when the Institute of Medicine published Crossing the Quality Chasm an increased emphasis has been in place, demanding that health care systems and providers take more responsibility and accountability for the quality of their practice (Burhans \& Alligood, 2010). Subsequently, in 2007, the Institute for Healthcare Improvement (2016) identified the patient experience of care (including quality and satisfaction) as one of the dimensions of the Triple Aim. Additional dimensions include improving the health of populations and reducing the cost of health care. The goal of the Triple Aim framework is to optimize health system performance while simultaneously addressing each of these dimensions, recognizing that the dimensions are interrelated. The quality of nursing practice has been recognized as a key driver of patient outcomes and patient safety (Burhans \& Alligood, 2010; Glarcher, 2015). Beck et al. (2013) clearly articulated the need to advance the measurement of the structures, processes, and outcomes that reflect nursing's contribution to quality care.

Despite this increased emphasis on quality care, a consistent definition of quality care has been evasive, and defining and measuring quality nursing care has been even more challenging. Quality of care is considered a subjective concept, which is 
stakeholder specific. The different definitions of quality care employed by nurses, patients, physicians, family members, and health care administrators are reflective of their personal knowledge, views and values (Burhans \& Alligood, 2010). Thus, each must be considered when assessing quality. Further compounding understanding of the concept of quality care, particularly from a nursing perspective, is the idea of quality care as both a process and an outcome of care.

For the purposes of the study, quality care was identified as an outcome of care processes. Further, quality of care was measured from the nurse's perspective, and defined as the ability [of the nurse] to focus on relationships with patients, meet patients' needs, and fulfill observer and advocacy responsibilities (Lynn, McMillen, \& Sidani, 2007a). Certainly, the perspective of patients and families is integral to understanding how care should be provided to meet needs and expectations, but the nurse's perspective is believed to be more reflective of the way in which care is actually provided (Lynn \& McMillen, 1999). In addition, the aim of the proposed study was to ascertain the nurse's perspective of the impact of prognosis-related communication and IPC on the ability to provide quality nursing care.

Definitions, attributes, consequences and necessary conditions of quality nursing care have been explored from a nursing perspective. Definitions incorporate the idea of patient needs and expectations and whether or not needs and expectations have been met (Williams, 1998). Through a grounded theory approach, Williams explored the concept of quality nursing care with 10 surgical nurses working in an acute care environment. High quality nursing care was identified as meeting patient needs. Conversely, low 
quality nursing care was perceived as an omission of the care required to meet patient needs.

Needs were identified as both physical and psychosocial. Nurses more frequently emphasize the importance of physical care needs, while patients at times place higher importance on psychosocial needs. Nursing competency is an expectation that patients have when entering a health care system, thus patients perceive that quality nursing care goes beyond just the required physical care (Lynn, McMillen, \& Sidani, 2007b). Psychosocial needs are believed to be met as the nurse plays a supportive role, communicating, providing information, caring, and advocating for the patient. When patient needs are met, favorable patient outcomes are achieved, and nursing care is thought to be "therapeutically effective" (Williams, 1998, p. 810). Therapeutically effective nursing care is believed to occur when therapeutically conducive relationships are formed between nurses and patients. Such relationships are characterized by rapport and trust.

Burhans and Alligood (2010) described the essential nature of such interactions and relationships as the "art of nursing" (p. 1694). Patient needs are met when the nurse aims to engage in caring, empathetic interactions with the patient. Interactions are grounded in responsibility, intentionality, and advocacy. Adult cancer patients reiterated these thoughts as they identified critical attributes of quality nursing care: professional knowledge, continuity, attentiveness, coordination, partnership, individualization, rapport and caring (Radwin, 2000). Each of these attributes were also linked with what patients identified as the outcomes of quality nursing care: sense of well-being and increased fortitude. In addition to these attributes, a sample of nearly 1,500 medical-surgical 
patients identified nurse characteristics (attitude and presentation) and the environment as integral aspects of quality nursing care (Lynn et al., 2007b).

Challenges certainly exist in the consistent provision of quality nursing care. Nurses generally have a good understanding of what constitutes quality nursing care, but actual practice is not always consistent with this understanding (Williams, 1998). In practice, the nurse's ability to provide quality nursing care is influenced by a number of factors including the amount of time available for care delivery, the availability of other team members, and collaboration among team members (Williams, 1998). An inability to provide quality nursing care can have a negative impact on both the patient and the nurse. Lack of quality nursing care can limit a patient's return to wellness, compromise safety, and reduce satisfaction (Williams, 1998). The inability to provide quality nursing care can leave nurses feeling dissatisfied and stressed, which can result in frustration and guilt. Such feelings can limit the nurse's ability to provide therapeutically effective care. Repeated inability to provide quality care can result in moral distress.

\section{Appraisal of the Literature}

The literature is clear that the disclosure of prognostic information to patients and families is a process that occurs over the course of multiple interactions with different members of the health care team. Previous findings support that physicians are generally the initial providers to disclose such information to patients and families. Nurses clearly play a role in this process, both formally and informally. A large number of descriptive studies, utilizing both qualitative and quantitative methods, have documented the different roles that nurses play in the process, but also highlight that in practice these roles are not clearly articulated and the nurse's role in the process is not always valued. 
These findings are generally from the nurse's perspective. A small number of studies reported significant associations between different individual nurse factors such as years of experience, educational preparation, practice setting, and past education regarding prognosis-related communication (Helft, Chamness, Terry, \& Uhrich, 2011; Hjelmsfors, Stromberg, Friedrichsen, Martensson, \& Jaarsma, 2014; Rassin et al., 2006).

IPC or lack thereof can have a significant impact on patient outcomes, health care provider job satisfaction, and appraisal of care quality. Through both qualitative and quantitative analyses, nurses identified IPC and communication as critical to the process of prognosis-related communication (des Ordons, Sharma, Heyland, \& You, 2015; Sheldon, Barrett, \& Ellington, 2006). Subjectively, nurses often report a lack of collaboration in regard to prognosis-related communication, which leaves them "working in the dark" (McLennon, Uhrich, et al., 2013, p. 119) when caring for patients and limits their communication with patients and families. Nurses describe mutual trust and relationships as essential to the therapeutic effectiveness of nursing care (Tobin, 2012; William, 1998). Thus, lack of IPC in this context has the potential to impact the quality of nursing care. Albeit with different measures, the importance of quality nursing care on patient outcomes is clearly articulated throughout the literature. The potential impact of the nurse's inability to provide what he or she perceives to be quality care is also well described. Qualitative data indicate that an inability to provide quality care can leave the nurse feeling stressed and dissatisfied (Burhans \& Alligood, 2010; Williams, 1998). Frequent exposure to distressing situations can lead to moral residue, which has the potential to further impair the nurse's ability to provide quality care and his/her intention to leave a position or the nursing profession altogether. 
A considerable amount of descriptive work has been done exploring nurses' experiences with prognosis-related communication. Surveys were utilized in most of the studies with others incorporating interviews or focus groups. Most of the surveys were generated by the investigators with limited documentation of instrument psychometrics. Over $50 \%$ of the papers had sample sizes of more than 100 participants. Only 5 reports explored associations among variables, thus limiting the strength of evidence surrounding any of the described associations. While statistical significance was reported in these papers, comments on effect size were not made. The current literature has built a foundation on which to start to explore further the concept of prognosis-related communication.

In conclusion, while the different concepts in the proposed research model are well-described, the relationships among concepts are suggested from primarily descriptive work, and true associations have not been fully explored in the context of prognosis-related communication. In addition, literature exploring these different concepts in the pediatric population is extremely limited and even more so in pediatric oncology.

\section{Gaps in the Literature}

Research targeting prognosis-related communication in the pediatric oncology population and the perceptions and experiences of the pediatric oncology nurse is glaringly absent. This study addressed the gap by measuring nurses' perceptions of their experiences with prognosis-related communication with parents of children with cancer. In addition, different individual nurse characteristics were explored to better understand the role they play in nurses' experiences. IPC is believed to influence the nurse's 
perception of the process of prognosis-related communication, therefore, the relationship between nurses' experiences with prognosis-related communication and IPC was analyzed. Finally, this research explored whether or not the nurse's perception of prognosis-related communication was associated with moral distress and the impact on the nurse's ability to provide quality nursing care within this context.

Armed with this new knowledge, changes in practice can be made to enhance IPC with the goal of improved provider communication and optimal patient care. Done skillfully, prognosis-related communication can increase parental and child awareness of the child's condition and projected disease trajectory, allowing for informed decision making and the maintenance of hope (Mack et al., 2007). Establishing and maintaining hope has been found to sustain many patients and their families throughout the illness trajectory, and therefore, is deemed critical to a quality health care experience (Kylma \& Juvakka, 2007). Further it is suggested that if nurses are better prepared and empowered to communicate with parents throughout this process, they will describe an increased ability to provide quality care to patients and their families, resulting in less moral distress. The results of this research therefore have the potential to address numerous gaps in our knowledge regarding prognosis-related communication in the pediatric oncology setting. While the findings may not be directly generalizable to nurses working with adult cancer patients or parents of children with other types of life-limiting illnesses, results may provide the framework for future research in these populations. 


\section{Assumptions}

The following assumptions derived from the researcher's ontology regarding the nurse's experience with prognosis-related communication influenced development of the proposed study:

1. Prognosis-related communication is a process that involves repeated discussions and interactions with parents and members of the healthcare team.

2. Prognostic information is communicated by different members of the healthcare team, primarily physicians.

3. Parents of children with cancer are the receivers of such communication.

4. Nurses play an integral role in the process of prognosis-related communication, but their role is not well-defined or recognized.

5. The level of collaboration and communication between the nurse and the physician influences the extent of the nurse's involvement in prognosis-related communication.

6. Physicians do not always value or recognize the importance of nurse involvement in the process of prognosis-related communication.

7. Lack of involvement in the process of prognosis-related communication or negative experiences with prognosis-related communication can have a negative impact on the nurse. Such negative experiences can lead to moral distress and impact the nurse's ability to provide quality care to his/her patients. 


\section{Purpose and Specific Aims}

The purpose of this research was to examine nurses' perceptions of their experiences with prognosis-related communication with parents of children with cancer, factors associated with their perceptions and experiences, and the associations with IPC, quality of care, and nurse moral distress. Specific aims to address the study's purpose were:

Specific Aim 1: Describe nurses' perceptions of their experiences with prognosisrelated communication with parents of children with cancer.

Specific Aim 2: Determine associations between individual nurse factors, nurse perceptions of prognosis-related communication, and interprofessional collaboration.

Specific Aim 3: Determine if individual nurse factors, nurse perceptions of prognosis-related communication, and interprofessional collaboration are associated with nurse perceptions of quality of care and nurse moral distress.

\section{Summary}

This chapter outlined the philosophical and conceptual underpinnings for exploring nurses' experiences with prognosis-related communication. The Quality-Caring Model(C), which aided in the development of the theoretical framework to evaluate the relationships proposed between study concepts and variables, was outlined. Each of these concepts and their relationships to one another were described in detail throughout the review of the literature. From the appraisal of the literature, numerous gaps in the literature were identified, particularly as it relates to these concepts in the situation- 
specific context of pediatric oncology. Therefore, this dissertation research aimed to produce new knowledge to inform the process of prognosis-related communication in pediatric oncology. 


\section{Chapter 3: Research Design and Methods}

Chapter Three, "Research Design and Methods," will provide a comprehensive overview of the research design and methods used to address the specific aims (described in Chapter 2). The study design and processes of sample selection, data collection, and data analysis are outlined in this chapter along with rationale to justify the decisions made.

\section{Research Design}

A non-experimental, cross-sectional correlational design was used to explore pediatric oncology nurses' perceptions of their experiences with prognosis-related communication with parents of children with cancer. Non-experimental study designs are utilized when the researcher does not intend to manipulate the predictor variables under investigation (Polit \& Beck, 2012). One type of non-experimental or observational study design is correlational. Correlational studies aim to describe and understand relationships among variables rather than to support causal inferences (Hulley, Cummings \& Newman, 2013; Polit \& Beck, 2012). In cross-sectional designs, all data are gathered at one single occasion or within a short period of time. Cross-sectional designs are appropriate when the goal is to describe variables and distribution patterns (Hulley et al., 2013). A crosssectional, correlational design was selected for the study for its ability to explore relationships among the 5 key study variables: individual nurse factors, nurse perceptions of prognosis-related communication, interprofessional collaboration, nurse perceived quality of care, and nurse moral distress. As little is known about this topic in the setting

of pediatric oncology, a cross-sectional, correlational design will increase the breadth and 
depth of understanding of the perceptions of pediatric oncology nurses and factors associated with these perceptions.

\section{SPECIFIC AIMS with Research Questions and Hypotheses}

Research questions or hypotheses were identified to specify the approach to addressing each specific aim.

Specific Aim 1: Describe nurses' perceptions of their experiences with prognosisrelated communication with parents of children with cancer.

Research Question 1: How do nurses rate the level of prognosis-related communication that they experience on the Prognosis-Related Communication in Oncology Nursing (PRCON) scale?

Specific Aim 2: Determine associations between individual nurse factors, nurse perceptions of prognosis-related communication, and interprofessional collaboration. Hypothesis 1 (H1): Individual nurse factors (more years of experience in pediatric oncology, a Master's degree or higher, practicing in the outpatient setting, and previous formal training in prognosis-related communication) will be associated with more positive scores on the PRCON scale.

Hypothesis 2 (H2): Individual nurse factors will be associated with more positive scores on the Collaborative Behavior Scale (CBS)-Part A [RN-MD Communication].

Hypothesis 3 (H3): PRCON and CBS will be positively correlated.

Specific Aim 3: Determine if individual nurse factors, nurse perceptions of prognosis-related communication, and interprofessional collaboration are associated with 
nurse perceptions of quality of care and nurse moral distress in the context of providerparent communication regarding prognosis.

Hypothesis 4 (H4): Individual nurse factors as well as more positive scores on the PRCON and CBS will be associated with higher levels of nurse perceived quality of care as measured by the Nurses' Assessment of Quality Scale - Acute Care Version (NAQS-ACV).

Hypothesis 5 (H5): Individual nurse factors as well as more positive scores on the PRCON and CBS will be associated with reduced levels of nurse moral distress as measured by the Moral Distress Scale - Revised (MDS-R) pediatric version.

Hypothesis 6 (H6): Higher levels of nurse perceived quality of care as measured by the NAQS-ACV will be correlated with reduced levels of nurse moral distress as measured by the MDS-R pediatric version.

The analytic model for the study is presented in Figure 3.

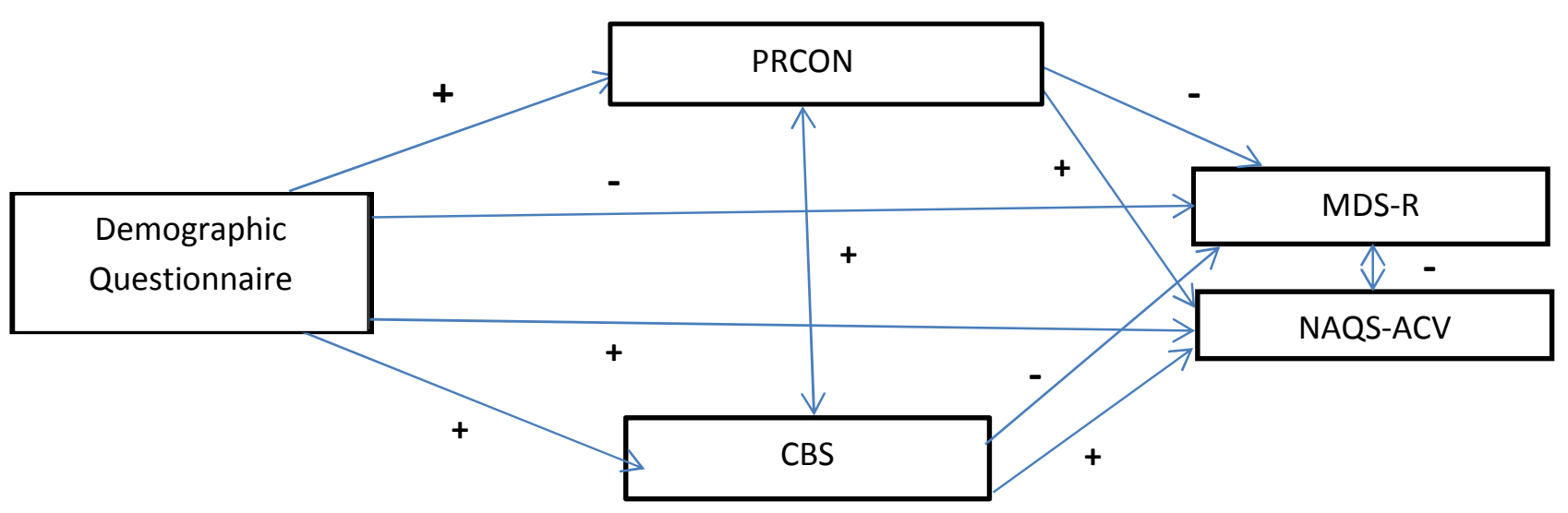

Figure 3. Analytic Model 


\section{Sample and Setting}

Participants were recruited from the membership roster of the Association of Pediatric Hematology/Oncology Nurses (APHON), a national association of 3,600 nurses and other health care professionals (APHON/Senior Operations Manager, personal communication, December 10, 2015). The core purpose of APHON is to support and advance nurses and their practice in order to optimize outcomes for children, adolescents, and young adults with cancer and blood disorders and their families (APHON, 2015).

APHON policies do not permit direct email contact with members by the investigator, but the investigator was able to contract with the national APHON office to distribute emails to the membership. In order to participate, nurses were required to be APHON members and able to read and write English.

Estimates of sample size were generated to determine the appropriate number of subjects required to obtain results that most accurately represent the reality of the population of interest (Browner, Newman \& Hulley, 2013). Sample size calculations require the following information: study hypotheses, identification of appropriate statistical tests, effect size, and levels of statistical significance and power (Browner et al., 2013). Effect size is identified by the investigator as the anticipated size of an association between the predictor and outcomes variables in the population, which will then be used to detect an association in the sample (Browner et al., 2013). Levels of statistical significance are set to determine whether results are sufficient to reject the null hypothesis, proposing no associations between variables. Power is the "probability of correctly rejecting the null hypothesis in a sample if the actual effect size in the population is greater than or equal to the specified effect size" (Browner et al., 2013, p. 
48). Conventionally, levels of statistical significance $(\alpha)$ are set at $p<0.05$ and power (1$\beta$ ) at $0.80-0.95$. Effect size is generally estimated from previous pilot work or other available data. When relevant data are unavailable, conventional effects sizes of small, medium, or large can be utilized. Effects sizes of a small to moderate amount are most common in nursing research (Polit \& Beck, 2012).

Prior to study implementation, power analysis for a regression model with a maximum of 6 predictors (years of experience in pediatric oncology, level of education, practice setting, formal training, composite score on PRCON, and composite score on CBS) with a moderate effect size of 0.15 , significance level of 0.05 , and $80 \%$ power was performed, resulting in a sample size estimate of 98 respondents $\left(\mathrm{G}^{*}\right.$ Power 3; Faul, Erdfelder, Lang, \& Buchner, 2007) (See Table 2). In an effort to increase study power and account for response rate and incomplete data, a goal of 300 respondents was established. This sample size was adequate for psychometric testing of the PRCON instrument (Tabachnick \& Fidell, 2001). In a similar study exploring the experiences of adult oncology nurses, a $29 \%$ response rate was achieved with a single mailing and no follow-up (Helft et al., 2011).

Table 2

Sample Size Estimates

\begin{tabular}{|c|c|c|c|c|c|}
\hline Hypothesis & $\begin{array}{l}\text { Predictor } \\
\text { Variables }\end{array}$ & $\begin{array}{c}\text { Level of } \\
\text { Significance }\end{array}$ & Effect Size & Power & $\begin{array}{c}\text { Required } \\
\text { Sample Size }\end{array}$ \\
\hline \multirow{2}{*}{$\begin{array}{l}\text { H1: Individual nurse } \\
\text { factors will be } \\
\text { associated with more } \\
\text { positive scores on the } \\
\text { PRCON scale. }\end{array}$} & \multirow{2}{*}{$\begin{array}{l}\text {-Experience } \\
\text {-Level of } \\
\text { education } \\
\text {-Practice } \\
\text { setting } \\
\text {-Formal } \\
\text { training }\end{array}$} & \multirow[t]{2}{*}{$p=<0.05$} & Moderate & $\begin{array}{l}.8 \\
.9\end{array}$ & $\begin{array}{l}\mathrm{n}=85 \\
\mathrm{n}=108\end{array}$ \\
\hline & & & Small & $\begin{array}{l}.8 \\
.9\end{array}$ & $\begin{array}{l}\mathrm{n}=602 \\
\mathrm{n}=776\end{array}$ \\
\hline
\end{tabular}




\begin{tabular}{|c|c|c|c|c|c|}
\hline \multirow{2}{*}{$\begin{array}{l}\text { H2: Individual nurse } \\
\text { factors will be } \\
\text { associated with more } \\
\text { positive scores on the } \\
\text { CBS. }\end{array}$} & \multirow{2}{*}{$\begin{array}{l}\text {-Experience } \\
\text {-Level of } \\
\text { education } \\
\text {-Practice } \\
\text { setting } \\
\text {-Formal } \\
\text { training }\end{array}$} & \multirow[t]{2}{*}{$p=<0.05$} & \multirow[t]{2}{*}{ Moderate } & \multirow{2}{*}{$\begin{array}{l}.8 \\
.9 \\
.8\end{array}$} & \multirow{2}{*}{$\begin{array}{l}\mathrm{n}=85 \\
\mathrm{n}=108 \\
\mathrm{n}=602 \\
\mathrm{n}=776\end{array}$} \\
\hline & & & & & \\
\hline \multirow[t]{4}{*}{$\begin{array}{l}\text { H3: PRCON and CBS } \\
\text { will be positively } \\
\text { correlated. }\end{array}$} & & \multirow[t]{4}{*}{$p=<0.05$} & $\begin{array}{l}\text { Moderate } \\
\text { Correlation } \\
(\mathrm{p}=.3)\end{array}$ & .8 & $n=67$ \\
\hline & & & $\begin{array}{l}\text { Moderate } \\
\text { Correlation } \\
(\mathrm{p}=.3)\end{array}$ & .9 & $\mathrm{n}=92$ \\
\hline & & & $\begin{array}{c}\text { Large } \\
\text { Correlation } \\
(\mathrm{p}=.5)\end{array}$ & .8 & $\mathrm{n}=23$ \\
\hline & & & $\begin{array}{c}\text { Large } \\
\text { Correlation } \\
(\mathrm{p}=.5)\end{array}$ & .9 & $\mathrm{n}=31$ \\
\hline \multirow{2}{*}{$\begin{array}{l}\text { H4: Individual nurse } \\
\text { factors as well as } \\
\text { more positive scores } \\
\text { on the PRCON and } \\
\text { CBS will be } \\
\text { associated with higher } \\
\text { levels of nurse } \\
\text { perceived quality } \\
\quad \text { of care as } \\
\text { measured by the } \\
\text { NAQS-ACV. }\end{array}$} & \multirow{2}{*}{$\begin{array}{l}\text {-Experience } \\
\text {-Level of } \\
\text { education } \\
\text {-Practice } \\
\text { setting } \\
\text {-Formal } \\
\text { training } \\
\text {-PRCON score } \\
\text {-CBS score }\end{array}$} & \multirow[t]{2}{*}{$p=<0.05$} & Moderate & $\begin{array}{l}.8 \\
.9\end{array}$ & $\begin{array}{l}\mathrm{n}=98 \\
\mathrm{n}=123\end{array}$ \\
\hline & & & Small & $\begin{array}{l}.8 \\
.9\end{array}$ & $\begin{array}{l}\mathrm{n}=688 \\
\mathrm{n}=878\end{array}$ \\
\hline \multirow{2}{*}{$\begin{array}{l}\text { H5: Individual nurse } \\
\text { factors as well as } \\
\text { more positive scores } \\
\text { on the PRCON and } \\
\text { CBS will be } \\
\text { associated with } \\
\text { reduced levels of } \\
\text { nurse moral distress as } \\
\text { measured by MDS-R, } \\
\text { pediatric version. }\end{array}$} & \multirow{2}{*}{$\begin{array}{l}\text {-Experience } \\
\text {-Level of } \\
\text { education } \\
\text {-Practice } \\
\text { setting } \\
\text {-Formal } \\
\text { training } \\
\text {-PRCON score } \\
\text {-CBS score }\end{array}$} & \multirow[t]{2}{*}{$p=<0.05$} & Moderate & $\begin{array}{l}.8 \\
.9\end{array}$ & $\begin{array}{l}\mathrm{n}=98 \\
\mathrm{n}=123\end{array}$ \\
\hline & & & Small & .8 & $\begin{array}{l}\mathrm{N}=688 \\
\mathrm{n}=878\end{array}$ \\
\hline $\begin{array}{l}\text { H6: Higher levels of } \\
\text { nurse perceived } \\
\text { quality of care as } \\
\text { measured by the }\end{array}$ & & $p=<0.05$ & $\begin{array}{l}\text { Moderate } \\
\text { Correlation } \\
(\mathrm{p}=.3)\end{array}$ & .8 & $\mathrm{n}=67$ \\
\hline
\end{tabular}




\begin{tabular}{|l|l|c|c|c|}
\hline $\begin{array}{l}\text { NAQS-ACV will be } \\
\text { correlated with } \\
\text { reduced levels of } \\
\text { nurse moral distress as } \\
\text { measured by the }\end{array}$ & & $\begin{array}{c}\text { Moderate } \\
\text { Correlation } \\
(\mathrm{p}=.3)\end{array}$ & .9 & $\mathrm{n}=92$ \\
\hline $\begin{array}{l}\text { MDS-R, pediatric } \\
\text { version. }\end{array}$ & $\begin{array}{c}\text { Large } \\
\text { Correlation } \\
(\mathrm{p}=.5)\end{array}$ & .8 & $\mathrm{n}=23$ \\
\hline & $\begin{array}{c}\text { Large } \\
\text { Correlation } \\
(\mathrm{p}=.5)\end{array}$ & .9 & $\mathrm{n}=31$ \\
\hline
\end{tabular}

\section{Study Variables and Instruments}

This study involved the completion of multiple instruments, which have been used in previous studies where they demonstrated adequate reliability and validity. The reliability and validity of each instrument are discussed in detail below.

\section{Prognosis-Related Communication in Oncology Nursing.}

The PRCON (Newman \& Helft, 2015) is a 20 -item instrument designed to characterize nurses' experiences with prognosis-related communication. Developed originally by Helft et al. (2011) as a survey, the original 34-item instrument consisted of a compilation of single-item questions exploring prognosis-related communication. No scale score was calculated. The instrument included two sections and a demographic questionnaire. The first section included 20 fixed-response items using a four-point Likert scale that measured the extent of disagreement or agreement (i.e., strongly disagree to strongly agree). The second section listed 14 items with a five-point Likert-type scale to measure frequency (i.e., always/almost always, often, sometimes, rarely, never). Content validity was established by practicing oncology nurses, but no additional psychometric 
testing was performed. The survey was mailed to members of the Oncology Nursing Society (ONS). A 29\% response rate was observed.

The original survey instrument was reviewed by this investigator, and identified as a potential measure of nurses' experiences with prognosis-related communication. Through a generous collaboration with Dr. Helft, survey data were shared with this investigator to perform psychometric testing to determine if the individual items in the scale could be aggregated into a valid and reliable measure. Construct validity was established with data obtained from the 394 nurses who returned the original survey. Factor analysis using principal components analysis with varimax rotation was utilized to explore if the items in the scale had an underlying factor structure. Analysis revealed a 3factor structure, accounting for $50 \%$ of the variance (Newman \& Helft, 2015). The three factors that make up the final 20-item instrument include MD Communication, RN Role, and Decision Making in the context of prognosis-related communication. Cronbach's alpha for the total scale was 0.75 , and subscale reliability estimates were 0.76 to 0.84 . A composite score can be calculated as well as subscale scores on the three different factors. In the original survey, lower scores indicated a more positive response, i. e., nurse comfort, agreement with the disclosure of prognosis-related communication, and involvement in the process. For ease of interpretation, the scale scoring will be reversed so that higher scores indicate more positive experiences.

Detailed development of the PRCON is described in the manuscript titled, “Reliability and Validity of a Tool to Assess Oncology Nurses' Experiences with Prognosis-Related Communication" (Newman \& Helft, 2015) in Appendix B. The PRCON scale is presented in Appendix C. 


\section{Collaborative Behavior Scale.}

The CBS (Stichler, 1989) (Appendix D) is a 20-item scale designed to determine the extent of collaborative behaviors that generally exist between the registered nurses and the physician providers on the respondent's unit. Nurses rate the responses on a 4point Likert scale, specifying the frequency of listed behaviors with " 1 " indicating behaviors occur "Rarely" and "4" indicating behaviors occur "Nearly Always." Scores are added together for one composite score (maximum score of 80) with higher totals indicating more collaborative relationships.

Factor analysis was performed to assess construct validity of the CBS. An alpha factoring technique with varimax rotation yielded a one-factor structure, accounting for $73 \%$ of the variance (Stichler, 1989). The content validity index of the original scale was reported at 0.91 (Stichler, 1989) with item-total correlations ranging from 0.78 to 0.90 . The standardized item alpha coefficient was 0.98 (Stichler, 1989). The scale was subsequently administered to 188 female nurses working in acute care hospitals. Cronbach's alpha remained high at 0.96 with average inter-item correlation at 0.57 (Stichler, 1990).

King and Lee (1994) administered the CBS to Navy physicians and nurses. Factor analysis again suggested a unidimensional tool with the first factor accounting for $64 \%$ of the variance (eigenvalue 12.8) and the second factor only accounting for 5\% (eigenvalue 1.01). These findings further support the construct validity of the instrument. The scale in this setting was found to reliably measure the construct of interdisciplinary collaboration with a Cronbach's alpha of 0.97 . Reliability was further supported by Almost and Laschinger (2002), who examined the relationships among nurse practitioner perceptions 
of workplace empowerment, collaboration with physicians and managers, and job strain. The CBS was used to measure collaboration with physicians. Cronbach's alpha was reported at 0.98 .

\section{Nurses’ Assessment of Quality Scale-Acute Care Version.}

The NAQS-ACV (Appendix E) was developed by Lynn et al. (2007a) as an instrument to document nurses' evaluations of the process of nursing care. Derived from qualitative interviews with acute care nurses, the items that make up the instrument reflect different aspects of "good nursing" care as described by nurses. Lynn et al. (2007a) contend that eliciting nurse perceptions of care quality is integral to a more comprehensive assessment of quality care. The instrument has three sections: nursing care and relationships between the nurse and the patient, acute care working environments, and intrinsic characteristics of the nurse. The first section, nursing care and relationships between the nurse and the patient, will be utilized in the proposed study. Lynn et al. (2007a) suggest using only the first section of the instrument if the patient is the unit of analysis or all of the sections when characterization of the nursing unit is the intent.

The original NAQS-ACV consisted of 138 items, and was administered to acute care nurses from 7 hospitals in the southeastern United States. The instrument was part of a 3-year longitudinal study. Of the 1,272 unique nurse respondents, 923 had complete data for analysis of the instrument (Lynn et al., 2007a). Because the questions differed substantially across sections, principal-axis factor analysis with oblique rotation was performed separately on each section to identify the underlying factor structure of each of the three sections. The first section originally contained 94 items, which were scored on a 
5-point Likert-type scale, ranging from "strongly disagree" to "strongly agree." Factor analysis revealed a 4 -factor structure for first section, which accounted for $51 \%$ of the variance. The four factors were labelled as Interaction, Vigilance, Individualization, and Advocate. Through factor analysis, the number of items in the first section was reduced to 45 , and mean inter-item correlations for the remaining items ranged from 0.47 to .57 . Cronbach's alpha was reported as ranging from .88 to .94 for each factor. The authors described the need for further establishing construct validity by evaluating the relationship between the NAQS-ACV and the attainment of achievable patient outcomes. No further papers were identified as using the NAQS-ACV.

Items were totaled for both factor and composite scores. Of note, the instrument has subsequently been modified by Dr. Lynn to a 4-point Likert-type scale. She indicated via personal communication that "While it was a 5-point response format initially, I have changed it to a 4-point one. There's no requirement for a neutral middle and I decided to drop it. People love to gravitate to neutral middles and over time I have definitely diminished their use" (December 19, 2015). Also, in order to assess nurses' perspectives of the quality of care provided in the context of prognosis-related communication, instructions on the instrument were modified slightly, asking nurses to think about a typical child with cancer whose parents were recently informed about the child's prognosis. The word "patient" in each item was replaced with "parent", as communication with parents is the focus of this research. Permission was obtained from Dr. Lynn to modify the content of the instrument as described. 


\section{Moral Distress Scale - Revised, Pediatric Version.}

MDS-R (Hamric, Borchers, \& Epstein, 2012) (Appendix F) was developed as a measure of levels of moral distress among healthcare professionals. The original scale was developed by Corley, Elswick, Gorman, and Clor (2001) to measure moral distress among critical care nurses. In an effort to increase its generalizability to different health care providers, Hamric et al. (2012) revised the scale, and created 6 parallel versions. Three focus on providers who practice in the adult setting; and three focus on providers who practice in the pediatric setting: nurses, physicians, and other health care providers. The revisions resulted in a 21 -item scale. Items are based on moral dilemmas that present in the healthcare environment. Each of the 21 items is scored by participants in terms of how often the situation arises (frequency) and how disturbing the situation is when it arises (termed "level of disturbance" on the scale; referred to as "intensity."). The scale for frequency ranges from 0 (never) to 4 (very frequently), and for intensity from 0 (none) to 4 (great extent). Frequency and intensity scores can each be summed and evaluated separately, but composite scores can also be calculated via a two-step process. First, the frequency score and the intensity score are multiplied for each of the 21 items. This creates a new variable for each item, the frequency $\mathrm{x}$ intensity (fxi) score. Next the composite score is obtained by summing each item's fxi score. The resulting score based on 21 items has a range of 0-336.

Content validity was established by 4 content experts on moral distress including all three of the authors and the director of a multihospital ethics program (Hamric et al., 2012). Each person independently reviewed each item, identifying the primary and secondary root causes of moral distress in each item. Eighty-eight percent interrater 
agreement was achieved with full agreement for 19 of the 21 items. One item was reworded, one was eliminated, and a new item created. Minor revisions were made to 5 other items. In addition a nurse and a physician, who led a palliative care service at a large, multihospital system, reviewed the final items for appropriateness and clarity of content. The scale was then administered to 37 physicians and 169 nurses including 12 pediatric physicians and 38 pediatric nurses, all of whom practiced in the intensive care setting. Reliability was established by calculating the Cronbach's alpha for the nurse (0.89) and physician populations ( 0.67 overall, 0.69 for attending physicians, 0.75 for pediatric physicians) as well as for all participants combined (0.88). Construct validity was evaluated through hypothesis testing, correlating moral distress with other variables as suggested by previous research. Each of the four hypotheses presented was supported including associations between years of experience, ethical climate, role in the health care team, intention to leave one's current position and moral distress. The authors concluded that testing revealed "promising evidence of instrument reliability and validity" (p. 6).

Outside of the critical care environment, Whitehead, Herbertson, Hamric, Epstein, and Fisher (2015) utilized the MDS-R to measure levels of moral distress among healthcare professionals within a large healthcare system. Of the 592 usable surveys, 395 (67\%) were completed by registered nurses (RN), 111 (19\%) by physicians, and 86 $(15 \%)$ by other healthcare providers. Moral distress was seen in varying degrees across all groups of healthcare providers. One of the authors' hypotheses suggested that healthcare providers intending to leave their positions due to moral distress would have higher scores on the MDS-R than those not intending to leave their positions. Their hypothesis was confirmed as a significant difference was found between mean scores on 
the MDS-R between healthcare providers who had considered leaving their current positions and those who had not, thus further supporting the construct validity of the instrument. Cronbach's alpha for the different groups was reported at 0.90 for the $\mathrm{RN}$ group, 0.88 for the physician group, and 0.90 for other providers. In another recent report, Allen et al. (2013) examined moral distress with the MDS-R among a multi-disciplinary sample. Internal consistency was again found to be robust with Cronbach's alpha of 0.880.95 .

\section{Demographic Questionnaire.}

An investigator-generated demographic questionnaire (Appendix G) was created to capture the following individual nurse factors: number of years as a pediatric oncology nurse, highest level of education (associate degree, baccalaureate degree, Master's degree, doctoral degree), primary area of practice (inpatient, outpatient), and extent of training and education in prognosis-related communication. Extent of training and education in prognosis-related communication will be assessed on a Likert scale, ranging from None/Almost None to A Great Deal. Additional information including participant age, gender, ethnic/racial group, number of years as a registered nurse, primary position, current clinical patient contact, percentage of time caring for children with cancer, and state of residence was used to describe the sample.

\section{Data Collection Methods}

Survey methodology was the primary means of collecting the required data elements. When considering use of an online or postal survey, the proposed research questions, available financial resources, scope of sampling, issues associated with timing, 
and the demographics of respondents should all be assessed (Reitz \& Anderson, 2013). Survey methodologies are generally flexible and broad in scope, and can be successful in reaching large numbers of people (Polit \& Beck, 2012; Reitz \& Anderson, 2013). In this study, survey methodology allowed data collection to be more extensive, obtaining data from a broad range of pediatric oncology nurses from across the country representing a range of hospital sizes, levels, and pediatric oncology service lines. Further, employing a web-based medium for the survey was cost effective, potentially minimized errors in data entry as respondents input data themselves, and resulted in timely access to data for analysis (Reitz \& Anderson, 2013). As research had not previously been performed with a sample of pediatric oncology nurses, all of these characteristics made web-based survey methodology the best choice for exploring the perceptions of pediatric nurses regarding their experiences with prognosis-related communication.

Eligible members of the APHON were asked to complete an online survey, which included study instruments and a demographic questionnaire. Strategies and procedures as outlined by Dillman, Smith, and Christian (2009) for web-based survey implementation were followed. After Institutional Review Board (IRB) approval was obtained, the national APHON office sent out an email to all APHON members inviting them to participate in the study. A link to the survey was provided in the email. The email consisted of an invitation to participate in the study, and communicated to the potential respondents what they were being asked to do, why they were being asked to do it, steps on how to access the survey, and what potential risks and benefits that may come from their participation. Respondents were also informed that the anticipated survey completion time was 15 to 30 minutes. The survey was available via SurveyMonkey®. 
The first screen of the survey included instructions for completing the survey, a review of the purpose of the research being performed, and instructions to contact the principal investigator (PI) if respondents had any questions about the study. The second screen included the necessary components of informed consent. Once reviewed, participants were asked to click to "Agree" to participate. Once participants "agreed" to participate, they were given access to the survey. The survey incorporated items from the 4 different study instruments and a demographics questionnaire. Upon completion of the online survey, respondents were offered a \$5 Target coupon code, if they were willing to provide their email address.

Two weeks after the initial email was sent, a second email from the national APHON office was sent out to all APHON members again inviting them to participate in the study. This follow-up email served as a reminder to those members who had not completed the survey. Almost 4 weeks after the $2^{\text {nd }}$ email was sent out, a final email invitation was sent out from APHON, inviting members to participate.

Only the PI had access to the survey data. No personal information including participant names was collected. Data captured in the survey were directly imported into SPSS for statistical analyses. All electronic files were password protected.

\section{Methodological Rigor}

Methodological rigor including efforts to minimize biases and control confounding variables is essential to strengthening inferences made from results of a research study. Threats to the validity of a study increase the chance that inferences may be wrong (Polit \& Beck, 2012), therefore, threats to internal and external validity must be assessed and addressed during the design, analysis, and interpretation phases of the 
research process. Internal validity is defined as "the degree to which it can be inferred that an observed outcome was caused by a treatment or independent variable, rather than by uncontrolled extraneous factors" (Polit, 2010, p. 402). External validity "concerns whether inferences about observed relationships will hold over variations in person, setting, time, or measures of the outcomes," (Polit \& Beck, 2012, p. 236), speaking to the generalizability of findings. Because of manipulation and random assignment, experimental research designs include a high degree of internal validity. Conversely nonexperimental designs grapple with competing explanations of what causes outcomes (Polit \& Beck, 2012). The non-experimental nature of the study presented a number of threats to both internal and external validity.

Convenience sampling was utilized in the proposed study, which introduced a potential selection bias (Onwuebuzie, 2000; Polit \& Beck, 2012). All APHON members were invited to participate via an email, but a bias exists in that not all pediatric oncology nurses are members of APHON. Further, only a subset of members responded. Members who responded may not be representative of members as a whole. Despite these potential biases, sample size calculations were performed to ensure that an adequate sample size was obtained in order to perform the identified statistical analyses. In addition, baseline characteristics of APHON members (as a whole) including role and geographic location, were compared to characteristics of the sample, and incorporated into the interpretation of findings. Finally, surveying the entire membership had the potential to include respondents of all ages, sections of the country, and size of cancer programs.

Instrumentation bias is introduced when utilizing different questionnaires to represent constructs in the study. Instrumentation bias occurs when instruments lack the 
appropriate level of internal consistency (i.e., low reliability) or are not valid as a result of inadequate content-, criterion-, and/or construct-related validity (Onwuebuzie, 2000). To address this potential threat, instruments with documented estimates of reliability and validity from prior studies were selected to represent the constructs in the proposed study. In addition, psychometric analyses were performed on each of the instruments, and results reported.

Testing bias generally refers to the sensitization that can occur when participants take a pre-test, which impacts their performance on a subsequent post-test (Polit \& Beck, 2012). While a pre-test/post-test design is not being used in the proposed study, the ordering of study instruments has the potential to impact responses (Dillman et al., 2009). Dillman et al. refer to this as cognitive-based order effect, when early questions influence the cognitive processing of later questions. Therefore, the ordering of the instruments must be carefully considered and evaluated when analyzing results. The demographic questionnaire was placed first, followed by the CBS and then the PRCON. Placing the CBS before the PRCON may have potentially reduced any influence the questions on the PRCON may have had on answers to the CBS. The MDS-R and the NAQS-ACV followed.

Several different types of external validity including population, ecological, and temporal validity have been described. Population validity refers to the extent to which the sample is reflective of the target population (Onwuebuzie, 2000). Population validity can be increased by utilizing large sample sizes and random sampling. While random sampling was not performed, a large sample of over 300 nurses from across the country was obtained. Ecological validity incorporates the extent to which findings can be 
generalized across settings, conditions, variables, and context (Onwuebuzie, 2000). Again, the hope with using a national survey was that a variety of different practice settings, geographic regions, and center sizes would be represented, expanding the generalizability of the findings. Finally, temporal validity assumes that findings will be consistent across time (Onwuebuzie, 2000). The cross-sectional nature of the study limits the temporal validity of the findings. The purpose of this observational study was to better understand the perceptions of pediatric oncology nurses in our current state of practice, thus temporal validity is not critical.

No study can be executed without potential measurement error. Therefore, the goal is to minimize error by aiming for prevention through thoughtful research design and readdressing potential error when analyzing the data (Hulley, Newman, \& Cummings, 2013). By addressing potential sources of error, the researcher can maximize the validity of inferences from what was observed in the study sample to the relevant population. Two main classifications of measurement error have been identified: random and systematic (Hulley et al., 2013). Both types of error can produce findings in a study sample that do not exist in the population (Newman, Browner, \& Hulley, 2013).

Random error is a "departure of a measurement from its true value due to chance variance" (Hulley et al., 2013, p. 343). Random error can be minimized by repeating measurements or increasing sample size. Use of a larger sample size increases the precision of the estimate. In an effort to minimize the risk of random error, power analyses were performed to identify the required number of respondents to provide meaningful results. 
Systematic error is generally referred to as bias, and refers to an error in measurement due to a shortcoming in the study's design, execution, or analysis (Hulley et al., 2013). Potential biases include situational contaminants, administration variations, instrument clarity, item sampling, and instrument format (Polit \& Beck, 2012). Systemic error can be minimized by establishing precise, well-delineated research methods. In addition, all variables and constructs should be well-defined, and valid and reliable instruments that are most representative of the constructs selected to measure predictor and outcome variables (Newman et al., 2013). To minimize the risk of systematic error, instruments with established reliability and validity were used to represent the variables of interest. Further each variable and construct were well-defined. In addition, electronic survey methodology ensures consistent delivery of the instruments with limited variance.

The most worrisome and frequent source of error is selection bias (Polit, 2010). Selection bias introduces unaccounted differences (confounding variables) between groups being compared that affect the outcome variable extraneous to the predictor variable (Polit \& Beck, 2012). To reduce the risk of selection bias, random sampling should be performed whenever feasible as they have a greater likelihood of being more representative of the population than nonrandom samples (Polit, 2010). If nonrandom sampling is employed, the researcher should seek a sample that is most representative of the population, acknowledging that findings will be limited in terms of generalizability. Although a random sample was not obtained, using the APHON membership roster to recruit subjects permitted access to the survey by a wide range of participants. Further, demographic information for APHON members as a whole was obtained from the national APHON office, which enabled assessment of differences between the population 
and the sample. Statistical analyses including t-tests, analysis of variance (ANOVA), Chi squared, and regression can be performed to assess for significant differences between and among groups.

Additional sampling biases include attrition, cohort, and nonresponse biases (Polit, 2010). In this dissertation research involving survey research, nonresponse bias was a potential threat. Nonresponse bias occurs when those from a sample who do not respond to a survey invitation significantly differ on some characteristic from those who respond to the survey in a way that is meaningful to study results (MacDonald, NewburnCook, Schopflocher, \& Richter, 2009). Strategies as outlined by MacDonald et al. (2009) and Dillman et al. (2009) were used to minimize nonresponse bias. Strategies included using an electronic survey platform (i.e., SurveyMonkey ${ }^{\circledR}$ ) that is user-friendly, incorporating information in the invitation email outlining the significance of the research and why response was needed, informing the respondent he or she can complete the survey in more than one sitting if needed, and sending a follow-up email (if needed) to remind members to respond if they had not already. Nonresponse bias can be random or systematic, and can also occur as both item nonresponse and unit nonresponse. Item nonresponse will be addressed as missing values. The focus of this section is on unit nonresponse, meaning the participant. After results have been obtained and if data review suggests a nonresponse bias is present, data will be adjusted by weighting or imputation techniques (MacDonald et al., 2009). In addition, the achieved response rate and any concerns for bias will be reported.

Statistical error describes the difference between the measurement obtained from the sample and the true value for the population. The risk of statistical error can be 
reduced during the design phase by ensuring an adequate sample size based on power analysis, which incorporates level of significance, power and effect size. Following data collection and during the data analysis phase, statistical tests can be performed to quantify the risk of results occurring by chance with a given sample. Several strategies were employed in designing the dissertation research and analyzing the data. First, sample size calculations were performed to ensure a sample size large enough to perform the statistical analyses, as outlined, reducing the risk that random error may impact the findings. Further, $\alpha$ was set at .05 , and $p$ values and confidence intervals are reported.

\section{Statistical Procedures and Rationale}

Data obtained in the SurveyMonkey® web-based survey were exported to SPSS, Version 24. Prior to analyses, the data were cleaned, assessed for normality and transformed as necessary. Missing data were analyzed to determine if items were missing completely at random or if items were related to other variables across cases. The Missing Values Analysis (MVA) function in SPSS was utilized to assess the extent of missing values for each item as well as the amount of missingness within each case. Using different statistical tests (such as $t$ tests or Chi square), the MVA module was used to evaluate for patterns of missingness, exploring relationships that may have existed between missing items and other variables within the dataset. Such relationships can introduce bias into the findings, and must be taken into consideration when data are analyzed and inferences are made. Case mean substitution, using the participant's scale or sub-scale mean, was be used for missing values on the PRCON, CBS, NAQS-ACV, and MDS-R, if less than $25 \%$ of the items were missing. 
Descriptive statistics were calculated (means and standard deviations) for age, number of years as a registered nurse, and number of years as a pediatric oncology nurse. Of note, in the survey, nurses were asked for their year of birth. Respondent's year of birth was subtracted from 2016, yielding the respondent's age in years. Age in years was used for all calculations. Frequencies were calculated for gender, racial and ethnic group, percentage of time spent caring for pediatric oncology patients, level of education, practice setting, and formal training in prognosis-related communication. Finally, psychometric evaluation of instruments including reliability of scales and subscales and exploratory factor analysis for validity were performed.

Specific Aim 1 was analyzed by examining composite and subscale scores from the PRCON. Descriptive statistics including measures of central tendencies, ranges, and frequencies are reported.

Specific Aim 2 was addressed using multiple regression and correlation. Multiple regression analyses were performed with individual nurse factors (experience in pediatric oncology, level of education, practice setting, and extent of formal training in prognosisrelated communication) functioning as predictor variables and PRCON and CBS as outcome variables in 2 separate regression analyses. Pearson's $r$ correlation was used to determine the relationship between PRCON and CBS.

Specific Aim 3 employed hierarchical multiple regression and correlation. Hierarchical regression analyses were performed with individual nurse factors each entered as predictor variables in the first stage. PRCON and CBS were then entered as predictor variables in the second stage. NAQS-ACV and MDS-R were the outcome 
variables. Pearson's $r$ correlation was used to determine the relationship between NAQS$\mathrm{ACV}$ and MDS-R.

Individual nurse factors identified as possible predictors of process and outcome variables included years of experience in pediatric oncology nursing, level of education, practice setting, and formal training in PRC. For regression analyses, three of the variables were dichotomized: education $(0=$ diploma, associate, or Bachelor's degree; $1=$ Master's or doctoral degree $)$; practice setting $(0=$ inpatient; $1=$ outpatient or inpatient/outpatient); and PRC training ( $0=$ none or a little bit; $1=$ moderate amount or great deal).

A significance level of $\mathrm{p}<.05$ was used for all statistical tests.

\section{Human Subjects Protection}

An IRB application was submitted to the Marquette University IRB. The IRB submission included the study protocol, a copy of the electronic survey invitation, and copies of all of the survey instruments. The protocol was given exempt status. When participants accessed the online survey, one of the introductory screens included the necessary components of informed consent. Once reviewed, participants were asked to click to "Agree" to participate. Once participants "agreed" to participate, they were allowed access to the study. Accessing and completing the online survey was completely voluntary. Participants were able to skip questions, if they preferred, and had the ability to stop the survey at any time. Internet Protocol (IP) information was not collected. Each participant was assigned a unique identification number. The PI was the only person with access to the SurveyMonkey ${ }^{\circledR}$ account. All documents and files generated over the 
course of the study were kept in either locked filing cabinets or password protected electronic files. This study was believed to pose minimal risk to respondents.

\section{Limitations}

Several limitations were identified prior to study implementation. First, sampling from a

professional organization may introduce selection bias, in that, nurses who are members of their professional organization may not be representative of all of the nurses who care for children with cancer. The perceptions of prognosis-related communication and the other variables of interest may differ between nurses who are and are not members of APHON.

Although initial work has been done to assess the validity and reliability of the PRCON, the instrument has not been further validated nor has it been used in the setting of pediatric oncology. In addition, instructions and items in the NAQS-ACV were modified in order to apply the instrument to the current sample. Modifying an instrument from the way in which it was originally tested may limit reliability. Further, all of the instruments are based upon nurses' perceptions without any objective measurements. While perceptions are the nurse's reality, perceptions are subjective, and may not be the same among nurses in other subspecialties or other health care professionals. Further while deemed an important measure of quality, not obtaining patient and family perspectives on quality is a limitation in that nurses and patients may have different evaluations of quality. Thus, perceptions can potentially limit both the internal and external validity of the findings. Finally, the cross-sectional nature of the research design 
does not support causal inferences. Future work should capitalize on research designs that address causation, such as experimental or quasi-experimental designs.

\section{Summary}

This chapter provided a detailed description of the research design and methods that were used to address the specific aims and related hypotheses of the dissertation research exploring pediatric oncology nurses' perceptions of their experiences with prognosis-related communication. The sample and setting along with the details of the survey methodology were described. All of the instruments along with their psychometric properties were depicted, and are available for review in the Appendix. The plans for statistical analyses were discussed as were measures to minimize error and provide valid and reliable findings. Finally, plans for the protection of human subjects were outlined. 


\section{Chapter Four: Results}

Chapter Four includes sample characteristics, descriptive statistics for study measures, and results of data analysis for each of the three specific aims and the associated research question and six hypotheses. The major findings of the study are presented in the manuscript, "Pediatric Oncology Nurses' Experiences with PrognosisRelated Communication" (Appendix H), and are not duplicated in this section. Additional analyses presented below include: (1) demographic and scale characteristics not presented in the major study findings manuscript, (2) additional detail on findings for the hypotheses, and (3) psychometric analyses of the PRCON and NAQS-ACV.

\section{Demographics}

Three hundred and thirty-eight pediatric oncology nurses responded to emails, inviting them to participate in the online survey. The initial email was sent to the 2,600 nurse members of APHON. After 2 weeks, 114 nurses had responded. A second email to all 2,600 nurse members was sent out on 5/13/2016. Eighty-one nurses responded to the second email. A third and final email was sent out to the 2,600 nurse members on 6/9/2016. Between this date and 6/20/2016 when the survey was closed, 143 additional nurses responded. After reviewing the initial consent screen, 8 nurses elected not to participate. Of the remaining 330 respondents, 2 nurses identified themselves as having “ 0 ” years of experience in pediatric oncology. One further identified him/herself as working for a patient advocacy organization. The other respondent indicated spending 0$25 \%$ time in direct care of children with cancer. Both of these cases were removed as they appeared to have limited to no direct experience caring for pediatric oncology 
patients and their families. Of the remaining 328 respondents, 7 did not complete any of the survey instruments, and 5 completed only the demographic section. Thus, these 12 cases were not included in the analyses. The remaining 316 respondents completed at least one of the study instruments and were included in the analyses. Most of the demographic characteristics of the sample are presented in the manuscript, "Pediatric Oncology Nurses’ Experiences with Prognosis-Related Communication” (Appendix H). In the manuscript, data on several demographic categories were aggregated for analysis. A detailed description is reported here. When asked about ethnicity, 295 (93.4\%) of nurse respondents classified themselves as Non-Hispanic or Latino, and 17 (5.4\%) classified themselves as Hispanic or Latino. Nurses were also asked to choose with which racial group they identified, and were allowed to select as many options as they felt applied. Thirteen respondents chose "Other" (Table 3). The category of "Other" was maintained for analyses. Because of the limited variability in Ethnicity, Race rather than ethnicity was utilized in all analyses.

Table 3

“Other” Race Categories

\begin{tabular}{|l|c|}
\hline Other Race Categories & $\mathbf{n}=\mathbf{1 3}$ \\
\hline White and Native Alaskan/American Indian & 3 \\
\hline Asian and White & 2 \\
\hline African & 2 \\
\hline Black/White/Native Alaskan/American Indian & 1 \\
\hline Egyptian & 1 \\
\hline Filipino & 1 \\
\hline Indian/Irish/German & 1 \\
\hline Mexican American & 1 \\
\hline White/Native Hawaiian or Other Pacific Islander & 1 \\
\hline
\end{tabular}


In response to highest level of education achieved, 7 nurses responded "Other." Five nurses indicated they had graduated from a diploma program, and one indicated she became a registered nurse through a school of nursing. Two nurses reported they had achieved a nurse practitioner certificate. Three nurses indicated that they were in the processing of pursuing a Master's degree. For the purpose of regression analyses, six of these responses were coded as “ 0 ” for Associate/Bachelor's degree, and one was coded as “1” for Master's/Doctoral degree. In regards to practice location, two nurses added that they had an academic appointment in addition to their clinical positions; both were coded as " 1 ” for Outpatient for analyses. The majority of nurses $(n=176,56.2 \%)$ spend 76$100 \%$ of their time in the direct care of children with cancer while $57(18.2 \%)$ reported spending $51-75 \%$ of their time in direct care. Fifty nurses $(16.0 \%)$ with one or more years of experience in pediatric oncology reported spending $0-25 \%$ of their time in the direct care of children with cancer and 30 nurses $(9.6 \%)$ spend $25-50 \%$ of their time. Finally, 198 nurses (63.3\%) reported working in Magnet巴 institutions, whereas $104(33.2 \%)$ did not work in Magnet ${ }^{\circledR}$ institutions. Eleven (3.5\%) nurses indicated this was not applicable, and 3 nurses did not answer this question. "Not applicable" responses were recoded as " 1 " or "No" for the purpose of analysis.

Demographic information about all national APHON members was obtained from the national APHON office (N. Wallace, personal communication) and compared to the study sample (Table 4). The largest percentage of respondents were staff nurses (43\%), and staff nurses make up the majority of the APHON membership (58\%). Nurse practitioners $(17 \%)$ and nurse coordinators $(14 \%)$ were represented in the study sample more frequently than the membership at large (12\% and 3\% respectively). About $19 \%$ of 
the APHON membership is made up of nurse researchers, but only $2 \%$ of study respondents were nurse researchers. Finally, the role of "research nurse" was included in the survey, and $5 \%$ of respondents reported this position. This role is not uniquely identified within the APHON database, and therefore, is not comparable. These nurses may be included in the $226(6 \%)$ APHON members who, when asked about their primary position, reported "None of the Above."

Table 4

Comparison of Sample and National APHON Member Characteristics

\begin{tabular}{|c|c|c|c|c|c|}
\hline & & \multicolumn{2}{|c|}{$\begin{array}{c}\text { Study } \\
\text { Sample }\end{array}$} & \multicolumn{2}{|c|}{$\begin{array}{l}\text { National } \\
\text { APHON }\end{array}$} \\
\hline & & n & $\%$ & $\mathbf{n}$ & $\%$ \\
\hline Highest Educational & & \multicolumn{2}{|c|}{$\mathrm{N}=314$} & \multicolumn{2}{|c|}{$\mathrm{N}=3600$} \\
\hline & Associate's Degree & 22 & 7 & - & - \\
\hline & Bachelor's Degree & 156 & 49 & - & - \\
\hline & Master's Degree & 117 & 37 & - & - \\
\hline & Doctoral Degree & 12 & 4 & - & - \\
\hline & Other & 7 & 2 & - & - \\
\hline Primary Position & & \multicolumn{2}{|c|}{$\mathrm{N}=316$} & & \\
\hline & Staff nurse & 137 & 43 & 2098 & 58 \\
\hline & Nurse practitioner & 52 & 17 & 445 & 12 \\
\hline & Nurse coordinator & 45 & 14 & 104 & 3 \\
\hline & $\begin{array}{l}\text { Nurse administrator } \\
\text { (director/supervisor/manager) }\end{array}$ & 22 & 7 & 305 & 8 \\
\hline & Educator & 21 & 7 & 197 & 5 \\
\hline & Clinical nurse specialist & 17 & 5 & 157 & 4 \\
\hline & Research nurse & 16 & 5 & - & - \\
\hline & Researcher & 6 & 2 & 68 & 19 \\
\hline & None of the above & - & - & 226 & 6 \\
\hline \multirow[t]{4}{*}{$\begin{array}{l}\text { Primary Area of } \\
\text { Practice }\end{array}$} & & \multicolumn{2}{|c|}{$\mathrm{N}=312$} & \multicolumn{2}{|c|}{$\begin{array}{ll}220 & 0 \\
\end{array}$} \\
\hline & Inpatient & 104 & 33 & - & - \\
\hline & Outpatient & 130 & 42 & - & - \\
\hline & Both inpatient and outpatient & 78 & 25 & - & - \\
\hline Employment Status & & \multicolumn{2}{|c|}{$\mathrm{N}=315$} & & \\
\hline & Full time & 271 & 86 & - & - \\
\hline & Part time & 39 & 12 & - & - \\
\hline
\end{tabular}




\begin{tabular}{|l|l|c|c|c|c|c|}
\hline & Casual or per diem & 4 & 1 & & - & - \\
\hline & Other & 1 & 0.3 & & - & - \\
\hline Region of Practice & & $\mathrm{N}=303$ & & \multicolumn{2}{|c|}{$\mathrm{N}=3476$} \\
\hline & Midwest & 75 & 25 & & 733 & 21 \\
\hline & Southeast & 69 & 23 & & 712 & 21 \\
\hline & Northeast & 59 & 19 & & 776 & 22 \\
\hline & West & 50 & 17 & & 842 & 24 \\
\hline & Southwest & 43 & 14 & & 368 & 11 \\
\hline & Alaska/Hawaii & 7 & 2 & & 22 & 0.01 \\
\hline & Washington DC & - & - & & 22 & 0.01 \\
\hline
\end{tabular}

\section{Scale Characteristics}

\section{Preliminary Screening of Data}

After the survey was closed, data obtained in the SurveyMonkey ${ }^{\circledR}$ web-based survey platform were exported to SPSS, Version 24. Demographic variables and instrument responses were analyzed for missing values. The Missing Values Analysis (MVA) function in SPSS was utilized to assess the extent of missing values for each item as well as the amount of missingness within each case. No more than $4 \%$ of values were missing for any of the demographic variables. "In what year were you born?" and "In which state do you work?" had the most missing values ( $n=13$ for both, $4.1 \%)$. Missingness on other demographic variables ranged from 0 to 4 missing responses. No patterns were identified among missing values. Of the 316 cases, none had more than 3 variables missing.

Of all the missing items, MVA only identified a significant difference by age for those who did and did not answer MDS Frequency (Present, $n=260$; Missing, $n=43$ ) and Intensity (Present, $n=255$; Missing, $n=48$ ) Question \#7, "Continue to participate in care for a hopelessly ill child who is being sustained on a ventilator, when no one will 
make a decision to withdraw support." Respondents who were younger $[M=43.6$ years (for both frequency and intensity) were more likely to have answered the question than those who were older [ $M=47.2$ years (frequency) and 47.0 (intensity)] [MDS Frequency 07: $t(56.7)=-2.1, p=.04]$ [MDS Intensity 07: $t(67.6)=-2.2, p=.03$ ]. As these were only 2 items within the instrument and in order to maintain reliability and validity of the instrument, these items were not deleted. Little's MCAR test exploring calculated age, years as RN, years as pediatric oncology RN, PRCON composite score, CBS composite score, NAQS composite score, and MDS summed score was not significant $\left(X^{2}(42)=\right.$ $38.01, p=.65)$, suggesting missing values were missing completely at random. Subsequently case mean substitution, using the participant's scale mean, was used for missing values on the PRCON, CBS, NAQS-ACV, and MDS-R, if less than $25 \%$ of the items were missing.

Prior to applying the described statistical tests, preliminary analyses were conducted to ensure that there were no outliers or violations of assumptions of normality and linearity. Continuous variables (age, years as registered nurse, and years as pediatric oncology nurse) were assessed. Age in years ranged from 24 to 70 . The distribution of scores were not skewed (.03), but slightly kurtotic (-1.06) (Kolmogorov-Smirnov $=.08, p$ $=.00)$. Review of the shape of the distribution revealed a near normal distribution shape. Outliers were not identified on box plot. Years as a registered nurse ranged from 1 to 46. The distribution of scores were not skewed (.26), but slightly kurtotic (-1.09) (Kolmogorov-Smirnov $=.11, p=.00)$. On examination of the histogram, the distribution appeared relatively normal, and no outliers were identified on box plot. Years as a pediatric oncology nurse ranged from 1 to 40. The distribution of scores demonstrated a 
slight positive skew (.49) and mild kurtosis (-.78) (Kolmogorov-Smirnov $=.10, p=.00)$. This slight positive skew was identified upon review of the histogram. No outliers were identified on box plot. With larger samples, Tabachnick and Fidell (2007) recommend evaluating the shape of the distribution instead of using formal inference tests to assess normality and kurtosis as the impact of departure from zero diminishes with large sample sizes. As no significant violations of normality or linearity were identified, no transformations were required.

Composite scale scores on the different instruments were also assessed for outliers and violations of assumptions of normality and linearity. PRCON composite scores ranged from 29 to 69 (possible range 20 to 80 ) with a mean score of 52.2. Minimal skewness and kurtosis were noted (-.08 and .95, respectively) (Kolmogorov-Smirnov $=.08, p=.00)$. Review of the histogram and Normal Q-Q plot demonstrated a normal distribution and reasonably straight line. Ten outliers were identified on box plot; 5 high and 5 low, making up 3.3\% of the sample. The 5\% trimmed mean was examined, and was found to be quite similar to the standard mean, both at 52.2. Tabachnick and Fidell (2007) indicate that in large samples a small percentage of outliers are expected. For this instrument, as the trimmed mean was equal to the calculated mean of the sample, the outliers did not appear to affect the results. CBS scores ranged from 24 to 80 (possible range 20 to 80$)$ with a mean score of 64.7. Mild negative skew (-.61) and kurtosis (-.43) were noted $($ Kolmogorov-Smirnov $=.12, p=.00)$. A negative skew was also appreciated on the histogram. Only one low outlier was noted on box plot. NAQS-ACV scores ranged from 124 to 180 with a mean score of 153.4 (possible range 45 to 180). Minimal skew (.06) was noted, but mild kurtosis (-1.46) was identified (Kolmogorov-Smirnov $=.14, p=$ 
$.00)$. Histogram demonstrated a relatively flat distribution. No outliers were identified on the box plot. MDS scores ranged from 0 to 222 (possible range 0-336) with a mean score of 63.9. The distribution was noted to be positively skewed (1.21) and kurtotic (2.02) $($ Kolmogorov-Smirnov $=.11, p=.00)$. Inspection of the histogram demonstrated a positive skew. Ten high outliers (3.7\% of sample) were identified with one considered an extreme outlier, which is more than 3 times the interquartile range above the $3^{\text {rd }}$ quartile (Polit, 2010). Transformation of this variable was performed using square root, logarithmic, and inverse transformations. The square root transformation of MDS data resulted in a skew statistic of -.01 and a normal distribution of scores on histogram. The transformed data were used in a hierarchical regression equation, as per Specific Aim 3, and final $\mathrm{R}^{2}$ of the final model was .01 less than the non-transformed data. Therefore, the decision was made to proceed with the analyses using non-transformed data. Logarithmic and inverse transformations did not improve the skew.

\section{Scale Statistics}

Scale statistics are reported in the manuscript, "Pediatric Oncology Nurses' Experiences with Prognosis-Related Communication (Table 3, Appendix H). A detailed analysis was conducted of highest and lowest scoring items reported items on all of the measures (Table 5). 
Table 5

Top and Low-Scoring Items on Each Instrument

\begin{tabular}{|c|c|c|c|c|c|}
\hline & CBS & PRCON & NAQS-ACV & MDS-R & MDS-R \\
\hline & & & & Intensity (Distress) & Frequency \\
\hline & Frequency & Agree/Disagree & Agree/Disagree & Level & \\
\hline $\begin{array}{l}\text { Highest } \\
\text { Scores }\end{array}$ & $\begin{array}{l}\text { 1. Committed to } \\
\text { working as } \\
\text { team } \\
\text { 2. Support other } \\
\text { as team } \\
\text { members } \\
\text { 3. Trust each } \\
\text { other } \\
\text { 4. Work } \\
\text { together as team } \\
\text { 5. Work as } \\
\text { partners }\end{array}$ & $\begin{array}{l}\text { 1. Require prognosis to } \\
\text { make decisions about } \\
\text { hospice care } \\
\text { 2. Require prognosis to } \\
\text { make decisions about } \\
\text { treatment including } \\
\text { clinical trials } \\
\text { 3. Require prognosis to } \\
\text { make decisions about } \\
\text { child's care } \\
\text { 4. Most doctors I work } \\
\text { with are skilled at } \\
\text { discussing prognosis } \\
\text { information } \\
\text { 5. I cannot advocate for } \\
\text { patients when they } \\
\text { don't understand } \\
\text { prognosis }\end{array}$ & $\begin{array}{l}\text { 1. Be } \\
\text { compassionate } \\
2 . \text { Be kind and } \\
\text { friendly } \\
\text { 3. Introduce } \\
\text { myself } \\
\text { 4. Be sensitive } \\
\text { 5. Be dedicated } \\
\text { and } \\
\text { conscientious }\end{array}$ & $\begin{array}{l}\text { 1. Assist a physician } \\
\text { who is providing } \\
\text { incompetent care } \\
\text { 2. Provide care that } \\
\text { does not relieve } \\
\text { suffering because of } \\
\text { fears that increasing } \\
\text { pain meds with cause } \\
\text { death } \\
\text { 3. Take no action on } \\
\text { observed ethical } \\
\text { issue because I was } \\
\text { asked not to } \\
\text { 4. Witness medical } \\
\text { students performing } \\
\text { painful procedures to } \\
\text { increase skills } \\
5 . \text { Work with unsafe } \\
\text { staffing levels }\end{array}$ & $\begin{array}{l}\text { 1. Follow family } \\
\text { wishes to continue } \\
\text { life support } \\
\text { 2. Follow family } \\
\text { wishes to not discuss } \\
\text { death with dying } \\
\text { child who asks } \\
\text { 3. Initiate life-saving } \\
\text { actions when I think } \\
\text { they prolong death } \\
\text { 4. Carry out orders } \\
\text { for unnecessary tests } \\
\text { and treatments } \\
5 . \text { Witness providers } \\
\text { giving "false hope" }\end{array}$ \\
\hline
\end{tabular}




\begin{tabular}{|c|c|c|c|c|c|}
\hline $\begin{array}{l}\text { Lowest } \\
\text { Scores }\end{array}$ & $\begin{array}{l}\text { 1.Recognize } \\
\text { interdependence } \\
\text { to meet goals } \\
\text { 2. Make an } \\
\text { effort to resolve } \\
\text { conflict } \\
\text { 3. Work as } \\
\text { "equals" to } \\
\text { accomplish } \\
\text { goals } \\
\text { 4. Problem } \\
\text { solve together } \\
\text { 5. Feel my } \\
\text { input is valued }\end{array}$ & $\begin{array}{l}\text { 1. Feel comfortable } \\
\text { telling parents that the } \\
\text { child will probably die } \\
\text { if they ask me } \\
\text { 2. Physician discomfort } \\
\text { with giving bad news } \\
\text { is a barrier to } \\
\text { understanding } \\
\text { prognosis (reverse } \\
\text { coded) } \\
\text { 3. When asked, } \\
\text { oncology nurses should } \\
\text { provide life expectancy } \\
\text { 4. I am comfortable } \\
\text { providing life } \\
\text { expectancy, if asked } \\
5 . \text { I feel it is primarily } \\
\text { the physician's } \\
\text { responsibility to } \\
\text { discuss prognosis } \\
\text { (reverse coded) }\end{array}$ & $\begin{array}{l}\text { 1. Plan care } \\
\text { based on parent } \\
\text { expectations } \\
\text { 2. Organize time } \\
\text { 3. Appear ready } \\
\text { 4. Allow enough } \\
\text { time so patient } \\
\text { not rushed } \\
\text { 5. Get the job } \\
\text { done on time }\end{array}$ & $\begin{array}{l}\text { 1. Increase dose of } \\
\text { sedatives that I } \\
\text { believe could hasten } \\
\text { death } \\
\text { 2. Follow family } \\
\text { wishes to continue } \\
\text { life support } \\
\text { 3. Carry out orders } \\
\text { for unnecessary tests } \\
\text { and treatments } \\
\text { 4. Initiate life-saving } \\
\text { actions when I think } \\
\text { they prolong death } \\
\text { 5. Continue to care } \\
\text { for child, sustained } \\
\text { on ventilator, when } \\
\text { no one will make } \\
\text { decision to withdraw } \\
\text { support }\end{array}$ & $\begin{array}{l}\text { 1. Take no action } \\
\text { about an observed } \\
\text { ethical issue because } \\
\text { requested to do } \\
\text { nothing } \\
\text { 2. Avoid action when } \\
\text { I learn of an error } \\
\text { that was not reported } \\
\text { 3. Witness medical } \\
\text { students performing } \\
\text { painful procedures to } \\
\text { increase skills } \\
\text { 4. Assist a physician } \\
\text { who is providing } \\
\text { incompetent care } \\
\text { 5. Ignore situations } \\
\text { in which parents } \\
\text { have not been given } \\
\text { enough information } \\
\text { to provide informed } \\
\text { consent }\end{array}$ \\
\hline
\end{tabular}




\section{Additional Details on Findings for Hypotheses}

\section{Hypothesis 1}

Individual nurse factors (more years of experience in pediatric oncology, a Master's degree or higher, practicing in the outpatient setting, and previous formal training in PRC) will be associated with more positive scores on the PRCON scale.

Additional analyses were performed to assess for any associations among other individual nurse factors and the PRCON (Table 6). A significant difference in PRCON scores based on role was identified, but no differences in PRCON scores were found based on race, employment status, percent of time spent in direct care, or Magnet ${ }^{\circledR}$ designation.

Table 6

PRCON Scores and Individual Nurse Factors

\begin{tabular}{|c|c|c|c|}
\hline $\begin{array}{c}\text { Individual Nurse } \\
\text { Factors }\end{array}$ & Test Statistics & & $\begin{array}{c}\text { PRCON RN } \\
\text { Role Subscale } \\
\text { Mean (SD) }\end{array}$ \\
\hline \multirow[t]{8}{*}{ Role } & $F(7,294)=5.9, p<.001$ & Staff nurse & $50.5(5.8)^{\mathrm{a}}$ \\
\hline & & RN coordinator & $52.1(5.3)^{\mathrm{b}}$ \\
\hline & & Research nurse & $54.5(6.1)$ \\
\hline & & Educator & $49.9(6.9)^{\mathrm{c}}$ \\
\hline & & Nurse administrator & $51.7(5.4)$ \\
\hline & & Clinical nurse specialist & $54.9(6.0)$ \\
\hline & & Nurse practitioner & $56.0(6.2)^{\mathrm{a}, \mathrm{b}, \mathrm{c}}$ \\
\hline & & Nurse researcher & $54.4(4.5)$ \\
\hline Magnet $\AA$ designation & $t(298)=.31, p=.76$ & & \\
\hline Race & $F(4,295)=.82, p=.51$ & & \\
\hline Employment status & $t(298)=1.65, p=.10$ & & \\
\hline$\%$ direct care & $F(3,295)=.04, p=.99$ & & \\
\hline
\end{tabular}

Based on Tukey test:

$\mathrm{a}=$ Significant difference between staff nurse and nurse practitioner scores, $p=<.001$

$\mathrm{b}=$ Significant difference between RN coordinator and nurse practitioner scores, $p=<.05$

$\mathrm{c}=$ Significant difference between educator and nurse practitioner scores, $p=<.001$ 
Analyses were also performed to detect any significant differences in PRCON subscale scores (RN Role, MD Communication, and Decision Making) based on the nurse's role, employment status, percent of time spent in direct care, race, and employment in an institution with Magnet ${ }^{\circledR}$ designation. A significant difference was found on RN Role subscale scores based on the nurse's role and employment status (Table 7). No differences in individual nurse factors were found for either the MD Communication or Decision Making subscales.

Table 7

PRCON RN Role Subscale and Individual Nurse Factors

\begin{tabular}{|c|c|c|c|}
\hline $\begin{array}{l}\text { Individual Nurse } \\
\text { Factors }\end{array}$ & Test Statistics & & $\begin{array}{c}\text { PRCON RN } \\
\text { Role Subscale } \\
\text { Mean (SD) } \\
\end{array}$ \\
\hline \multirow[t]{8}{*}{ Role } & $\begin{array}{l}F(7,282)=11.69, p< \\
.001\end{array}$ & Staff nurse & $16.8(3.5)^{\mathrm{a}, \mathrm{b}}$ \\
\hline & & RN coordinator & $17.5(3.3)^{\mathrm{c}}$ \\
\hline & & Research nurse & $20.7(4.0)^{b}$ \\
\hline & & Educator & $17.6(3.7)^{\mathrm{d}}$ \\
\hline & & Nurse administrator & $17.6(3.9)^{\mathrm{e}}$ \\
\hline & & Clinical nurse specialist & $19.7(4.6)$ \\
\hline & & Nurse Practitioner & $21.9(3.8)^{\mathrm{a}, \mathrm{c}, \mathrm{d}, \mathrm{e}}$ \\
\hline & & Nurse researcher & $20.5(2.4)$ \\
\hline Magnet $(\mathbb{A}$ designation & $t(286)=1.04, p=.30$ & & \\
\hline Race & $F(4,283)=.34, p=.85$ & & \\
\hline \multirow[t]{2}{*}{ Employment status } & $t(283)=3.21, p<.001$ & Full time & $18.5(4.1)$ \\
\hline & & Part time & $16.2(3.5)$ \\
\hline$\%$ direct care & $F(3,284)=.15, p=.93$ & & \\
\hline
\end{tabular}

Based on Tukey test:

$\mathrm{a}=$ Significant difference between nurse practitioner and staff nurse scores, $\mathrm{p}<.001$

$\mathrm{b}=$ Significant difference between staff nurse and research nurse scores, $\mathrm{p}<.001$

$\mathrm{c}=$ Significant difference between nurse practitioner and RN coordinator scores, $\mathrm{p}<.001$

$\mathrm{d}=$ Significant difference between nurse practitioner and educator scores, $\mathrm{p}<.001$

$\mathrm{e}=$ Significant difference between nurse practitioner and nurse administrator scores, $\mathrm{p}<.001$ 


\section{Hypothesis 2}

\section{CBS. \\ Individual nurse factors will be associated with more positive scores on the}

Additional analyses were performed to assess for any associations among other individual nurse factors and the CBS. A one-way between subjects ANOVA was performed to assess for differences in CBS scores among the different roles that nurses assume. A significant difference in CBS scores was found based on role $[F(7,308)=$ $2.11, p=.04]$. Post hoc comparisons using the Tukey HSD test indicated that the mean score for nurse practitioners $(M=69.5, \mathrm{SD}=11.8)$ was significantly higher than the scores for staff nurses $(M=62.3$, SD 13.4).

When examining CBS scores, a significant difference was also identified by race (Table 8$).$ Caucasians accounted for $92 \%(n=289)$ of respondents with only a small number of minorities falling into separate race categories, limiting the statistical tests that could be performed. For this reason, all of the other race categories (Asian, Black/African American, Hispanic, and Other; $\mathrm{n}=25$ ) were collapsed into one category to allow for comparison. A t-test was performed, which demonstrated a significant difference in CBS scores between Caucasians $(\mathrm{M}=65.3, \mathrm{SD}=12.9)$ and all other races $(\mathrm{M}=57.2, \mathrm{SD} 16.0$; $\mathrm{t}(312)=2.95, p=.003)$ 
Table 8

Comparison of CBS Scores by Race

\begin{tabular}{|l|c|c|c|}
\hline \multicolumn{1}{|c|}{ Race } & n & Mean CBS Score & SD \\
\hline Asian & 8 & 66.0 & 13.5 \\
\hline Caucasian & 289 & 65.3 & 12.9 \\
\hline Black/African American & 3 & 61.3 & 14.2 \\
\hline Hispanic & 1 & 60.0 & - \\
\hline Other & 13 & 50.6 & 16.4 \\
\hline Total & 314 & 64.6 & 13.3 \\
\hline
\end{tabular}

Hypothesis 4

Individual nurse factors as well as more positive scores on the PRCON and CBS will be associated with higher levels of nurse perceived quality of care as measured by the NAQS-ACV.

Additional analyses were performed to assess for associations between individual nurse factors and scores on the NAQS-ACV. No significant differences were found based on role, race, employment status, percent time spent in direct care, or employment in a hospital with Magnet ${ }^{\circledR}$ designation.

\section{Hypothesis 5}

Individual nurse factors as well as more positive scores on the PRCON and CBS will be associated with reduced levels of moral distress as measured by the MDS-R. 
Additional analyses were performed to assess for associations between individual nurse factors and scores on the MDS-R. No significant differences were found based on role, race, employment status, percent time spent in direct care, or employment in a hospital with Magnet ${ }^{\circledR}$ designation.

In addition to the Likert-type questions that make up the MDS-R, the end of the instrument also includes a question that asks respondents whether they have ever considered quitting or actually left a clinical position because of discomfort with the way patient care was handled. This question was included in the current study. Potential responses included "No," "Considered quitting a clinical position," or "Left a clinical position." Nearly $30 \%$ of respondents indicated that they had either left a position $(n=$ 28 ) or had considered leaving a position $(n=63)$. MDS-R scores were noted to be highest among nurses who had considered leaving, but had not left a position $(\mathrm{M}=80.5$, SD 42.0), and were significantly higher than nurses who had not considered leaving $[M=$ 56.3, SD 32.8; Welch's $F(2,60.9)=9.61, p<.001)$. One-way ANOVA with post hoc analysis also demonstrated a significant difference in CBS scores between nurses who had not considered leaving $(M=66.2, \mathrm{SD} 12.7)$ and nurses who had considered leaving a position $[M=60.2$, SD $14.2 ; F(2,266)=4.92, p=.01]$. No differences were found among other individual nurse factors, although some of the analyses were limited by a low number of cases in different categories. No significant differences were found between consideration of leaving and PRCON or NAQS-ACV total scale scores although nurses who had considered leaving a position scored significantly lower on the MD Communication subscale of the PRCON $[M=21.4$ (SD 3.6) versus $M=19.8$ (SD 4.1)] 
than those who had never left or considered leaving a position, $p=.01 ;[F(2,252)=$ $5.37, p=.01]$.

At the end of the MDS-R, respondents were asked to describe situations in their practice, beyond the 21 presented, in which they had experienced distress. These were also rated on frequency and intensity. Respondents identified 75 unique situations. Some of which were similar to those presented in the instrument. Other situations fell into 4 distinct categories: personal, patient/family, physician, and institutional. Examples of situations are described in Table 9.

Table 9

Categories of Morally Distressing Situations

\begin{tabular}{|c|c|c|}
\hline Category & Themes & Examples \\
\hline \multirow[t]{2}{*}{ Personal } & Witness to suffering & $\begin{array}{l}\text { "Watching a patient suffer and not feeling } \\
\text { that my actions were helping (this is rare, } \\
\text { but greatly distressing)" }\end{array}$ \\
\hline & $\begin{array}{l}\text { Having information } \\
\text { unknown to the family }\end{array}$ & $\begin{array}{l}\text { "Knowing a patient has had recurrence or } \\
\text { disease based on labs or scans and } \\
\text { parents don't know yet" }\end{array}$ \\
\hline \multirow[t]{4}{*}{ Patient/Family } & $\begin{array}{l}\text { Demanding and } \\
\text { emotionally challenging }\end{array}$ & $\begin{array}{l}\text { "Caring for an emotionally/socially } \\
\text { abusive patient without } \\
\text { physician/administration } \\
\text { acknowledgement of issue or willingness } \\
\text { to deal with issue" }\end{array}$ \\
\hline & $\begin{array}{l}\text { Disagreement among } \\
\text { patients and } \\
\text { parents/family }\end{array}$ & $\begin{array}{l}\text { "Giving chemotherapy to a child who did } \\
\text { not want to continue but whose parents } \\
\text { and physician wanted this" }\end{array}$ \\
\hline & $\begin{array}{l}\text { Parents not putting the } \\
\text { child's needs first }\end{array}$ & $\begin{array}{l}\text { "Not treating child's pain who was } \\
\text { terminal because the mother refused to } \\
\text { admit he was in pain and did not allow } \\
\text { him to voice his pain" }\end{array}$ \\
\hline & $\begin{array}{l}\text { Cultural/ethnic/religious } \\
\text { or alternative health } \\
\text { beliefs }\end{array}$ & $\begin{array}{l}\text { "Certain ethnic family withholding } \\
\text { treatment due to bishop's/church refusal } \\
\text { to pay for treatment. The child suffered } \\
\text { and died a terrible death despite our help } \\
\text { to manage his pain", }\end{array}$ \\
\hline
\end{tabular}




\begin{tabular}{|c|c|c|}
\hline & $\begin{array}{l}\text { Perceived incompetent } \\
\text { parents }\end{array}$ & $\begin{array}{l}\text { "Parents with child abuse history making } \\
\text { decisions I don't think are in bests } \\
\text { interest of child" }\end{array}$ \\
\hline & $\begin{array}{l}\text { Patient/parent refusal to } \\
\text { accept prognosis }\end{array}$ & $\begin{array}{l}\text { "Patient was terminal but family does not } \\
\text { accept diagnosis, and feels like people are } \\
\text { [not] telling them the prognosis-even } \\
\text { though they are clearly told" }\end{array}$ \\
\hline & $\begin{array}{l}\text { Unrealistic expectations } \\
\text { of treatment options }\end{array}$ & $\begin{array}{l}\text { "Families wanting to pursue phase } 1 \\
\text { trials, expecting cure" }\end{array}$ \\
\hline \multirow[t]{4}{*}{ Physician } & $\begin{array}{l}\text { Lack of continuity } \\
\text { among providers }\end{array}$ & $\begin{array}{l}\text { "Have to deal with families when getting } \\
\text { two different ways of doing things from } \\
\text { different doctors on team" }\end{array}$ \\
\hline & $\begin{array}{l}\text { Refusal to introduce } \\
\text { palliative/hospice care }\end{array}$ & $\begin{array}{l}\text { "Physicians refusing to consult palliative } \\
\text { care team for an end of life patient } \\
\text { because the physicians wanted to initiate } \\
\text { more treatment. The family did express } \\
\text { an interest in the consult and was hesitant } \\
\text { about continuing treatment." }\end{array}$ \\
\hline & $\begin{array}{l}\text { Lack of support of } \\
\text { nursing role }\end{array}$ & $\begin{array}{l}\text { "I have been asked not to be involved in, } \\
\text { present during prognosis conversations } \\
\text { because it "wasn't my role"" }\end{array}$ \\
\hline & $\begin{array}{l}\text { Not providing clear } \\
\text { prognostic information }\end{array}$ & $\begin{array}{l}\text { "Frequently our stem cell transplant } \\
\text { patients have gone to the PICU and died } \\
\text { there. The parents reflect that they didn't } \\
\text { see it coming, even tho the nurses did. } \\
\text { The physicians keep hoping for } \\
\text { something to change, but it leaves the } \\
\text { parents in a bad place for a short time." }\end{array}$ \\
\hline \multirow[t]{3}{*}{ Institutional } & $\begin{array}{l}\text { Lack of available } \\
\text { support services, such } \\
\text { as social work, } \\
\text { palliative care, etc. }\end{array}$ & $\begin{array}{l}\text { "Lack of supportive services, social } \\
\text { services, psych, child life, to assist } \\
\text { families in understanding and coping } \\
\text { with serious diagnoses" }\end{array}$ \\
\hline & $\begin{array}{l}\text { Lack of recognition of } \\
\text { staff distress }\end{array}$ & $\begin{array}{l}\text { "The institution not acknowledging we } \\
\text { are people with feelings who care for } \\
\text { these patients and instead think we are } \\
\text { robots who continue to function without } \\
\text { acknowledgement of compassion fatigue" }\end{array}$ \\
\hline & $\begin{array}{l}\text { Lack of punitive action } \\
\text { for incompetent staff }\end{array}$ & $\begin{array}{l}\text { "Failure of leadership to discipline or fire } \\
\text { incompetent nurses because 'a warm } \\
\text { body is better than nobody", }\end{array}$ \\
\hline
\end{tabular}




\section{Hypothesis 6}

Higher levels of nurse perceived quality of care as measured by the NAQSACV will be correlated with reduced levels of nurse moral distress as measured by the MDS-R pediatric version.

Correlations between the MDS-R and subscales of the NAQS-ACV were examined (Table 10).

Table 10

Correlation between MDS-R and NAQS-ACV Subscales

\begin{tabular}{|l|l|}
\hline & \multicolumn{1}{|c|}{ MDS-R } \\
\hline NAQS-ACV & $r=-.16^{*}$ \\
& $p=.01$ \\
& $\mathrm{n}=266$ \\
\hline -Vigilance & $r=-.18^{*}$ \\
& $p=.00$ \\
& $\mathrm{n}=266$ \\
\hline -Advocate & $r=-.15^{*}$ \\
& $p=.02$ \\
& $\mathrm{n}=268$ \\
\hline -Individualization & $r=-.16^{*}$ \\
& $p=.01$ \\
& $\mathrm{n}=266$ \\
\hline -Interaction & $r=-.11$ \\
& $p=.07$ \\
& $\mathrm{n}=268$ \\
\hline
\end{tabular}

\section{Additional Analyses}

\section{Psychometric Evaluation of PRCON}

The PRCON was initially developed as a survey with descriptive results reported by item, without aggregation to scale scores or testing of psychometric properties. In 
collaboration with the primary author of the instrument, psychometric analysis was performed on the survey. Revisions were made, and preliminary reliability and validity estimates were reported. (Newman \& Helft, 2015). In this study, the PRCON was used in a prospective manner with a sufficient sample to perform additional reliability and validity testing. The 20 items of the PRCON were subjected to principal components analysis (PCA) using SPSS, Version 24. Prior to performing PCA, the suitability of data for factor analysis was assessed. Inspection of the correlation matrix revealed the presence of coefficients of 0.3 and above. The Kaiser-Meyer-Olkin value was .81, exceeding the recommended value of 0.6, and Bartlett's Test of Sphericity reached statistical significance $(p=.00)$, supporting the factorability of the correlation matrix (Pallant, 2010).

PCA revealed the presence of four components with eigenvalues exceeding 1 , explaining $20.9 \%, 16.6 \%, 13.1 \%$ and $5.7 \%$ of the variance respectively. An inspection of the scree plot revealed a clear break after the $3^{\text {rd }}$ component, suggesting a more robust 3 factor solution. This was further supported by the results of Parallel Analysis, which showed only three components with eigenvalues exceeding the corresponding criterion values for a randomly generated data matrix of the same size (20 variables x 316 respondents).

A three-component solution explained a total of $50.7 \%$ of the variance, with Component 1 (RN Role subscale) contributing 20.9\%, Component 2 (MD Communication subscale) contributing 16.6\% and Component 3 (Decision Making subscale) contributing $13.1 \%$. To aid in the interpretation of these components, oblique rotation was performed as correlations among factors were low (Meyers, Gamst \& 
Guarino, 2006). All three components showed a number of strong loadings, with most items loading moderately strongly on only 1 component. These findings support past research on the PRCON, which suggested a 3-component instrument (Newman \& Helft, 2015).

Cronbach's alpha for the total scale was .75, which is deemed acceptable for new instruments (DeVellis, 2003). No further items were recommended for elimination based on review of alpha if item deleted values. Subscale characteristics were also calculated (Table 11). Correlation between factors was found to be low, and factor-to-total scale correlations were significant for all subscales, indicating distinct dimensions of the same underlying construct.

Table 11

PRCON Inter-Item and Inter-Scale Correlations

\begin{tabular}{|l|c|c|c|c|c|c|}
\hline & $\begin{array}{c}\text { Average } \\
\text { Inter-Item } \\
\text { Correlations } \\
\text { (Range) }\end{array}$ & $\begin{array}{c}\text { Item-Total } \\
\text { Correlations }\end{array}$ & \multicolumn{3}{|c|}{ Inter-Scale Correlations } \\
\hline & & & $\begin{array}{c}\text { MD } \\
\text { Communication }\end{array}$ & $\begin{array}{c}\text { RN } \\
\text { Role }\end{array}$ & $\begin{array}{c}\text { Decision } \\
\text { Making }\end{array}$ & $\begin{array}{c}\text { Total } \\
\text { Scale }\end{array}$ \\
\hline $\begin{array}{l}\text { MD } \\
\text { Communication } \\
\alpha=.80\end{array}$ & $\begin{array}{c}.33 \\
(.14-.55)\end{array}$ & $.39-.68$ & - & .10 & -.10 & $.67^{* *}$ \\
\hline $\begin{array}{l}\text { RN Role } \\
\alpha=.84\end{array}$ & $\begin{array}{c}.39 \\
(.14-.61)\end{array}$ & $.33-.70$ & .10 & - & .02 & $.75^{* *}$ \\
\hline $\begin{array}{l}\text { Decision Making } \\
\alpha=.79\end{array}$ & $\begin{array}{c}.51 \\
(.33-.69)\end{array}$ & $.44-.79$ & -.10 & .02 & - & $.29^{* *}$ \\
\hline $\begin{array}{l}\text { Total Scale } \\
a=.75\end{array}$ & & & $.67^{* *}$ & $.75^{* *}$ & $.29^{* *}$ & \\
\hline
\end{tabular}

$* *$ Correlation is significant at the $<0.01$ level. 


\section{Psychometric Evaluation of NAQS-ACV}

The NAQS-ACV was developed to document the nurse's assessment of quality of care, as a process (Lynn et al., 2007a). The instrument has three sections: nursing care and relationships between the nurse and the patient, acute care working environments, and intrinsic characteristics of the nurse. When the initial psychometric analyses including factor analysis were performed, each of the sections were analyzed separately. The first section originally had 94 items, but was reduced to 45 after principal-axis factor analysis.

The first section of the NAQS-ACV was used in this study as recommended when the patient is the unit of analysis rather than the nursing unit. The first section contains four subscales, which are labelled as Interaction, Vigilance, Individualization, and Advocate. The reported study used the NAQS-ACV in a prospective manner with a different population and also generated a composite score, which has not previously been reported. Thus, to ensure the reliability and validity of the instrument, psychometric evaluation was undertaken. The 45 items of the NAQS-ACV were subjected to principalaxis factor analysis using SPSS, Version 24. Prior to performing factor analysis, the suitability of data was assessed. Inspection of the correlation matrix revealed the presence of coefficients of 0.3 and above. The Kaiser-Meyer-Olkin value was 0.95 , exceeding the recommended value of 0.6 , and Bartlett's Test of Sphericity reached statistical significance $(p=.00)$, supporting the factorability of the correlation matrix (Pallant, 2010).

Principal-axis factor analysis was carried out to re-examine the factor structure of the NAQS-ACV. Principal-axis factor analysis revealed the presence of six components 
with eigenvalues exceeding 1 , explaining $67.5 \%$ of the variance (Component $1: 49.2 \%, 2$ : $6.9 \%, 3: 4.0 \%, 4: 2.6 \%, 5: 2.5 \%$, and $6: 2.3 \%$ ). An inspection of the scree plot revealed a clear break after the 3 rd component, suggesting a more robust 3 factor solution. This was further supported by the results of Parallel Analysis, which showed only three components with eigenvalues exceeding the corresponding criterion values for a randomly generated data matrix of the same size (45 variables x 316 respondents).

Despite suggestion of a more robust 3-factor solution, principal-axis factor analysis with direct oblimin rotation was employed to examine a 4-component solution as has been previously described (Lynn et al., 2007a). Direct oblimin was performed as correlations among factors were noted to be high (Tabachnick \& Fidell, 2001). A forced 4-factor solution explained $62.7 \%$ of the variance (Component 1: 49.2\%, 2: 6.9\%, 3: 4\%, and $4: 2.6 \%$ ). Review of the pattern matrix demonstrated that 30 of the original 45 items $(66.7 \%)$ loaded highest on their original primary factors. Sixteen items $(35.6 \%)$ crossloaded on different factors with a difference of $</=.2$ among factors; 15 items crossloaded on three or more factors.

Principal-axis factor analysis with direct oblimin rotation was used to force a 3component solution as suggested by analysis of the screen plot, parallel analysis, and the number of cross-loadings identified in the 4-component solution. A 3-component solution explained $60.1 \%$ of the variance (Component 1: 49.2\%, Component 2: 6.9\%, and Component 3: 4.0\%). Rotation analysis demonstrated 4 items within the first component, 21 items within the second component, and 20 items within the third component. Twelve of the items $(26.7 \%) \mathrm{had}</=0.2$ between component loadings. The first component included four items; all from the original "Advocate" subscale with the NAQS-ACV. The 
second component consisted of 19 items identified as the "Interaction" subscale, and two items from the "Individualization" subscale. Both of these two items had $</=0.2$ point different between component loadings. Finally, the third component included 20 items; 10 from the "Vigilance," six from the "Advocate" and four from the "Individualization" subscales.

Cronbach's alpha for the total scale was 0.98 , which is suggestive of robust internal validity (Polit, 2010). Reliability of subscales was also strong (Table 12). Correlation between factors was found to be high, and factor-to-total scale correlations were significant for all subscales, indicating distinct dimensions of the same underlying construct.

Table 12

NAQS-ACV Inter-Item and Inter-Scale Correlations

\begin{tabular}{|c|c|c|c|c|c|c|c|}
\hline & Item-Total & Inter-Item & & Intel & Scale Correlations & & \\
\hline & & & Vigilance & Interaction & Individualization & Advocate & $\begin{array}{l}\text { Total } \\
\text { Scale }\end{array}$ \\
\hline $\begin{array}{l}\text { Vigilance } \\
\alpha=.91\end{array}$ & $.44-.77$ & $.51(.32-.70)$ & - & $.69 * *$ & $.80 * *$ & $.82 * *$ & $.88 * *$ \\
\hline $\begin{array}{l}\text { Interaction } \\
\alpha=.96\end{array}$ & $.35-.81$ & $.57(.17-.95)$ & $.69 * *$ & - & $.79 * *$ & $.78 * *$ & $.93 * *$ \\
\hline $\begin{array}{l}\text { Individualization } \\
\alpha=.85\end{array}$ & $.54-.76$ & $.49(.40-.68)$ & $.80 * *$ & $.79 * *$ & - & $.79 * *$ & $.90 * *$ \\
\hline $\begin{array}{l}\text { Advocate } \\
\alpha=.94\end{array}$ & $.66-.78$ & $.61(.46-.77)$ & $.82 * *$ & $.78 * *$ & $.79 * *$ & - & $.90 * *$ \\
\hline $\begin{array}{l}\text { Total Scale } \\
a=.98\end{array}$ & & & $.88 * *$ & $.93 * *$ & $.90 * *$ & $.90 * *$ & \\
\hline
\end{tabular}

$* *$ Correlation is significant at the $<0.01$ level. 


\section{Summary}

This chapter provides a detailed description of the results of quantitative analyses performed to address the identified specific aims, research questions and hypotheses.

Results from supplementary analyses also provided. 


\section{Chapter 5: Discussion}

Chapter Five includes discussion of the results and interpretation of findings. Discussion and interpretation of major findings as well as implications for practice are presented in the manuscript, "Pediatric Oncology Nurses' Experiences with PrognosisRelated Communication" (Appendix H). This chapter includes discussion of the additional results and interpretations related to the hypotheses and psychometric analyses of PRCON and NAQS-ACV presented in Chapter 4.

\section{Interpretation of Findings}

\section{Demographics}

Respondent demographics appear to be reflective of nurses as a whole as well as that of pediatric oncology nurses. Most respondents were White/Caucasian and female, which is consistent with the race and gender demographics of the nursing workforce in the United States and APHON members [American Association of Colleges of Nursing $(\mathrm{AACN}), 2015 ; \mathrm{N}$. Wallace, personal communication]. Nurses in the sample population were slightly younger than the general nursing workforce (44 years versus 47 years) (AACN, 2014), and were more educated. Only 13.2\% of the general nursing workforce has a Master's or doctoral degree (AACN, 2011), while $41 \%$ of respondents in the current study had a Master's or doctoral degree. Nurse practitioners and nurse coordinators made up a larger portion of the sample than in the general APHON membership. Both of these roles tend to be more autonomous than that of staff nurses, which may impact their participation in prognosis-related conversations. Thus, nurses in these roles may have more experience in prognosis-related discussions, possibly 
increasing their interest in the topic under investigation. Finally, nurse researchers in the sample had less representation than the APHON membership as a whole, which may be reflective of nurse researchers having limited participation in prognosis-related discussions, and therefore less experience from which to answer the survey items. Findings, therefore, can be applied to nurses across a variety of different roles and educational levels in practice.

\section{Scale Statistics}

\section{High and low scoring items.}

Review of high and low scoring items on each of the instruments provides additional understanding of the different concepts under investigation. High scoring items on the PRCON reflect strong agreement that the revelation of prognostic information is integral to decision making, and the notion that physicians are generally skilled in providing such information. Interestingly, one of the lower scoring items suggests that physician discomfort with providing such information can be a barrier to parental understanding of prognostic information. Other lower scoring items surround the lack of nurse comfort in providing parents with life expectancy estimates or with discussing a child's impending death. Based on these responses, nurses seem to defer to their physician colleagues to initiate and respond to prognostic questions.

High scoring items on the CBS demonstrate a sense of teamwork or partnership when working with physician colleagues; a partnership which is supportive and demonstrates trust in the other. Low scoring items reflect the divide that continues to exist between physicians and nurses. While working as part of a team with nurses, 
physicians continue to see themselves as "captains" of the team, and nurses often share this perception. Physicians generally provide direction for the treatment plan, and the nurse follows through with the plan. Physicians do not always recognize the interdependent nature of the physician-nurse relationship or value the input that nurses provide. These items reinforce the need for interprofessional education to provide clarity regarding nurse and physician roles and how they can best complement each other.

The NAQS-ACV asked respondents to consider aspects of nursing care that they are generally able to provide in the context of prognosis-related communication. Scores on the NAQS-ACV were high with means on the subscales ranging from 3.2 to 3.5 out of 4, indicating a high level of agreement on most of the items. High scoring items acknowledged the characteristics that are often attributed to a "good" nurse, i.e., being compassionate, kind, and sensitive. Particularly in the context of prognosis-related communication, nurses recognized the value of being sensitive and conscientious, which suggests a mindfulness about their practice based on a holistic assessment of the parents and their needs. Interestingly, items rated lower centered around time, i.e., having time to plan care based on parental expectations or having enough time to not feel rushed. Time has previously been identified as a barrier to participation in prognosis-related communication (Newman, 2016). Engaging in prognosis-related communication including participation in physician-parent discussions can be time-consuming, which can challenge the nurse who is time-constrained in caring for multiple patients. Allowing time to engage in active listening when talking with parents may not be possible in the middle of a busy work day. Strategies must be identified to enable nurses to carve out 
time to participate in such discussions in order to provide the education and meet the supportive needs of parents.

As described in the manuscript, "Pediatric Oncology Nurses' Experiences with Prognosis-Related Communication," (Appendix H), nurses overall scored quite low on the MDS-R, which is similar to a group of pediatric nurses in the southeastern United States (Trotochaud et al., 2015). Both groups scored within the first quartile of the range of possible scores, suggesting low levels of moral distress. When examining high and low scoring items on both the Frequency and Intensity subscales, the most distressing situations included working with other members of the healthcare team, who were incompetent or behaving in an unethical manner. Fortunately, none of these occur frequently. In fact, a nurse's inaction to observed ethical issues was the least frequently occurring situation. Similarly, three of the five most frequently reported items, scored the lowest in terms of intensity. The two other items with highest frequency scores surrounded communication, i.e., not discussing death with dying child and witnessing providers giving false hope. Both topics have previously been identified by nurses as challenges to prognosis-related communication (Citak, Tourner, \& Gunes, 2013; McLennon, Lasiter, et al., 2013; McLennon, Uhrich, et al., 2013; Noble, Price, \& Porter, 2015). Findings are supportive of the overall low mean score on the MDS-R, but highlight an opportunity to improve communication practices surrounding the dying patient.

\section{Hypothesis 1}

While seventeen percent of the variance in PRCON scores was explained by the proposed model, additional analyses were performed to identify other variables which 
may enhance the model. Interestingly, while level of education was not significantly associated with PRCON scores, nurse practitioners (as classified by Current Position) scored significantly higher than staff nurses, nurse coordinators, and nurse educators on the PRCON. By nature of their educational preparation and licensure, nurse practitioners are expected to function in more autonomous roles. Thus, nurse practitioners may assume more responsibility for engaging in or even leading prognostic conversations (O'Brien et al., 2009; Oncology Nursing Society, 2016). As nurse practitioners also work interdependently with their physician partners, they may also have more opportunity to partner or collaborate to discuss prognosis (Almost \& Laschinger, 2002); all of which may improve their experiences with the process.

\section{Hypothesis 2}

Similar to the findings with the PRCON instrument, additional analyses exploring demographic variables found that nurse practitioners had higher CBS scores than staff nurses. Full-time nurses also reported greater collaboration with their physician colleagues than nurses who work part-time. When nurses work more hours, they more readily encounter their physician colleagues and interact with them on a more frequent basis. This allows more opportunities for working relationships to develop based on familiarity and trust, potentially increasing the opportunity and openness to collaboration.

The role of the nurse practitioner differs significantly from that of the staff nurse. Job descriptions, education, and training better position nurse practitioners to collaborate with their physician colleagues. In fact, when the first pediatric nurse practitioner program was developed by Dr. Henry Silver and Dr. Loretta Ford in 1960s, collaboration was considered an essential component (Silver \& Ford, 1967). Nurse practitioners work 
more closely with physicians, at times under the auspices of a formal collaborative agreement, than staff nurses do as they often share patient loads and work together to establish shared goals and plans of care to ensure the highest quality of care for patients. Development of shared goals requires an environment that promotes trust, mutual respect, and open communication; all critical components of collaboration (Hallas, Butz, \& Gitterman, 2004). This is particularly true in a sub-specialty practice like pediatric oncology. Although not described in the pediatric oncology literature, a neurosurgical team described the development of a tandem care model, which was built on collaboration between a nurse practitioner and a neurosurgeon. Together these providers provided holistic care to patients with the shared goal of providing optimal patient outcomes and satisfaction (Herrmann \& Zabramski, 2005). Collaboration is clearly a vital component of nurse practitioner practice.

\section{Hypothesis 4}

None of the individual nurse factors collected for the study were found to be significant predictors of quality of care including factors identified in the model. Scores on the NAQS-ACV were high, that is, within the fourth quartile of the range of scores, indicating perceived provision of a high-quality of care. Limited variability was identified in these scores. Only a portion of the NAQS-ACV was used in the current study, the "Nursing Care and Relationships between the Nurse and the Patient" section. Many of the items in this section of the instrument represent activities and behaviors that are considered inherent components of nursing practice, i.e., "Provide for parent's privacy" and "Explain procedures and new situations to the parent." Utilizing other sections of the instrument, "Acute Care Working Environment" and "Intrinsic Characteristics of the 
Nurse," may have resulted in more variability in scores, and the differentiation of scores based on different nurse factors. Past research (Williams, 1998) has demonstrated that limited amounts of time, availability of other team members, and collaboration among team members can all impact the nurse's perception of care quality. While a number of the items in the NAQS-ACV referenced the time factor and nurse-physician collaboration was also examined, teamwork with other nurses or nursing assistants and the work environment were not explored.

\section{Hypothesis 5}

Similar to a number of previous studies exploring moral distress among health care providers (HCP), nurses who have considered or actually left a position due to discomfort with the way patient care was handled reported significantly higher levels of moral distress (Cavaliere, et al., 2010; Hamric \& Blackhall, 2007; Hamric et al., 2012). Over one-third of nurses in this sample reported previously considering or actually leaving a position for such reasons. Findings are similar to that reported out of a single pediatric healthcare system in the southeast (Trotochaud, Coleman, Krawiecki, \& McCracken, 2015), where $12.5 \%$ of nurses reported previously leaving a position, and $24.3 \%$ indicated consideration of leaving. In the only study exploring moral distress among pediatric hematology/oncology, $15.2 \%$ of nurses had considered leaving their position, and $13.7 \%$ had actually left or changed jobs due to moral distress (Lazzarin, Biondi, \& DiMauro, 2012). These numbers are alarming considering the importance of nurse retention in the current era of health care (Dotson, Dave, Cazier, \& Spaulding, 2014). Retention of experienced nurses specializing in the care of pediatric oncology patients is critical to ensuring the ongoing provision of quality care. Therefore, the 
distress experienced by nurses must be acknowledged and efforts made to identify root causes and intervene in an attempt to reduce the level of distress.

In addition to the items that make up the MDS-R, respondents identified many other unique situations in which they experienced distress. These situations were categorized as personal, patient/family, physician, or institutional in nature. Generating a better understanding of what situations are morally distressing to nurses, particularly in the context of prognosis-related communication, can drive interventions to minimize exposure, potentially maximize retention, and promote a more positive interprofessional environment. A key component appears to be collaboration with physician colleagues as nurse-physician collaboration, quality of care and moral distress were found to be linked in this study.

\section{Additional Analyses}

\section{Psychometric evaluation of PRCON.}

Exploratory factor analysis of the PRCON administered in a prospective fashion provides ongoing evidence of the validity of the instrument. A robust 3-factor solution was identified, which is consistent with previous analyses (Newman \& Helft, 2015). Cronbach's alpha (0.75) continues to fall within an acceptable range. Future studies incorporating the PRCON into research in different settings and with different populations will provide additional evidence to support of the reliability and validity of the instrument. 


\section{Psychometric evaluation of NAQS-ACV.}

Principal-axis factor analysis was performed to assess the validity and structure of the NAQS-ACV. While initial instrument development documented the validity of the instrument (Lynn et al., 2007a), no additional studies were identified that used the NAQS-ACV or reported its validity. The variance in the data from this study was best explained by a 3-component solution versus a 4-component solution as described by the original authors. In the current sample, almost $50 \%$ of the variance arose from one of the factors; the factor made up of only 4 items. Each of these items also had significant crossloadings on other items within the instrument. The second component was made up of items primarily from the "Interactive" subscale, whereas the third component was made up of items from 3 of the subscales. Fifty percent of the items in the third component had significant cross-loadings. Both Cronbach's alpha was high for the entire scale (.98) as were correlations among factors (.69-.93), which suggests that with this sample the individual subscales may not be as unique as documented by Lynn et al. The high number of items with significant cross-loadings implies that some of the items may need to be deleted from the scale or modified. The "Advocate" and "Interactive" subscales appear stable, but additional refinement including item reduction is required to better identify the core constructs of the $3^{\text {rd }}$ and possibly $4^{\text {th }}$ subscales.

\section{Theoretical Implications of Findings}

The Quality Caring Model $\odot$ (Duffy \& Hoskins, 2003) provided the framework from which to establish and explore relationships among the study variables. The findings of this study add to the validity of the model, linking structural factors with 
process and outcomes. Structural factors or the causal past of nurses including years of experience in pediatric oncology nursing, practice location, and previous training in prognosis-related communication were significantly associated with the processes of care or caring relationships found in interprofessional collaboration and the process of prognosis-related communication. Findings indicate that the independent relationships the nurse develops with the patient and family in relation to prognosis-related communication appear to be influenced by the collaborative relationship the nurse has with the physician. These type of professional encounters, as described by Duffy and Hoskins, support the proposition suggesting the 3-dimensional nature in which "caring relationships exist among patients, nurses, and other health professions" (p. 83), and how nursing outcomes can then be unique or shared. Prognosis-related communication and nurse-physician collaboration, the process variables in this study, were significantly linked with the terminal outcomes of quality of care and nurse moral distress.

Review of the findings in the context of the Quality Caring Model(C) provides direction for further research in this area as well as strategies for improving interprofessional relationships in the work environment. Findings highlight the interprofessional relationship that exists between nurses and physicians in disclosing prognosis-related communication and the potential impact of this relationship on outcomes. Educational interventions should be developed surrounding prognosis-related communication, and such interventions should be interprofessional in nature. Nurses and doctors need to learn together about this delicate topic, and also develop a better understanding of each other's roles. Physicians need to more readily acknowledge the knowledge, training, and experience that nurses have and the ways in which nurses can 
contribute both uniquely and collaboratively to health care outcomes. Nurses need to actively engage their physician colleagues, and better present the unique characteristics that nurses bring to the health care team. As described by Duffy and Hoskins, "the work of nursing is relationship-centered" (p. 80), and this aspect of nursing can be undervalued. The development of such relationships provides the foundation on which these challenging conversations can be initiated, but nurses need to feel more confident in their unique role and feel more comfortable with prognostic conversations. Guided by the Quality Caring Model $\odot$, future research can explore unique interventions that nurses can provide in the context of prognosis-related communication along with collaborative interventions with physician colleagues or other members of the health care team. The current study explored outcomes from the nurse's perspective. Future research should look more directly at patient outcomes such as patient satisfaction, patient comfort, knowledge and even quality of life.

\section{Methodological, Theoretical, and/or Statistical Importance of the Findings}

The use of a cross-sectional, online survey format allowed for wide distribution of the survey with resulting representation of pediatric oncology nurses from across the country. As an initial exploration into pediatric oncology nurses' experiences with prognosis-related communication, a cross-sectional methodology allowed for a preliminary description of the phenomenon under investigation as well as exploration among study variables. Findings suggested strong associations among variables, particularly prognosis-related communication and interprofessional collaboration, which can provide the foundation for future investigations to explore these relationships in a prospective manner linking processes with outcomes. A prospective evaluation of study 
variables has the potential to establish causal relationships, which cross-sectional methods do not. While more efficient, cross-sectional survey formats do not allow for indepth exploration of complex issues, such a prognosis-related communication. Utilization of focus groups or interviews in addition to survey data would likely shed additional light on the topic, and provide further insight to guide future investigations.

\section{Relationship between the Findings, Previous Research, and the Theoretical/Conceptual Framework/Model}

Relationships are described and discussed in the manuscript, "Pediatric Oncology Nurses’ Experiences with Prognosis-Related Communication”(Appendix H).

\section{Implications for Nursing Practice}

Nurses clearly identified the importance of prognosis-related communication with parents particularly as it relates to decision making regarding the child's care, treatment, and possible enrollment in palliative or hospice services. Nurses also agreed that participation in prognosis-related discussions is within their scope of practice. Previously, nurses have identified a number of different roles they can play in the process including educator, care coordinator, supporter, facilitator, and advocate (Newman, 2016), but yet struggle to know what is expected of them. Findings suggest that pediatric oncology nurses are challenged in recognizing what their exact role is in the process, and feel underprepared to participate in such discussions especially when they were not included in the original conversation between the physician and the parents.

The significant correlation between experiences with prognosis-related communication and nurse-physician collaboration suggests that improved relations between nurses and physicians surrounding this topic will improve nurses' experiences 
with the process. In an effort to build relationships and enhance collaboration, nurses should aim to build bridges with their physician colleagues to open the door to improved communication regarding roles and role expectations. As part of such discussions, nurses can share their desire to participate more frequently in prognosis-related discussions, describe different roles they believe they can play, and further determine with their physician colleagues how nurses can be more active in the process. In order for this to occur, hospital administrators including both nursing and medicine must create a culture of collaboration, providing opportunities for nurses and physicians to dialogue about ways to enhance collaboration (Tang, Chan, Zhou, \& Liaw, 2013). Nurse practitioners appear to have better experiences with prognosis-related communication as well as more collaborative relationships with their physician colleagues. Nurse practitioners should identify ways within their practice that they can aim to include staff nurses more in this process and these conversations; role modeling for their physician colleagues how to engage the bedside nurse in the process.

\section{Implications for Vulnerable Populations}

In the context of childhood cancer and prognosis-related communication, a number of different people are involved in the process: the patient, parent(s), physician, nurse, other family members and other health care providers. Certainly, the child with cancer is incredibly vulnerable, but the focus of the current work is on parents and nurses; both of whom have been identified as being vulnerable. For parents, when a child is newly diagnosed with cancer or experiencing cancer recurrence, critical conversations occur surrounding the child's diagnosis and prognosis. Due to physical, emotional, developmental, social, and spiritual reasons, receiving and accepting such devastating 
news can be challenging for parents, and understanding of prognosis is critical to decision making and having hope. Results from this study demonstrate that nurses understand the importance of prognosis-related discussions, but struggle to understand their role in the process. Therefore, in order to reduce the vulnerability of parents in this situation, interventions to improve collaboration and training for nurses surrounding prognosisrelated communication appear indicated. Further, soliciting from parents their views on the role and value of the nurse and nurse-physician collaboration in the prognostic disclosure process, is essential to developing interventions that meet patient and family needs.

The nurse is also vulnerable in this context. Nurses are placed in a precarious position as the physician is generally the first to share with the parents and often the child the news of a cancer diagnosis. Often physicians view themselves as singular decision makers, and do not think to include the nurse in prognostic discussions or solicit the nurse's views about disclosure to the patient and family (Lancaster, Kolakowsky-Hayner, Kovacich, \& Greer-Williams, 2015). If the nurse is not involved in these conversations, he or she may not know exactly what was discussed with the family, making it difficult to interact with the family and potentially limiting the nurse's ability to function commensurate with his/her position. In previous studies, nurses have identified negative attitudes toward the importance of communication as one of the primary barriers to collaboration (Weaver et al., 2015). Findings from this study suggest that nurses who have more collaborative relationships with their physician colleagues have better experiences with prognosis-related communication and less moral distress. While nurses in the current sample rated collaboration with their physician colleagues highly, over 
$50 \%$ of nurses indicated that they were often unaware of when prognostic conversations with parents had occurred. Communication regarding these discussions is critical to ensuring optimal collaboration and patient care quality, therefore nurses must feel empowered to participate in prognosis-related discussions whenever possible.

Results clearly demonstrate that nurses believe it is within their scope of practice to participate in such discussions, but they do not feel prepared to answer questions about prognosis and particularly life expectancy. Nurses with more training in prognosis-related communication were more comfortable with such conversations, suggesting that more training will empower nurses and they may have more confidence regarding their role in the process. Also, nurses who reported better experiences with prognosis-related communication described the provision of higher care quality and less moral distress. These findings further highlight the need for more training in this area.

\section{Implications for Nursing Education}

While nearly $30 \%$ of nurses reported some training or education regarding prognosis-related communication, a large percentage of nurses had received little or no training in prognosis-related communication. This limited amount of education appears to undermine the nurse's confidence in responding to questions posed by parents. Nurses appear to be unclear regarding their role in the process, which may prevent them from participating. Nurses must be able to communicate effectively with their physician colleagues to establish when such conversations are going to occur, and how the nurse can best contribute to the process.

Communication skills are an integral part of nursing practice, as nurses interface and interact so directly with a wide variety of individuals, whether it is with patients and 
families, other nurses, other health care providers, or different members of the community. Preparing nurses to effectively communicate begins at the undergraduate level. Education regarding the principles of "breaking bad news" should be included throughout professional nursing education, as regardless of one's practice setting or specialty as a nurse, he or she will have to participate in these types of conversations. Both didactic and opportunities for experiential learning via role play and/or simulation are required to help students achieve competence in communication (Little \& Bolick, 2014).

Nurses must be taught how to effectively communicate with their physician colleagues. Strategies to promote nurse-physician collaboration and communication must begin at the undergraduate level. The need for early initiation of interprofessional education and training has become well-recognized, as without it, doctors and nurses "only learn about the provision of health care through the lens of their own disciplines" (Fewster-Thuente, 2014, p. 641). Interprofessional education aims to ground students in the principles of teamwork, communication, and conflict resolution, recognizing the unique contributions and interpretations each member provides (Roberston \& Bandali, 2008). Increasingly simulation is being introduced as a method to enhance interprofessional education. Simulation allows for both the preparation and assessment of students and health care providers in a risk-free environment (Robertson \& Bandali, 2008). Interprofessional education of medical and nursing students using both high- and low-fidelity simulations has demonstrated improved understanding of team structure as well as professional roles and responsibilities (Fewster-Thuente, 2014; Robertson et al., 2010; Tofil et al., 2014). Communication has also been noted to be enhanced. 
The need for increased training around the communication of diagnostic and prognostic information or the breaking of bad news is now well-recognized. At the professional level, most studies have explored educational interventions targeted at different members of the health care team separately, i.e., physicians (Gough, Frydenberg, Donath, \& Marks, 2009; Park, Gupta, Mandani, Haubner, \& Peckler, 2010) or nurses (Milic et al., 2015). Fortunately, the need for collaborative, interprofessional education surrounding the topic of difficult communication has been recognized in academia, and reports of combined training activities are being reported. Through a combination of a variety of different modalities including lectures, small group discussions, instructional videos, role play, and simulation, medical and nursing students together are being trained in breaking bad news (Erickson, Blackhall, Brashers, \& Varhegyi, 2015; Gorniewicz et al., 2016; Schildmann, Harlein, Burchardi, Schlogl, \& Vollmann, 2006). The results of such interventions appear promising with participants reporting improved self-efficacy related to their communication skills and improved attitudes toward teamwork and collaboration.

Future educational interventions should aim to engage practicing nurses and physicians in interprofessional education and training around prognosis-related communication. Physicians at times can be intimidating or act condescendingly toward nurses (Tang et al., 2013), which can impair or inhibit effective communication. Nurses must be prepared to work through this in order to promote better communication and collaboration in an effort to ensure optimal patient care and patient safety. Interprofessional education promotes purposeful interactions and discussions between physicians and nurses and can allow for role play or simulation, providing both with the 
opportunity to participate in different aspects of the process and better understand the contributions of the other (Hendricks-Ferguson et al., 2015; McCaffrey et al., 2010; Messmer, 2008; Saylor, Vernoony, Selekman, \& Cowperthwait, 2016).

\section{Implications for Nursing Research}

The findings of this study contribute to knowledge development regarding prognosis-related communication in pediatric oncology, particularly the nurse's experience with the process, which has not previously been reported. This research will provide the foundation for ongoing research in this area. With better understanding of nurses' experiences with the process, work should be done to explore patient, parent, and physician perspectives of the nurse's role in the process. Past research has demonstrated that lack of understanding about roles and how different providers prioritize tasks can inhibit effective communication and collaboration between nurses and physicians (Tang et al., 2013). Different methods of interprofessional education for both prelicensure and practicing nurses that provide opportunities to interface with physicians will allow the opportunity to improve understanding of roles and responsibilities. The success of such methods can be measured by re-assessing nurses' experiences with the process as well as measures of collaboration. Once roles and perspectives have been better outlined, interventions can be developed to ensure optimal dissemination of prognosis-related communication. Critical to the development of future interventions is the recognition that such discussions are part of a process with patients and families rather than a one-time event. Future research should also aim to more directly measure patient and parent outcomes including measures related to decision making, hope, quality of care, and satisfaction. 


\section{Strengths and Limitations of Study}

This study is first to explore the nurse's experience with prognosis-related communication and the variables associated with the process and outcomes. While the response rate was lower than anticipated, a large sample was obtained, which appears to be representative of APHON members (Table 4) from across the country. Findings provide clear direction for future research and education, which has the potential to improve patient, family, and provider outcomes.

A number of limitations were identified, and are reported in the manuscript, "Pediatric Oncology Nurses' Experiences with Prognosis-Related Communication" (Appendix H).

\section{Conclusion}

This is the first study to explore the experiences of pediatric oncology nurses with prognosis-related communication. The study highlighted the importance of interprofessional collaboration and communication surrounding such discussions, and is a call to action to improve interprofessional education surrounding this topic. The relationships identified among communication, collaboration, quality of care, and moral distress suggest that by improving communication and collaboration not only will the quality of patient care likely improve, but nurse moral distress may also be reduced with potential downstream implications of fewer nurses leaving the nursing profession. Pediatric oncology nurses are an integral part of prognosis-related communication. Further work is indicated to highlight the caring presence of every nurse, and the 
significant impact nurses can make on patient and parent outcomes by facilitating effective communication between providers and families. 


\section{REFERENCES}

Adebayo, P. B., Abayomi, O., Johnson, P. O. Oloyede, T., \& Oyelekan, A. A. (2013). Breaking bad news in clinical setting - health professionals' experience and perceived competence in southwestern Nigeria: A cross sectional study. Annals of African Medicine, 12(4): 205-211.

Allen, R., Judkins-Cohn, T., deVelasco, R., Forges, E., Lee, R., Clark, L., . . Procunier, M. (2013). Moral distress among healthcare professionals at a health system. JONA'S Healthcare Law, Ethics and Regulation, 15(3), 111-118.

Almost, J., \& Laschinger, H. J. S. (2002). Workplace empowerment, collaborative work relationships, and job strain in nurse practitioners. Journal of the American Academy of Nurse Practitioners, 14, 408-420.

American Association of Colleges of Nursing. (2011). Nursing fact sheet. Retrieved from http://www.aacn.nche.edu/media-relations/fact-sheets/nursing-fact-sheet

American Association of Colleges of Nursing. (2014). Nursing shortage fact sheet. Retrieved from http://www.aacn.nche.edu/media-relations/NrsgShortageFS.pdf

American Association of Colleges of Nursing. (2015). Fact sheet: Enhancing diversity in the nursing workforce. Retrieved from http://www.aacn.nche.edu/mediarelations/diversityFS.pdf

American Cancer Society. (2016). What are the key statistics for childhood cancer? Retrieved from http://www.cancer.org/cancer/cancerinchildren/detailedguide/ cancer-in-children-key-statistics

Anderson, W. G., Cimino, J. W., Ernecoff, N. C., Ungar, A., Shotsberger, K. J., Pollice, L. A., ... Lo, B. (2015). A multicenter study of key stakeholders' perspectives on communicating with surrogates about prognosis in intensive care units. Annals of the American Thoracic Society, 12(2), 142-152.

Anderson, W. G., Puntillo, K., Boyle, D., Barbour, S., Turner, K., Cimino, J., . . . Grywalski, M. (2016). ICU bedside nurses' involvement in palliative care communication: A multicenter survey. Journal of Pain and Symptom Management, $51,589-596$.

Angeles-Llerenas, A., del Rio, A. A., Salazar-Martinez, E., Kraus-Weissman, A., Zamora-Munoz, S., Hernandez-Avila, M., . . . Lazcano-Ponce, E. (2003). Perceptions of nurses with regard to doctor-patient communication. British Journal of Nursing, 12, 1312-1321. 
Baggs, J. G., Schmitt, M. H., Mushlin, A. I., Mitchell, P. H., Eldredge, D. H., Oakes, D., $\&$ Hutson, A. D. (1999). Association between nurse-physician collaboration and patient outcomes in three intensive care units. Critical Care Medicine, 27, 19911998.

Barr, H., Koppel, I., Reeves, S., Hammick, M., \& Freeth, D. (2005). Effective interprofessional education: Assumption, argument and evidence. London: CAIPE.

Beck, S. L., Weiss, M. E., Ryan-Wenger, N., Donaldson, N. E., Aydin, C., Towsley, G. L., \& Gardner, W. (2013). Measuring nurses' impact on health care quality: Progress, challenges, and future directions. Medical Care, 51, S15-S22.

Browner, W. S., Newman, T. B., \& Hulley, S. B. (2013). Getting ready to estimate sample size: Hypotheses and underlying principles. In S. B. Hulley, S. R. Cummings, W. S. Browner, D. G. Grady, \& T. B. Newman (Eds.), Designing Clinical Research ( ${ }^{\text {th }}$ ed.) (pp. 43-83). Philadelphia, PA: Lippincott Williams \& Wilkins.

Buckman, R. (1992). How to break bad news: A guide for health care professionals. Baltimore, MD: The Johns Hopkins University Press.

Burhans, L. M. \& Alligood, M. R. (2010). Quality nursing care in the words of nurses. Journal of Advanced Nursing, 66(8), 1689-1697. doi: 10.1111/j.13652648.2010.05344.x

Butow, P. N., Dowsett, S., Hagerty, R., \& Tattersall, M. H. N. (2002). Communicating prognosis to patients with metastatic disease: What do they really want to know? Supportive Care in Cancer, 10, 161-168.

Carper, B. A. (1978). Fundamental patterns of knowing in nursing. Advances in Nursing Science, 1(1), 13-24.

Cattell, R. B. (1966). The screen test for the number of factors. Multivariate Behavioral Research, 1, 245-276.

Cavaliere, T. A., Daly, B., Dowling, D., \& Montgomery, K. (2010). Moral distress in neonatal intensive care unit RNs. Advances in Neonatal Care, 10(3), 145-156.

Citak, E. A., Toruner, E. K., \& Gunes, N. B. (2013). Exploring communication difficulties in pediatric hematology/oncology nurses. Asian Pacific Journal of Cancer Prevention, 14(9), 5477-5482. 
Clayton, J. M., Hancock, K. M., Butow, P. N., Tattersall, M. H. N., \& Currow, D. C. (2007). Clinical practice guidelines for communicating prognosis and end-of-life issues with adults in the advanced stages of a life-limiting illness, and their caregivers. Medical Journal of Australia, 186 Supplement, S76-S108.

Clayton, J. M., Hancock, K., Parker, S., Butow, P. N., Walder, S., Carrick., S., . . . Tattersall, M. H. N. (2008). Sustaining hope when communicating with terminally ill patients and their families: A systematic review. Psycho-Oncology, 17, 641-659.

Comfrey, A. L., \& Lee, H. B. (1992). A first course in factor analysis (2 ${ }^{\text {nd }}$ ed.). Hillsdale, NJ: Lawrence Erlbaum Associates, Publishers.

Compas, B. E., Bemis, H., Gerhardt, C. A., Dunn, M. J., Rodriguez, E. M., Desjardins, L., .. V Vannatta, K. (2015). Mothers and fathers coping with their children's cancer: Individual and interpersonal processes. Health Psychology, 34, 783793.

Corley, M. C., Elswick, R. K., Gorman, M., \& Clor, T. (2001). Development and evaluation of a moral distress scale. Journal of Advanced Nursing, 33, 250-256.

Corley, M. C. (2002). Nurse moral distress: A proposed theory and research agenda. Nursing Ethics, 9(6), 636-650.

D'Amour, D., Ferrada-Videla, M., San Martin Rodriguez, L., \& Beaulieu, M. D. (2005). The conceptual basis for interprofessional collaboration: Core concepts and theoretical frameworks. Journal of Interprofessional Care, 19(S1), 116-131.

Demirsoy, N., Elcioglu, O., \& Yildiz, Z. (2008). Telling the truth: Turkish patients' and nurses' views. Nursing Science Quarterly, 21, 75-79.

des Ordons, A. L. R., Sharma, N., Heyland, D. K., \& You, J. J. (2015). Strategies for effective goals of care discussions and decision-making: Perspectives from a multicentre survey of Canadian hospital-based healthcare providers. BMC Palliative Care, 14(1), 38 .

Dewar, A. (2000). Nurses' experiences in giving bad news to patients with spinal cord injuries. Journal of Neuroscience Nursing, 32, 324-330.

DeVellis, R. F. (2003). Scale development: Theory and applications $\left(2^{\text {nd }}\right.$ ed.). Thousand Oaks, CA: Sage Publications, Inc.

DeVon, H. A., Block, M. E., Moyle-Wright, P., Ernst, D. M., Hayden, S. J., Lazzara, D. J., . . Kostas-Polston, E. (2007). A psychometric toolbox for testing validity and reliability. Journal of Nursing Scholarship, 39(2), 155-164. 
Dillman, D. A., Smyth, J. D., \& Christian, L. M. (2009). Internet, mail, and mixed-mode surveys: The Tailored Design Method ( $2^{\text {nd }}$ ed.). Hoboken, NJ: John Wiley \& Sons, Inc.

Djukic, M., Kovner, C. T., Brewer, C. S., Fatehi, F. K., \& Cline, D. D. (2013). Work environment factors other than staffing associated with nurses' ratings of patient care quality. Health Care Management Review, 38(2), 105-114.

Donabedian, A. (1992). The role of outcomes in quality assessment and assurance. QRB. Quality review bulletin, 18(11), 356-360.

Dotson, M. J., Dave, D. S., Cazier, J. A., \& Spaulding, T. J. (2014). An empirical analysis of nurse retention: What keeps RNs in nursing? JONA: Journal of Nursing Administration, 44(2), 111-116.

Duffy, J. R., \& Hoskins, L. M. (2003). The Quality-Caring Model (): Blending dual paradigms. Advances in Nursing Science, 26(1), 77-88.

Dunn, M. J., Rodriguez, E. M., Barnwell, A. S., Grossenbacher, J. C., Vannatta, K., Gerhardt, C. A., \& Compas, B. E. (2012). Posttraumatic stress symptoms in parents of children with cancer within six months of diagnosis. Health Psychology, 31(2), 176.

Dunniece, U., \& Slevin, E. (2000). Nurses' experiences of being present with a patient receiving a diagnosis of cancer. Journal of Advanced Nursing, 32, 611-618.

Ellison, D. (2015). Communication skills. Nursing Clinics of North America, 50, 45-57.

Epstein, E. G., \& Hamric, A. B. (2009). Moral distress, moral residue, and the crescendo effect. The Journal of Clinical Ethics, 20(4), 330-342.

Erickson, J. M., Blackhall, L., Brashers, V., \& Varhegyi, N. (2015). An interprofessional workshop for students to improve communication and collaboration skills in endof-life care. American Journal of Hospice and Palliative Medicine, 32, 876-880.

Faul, F., Erdfelder, E., Lang, A. G., \& Buchner, A. (2007). G*Power 3: A flexible statistical power analysis program for the social, behavioral, and biomedical sciences. Behavior Research Methods, 39, 175-191.

Fawcett, J. (1999). An overview of conceptual models, theories, and research. In J. Fawcett (Ed.), The relationship of theory and research ( $3^{\text {rd }}$ ed.) (pp. 1-25). Philadelphia, PA: F. A. Davis Company.

Fewster-Thuente, L. (2014). A contemporary method to teach collaboration to students. Journal of Nursing Education, 53, 641-645. doi:10.3928/01484834-20141027-02 
Freeman, M., \& Vasconcelos, E. F. S. (2010). Critical social theory: Core tenets, inherent issues. New Directions for Evaluation, 2010(127), 7-19.

Georgaki, S., Kalaidopoulou, O., Liarmakopoulos, I., \& Mystakidou, K. (2002). Nurses’ attitudes toward truthful communication with patients with cancer: A Greek study. Cancer Nursing, 25, 436-441.

Glarcher, M., Schumacher, P., \& Fritz, E. (2015) Caring quality instruments. International Journal of Health Care Quality Assurance, 28, 532-559. http://dx.doi.org/10.1108/IJHCQA-01-2015-0010

Gorniewicz, J., Floyd, M., Krishnan, K., Bishop, T. W., Tudiver, F., \& Lang, F. (2016). I Breaking bad news to patients with cancer: A randomized control trial of a brief communication skills training module incorporating the stories and preferences of actual patients. Patient Education and Counseling. doi: 10/1016/j.pec.2016.11.008

Gough, J. K., Frydenberg, A. R., Donath, S. K., \& Marks, M. M. (2009). Simulated parents: Developing paediatric trainees' skills in giving bad news. Journal of Paediatrics and Child Health, 45(3), 133-138.

Griffiths, J., Ewing, G., Wilson, C., Connolly, M., \& Grande, G. (2015). Breaking bad news about transitions to dying: A qualitative exploration of the role of the district nurse. Palliative Medicine, 29(2), 138-146.

Guba, E. G. (1990). The alternative paradigm dialog. In E. G. Guba (Ed.), The paradigm dialog (Chapter 1). Newbury Park, CA: Sage Publications.

Hagerty, R. G., Butow, P. N., Ellis, P. M., Dimitry, S., \& Tattersall, M. H. N. (2005). Communicating prognosis in cancer care: A systematic review of the literature. Annals of Oncology, 16, 1005-1053.

Hagerty, R. G., Butow, P. N., Ellis, P. A., Lobb, E. A., Pendlebury, S., Leighl, N., . . Tattersall, M. H. N. (2005). Communicating with realism and hope: Incurable cancer patients' views on the disclosure of prognosis. Journal of Clinical Oncology, $23,1278-1288$.

Hallas, D. M., Butz, A., \& Gitterman, B. (2004). Attitudes and beliefs for effective pediatric nurse practitioner and physician collaboration. Journal of Pediatric Health Care, 18(2), 77-86.

Hamric, A. B., \& Blackhall, L J. (2007). Nurse-physician perspectives on the care of dying patients in intensive care units: Collaboration, moral distress, and ethical climate. Critical Care Medicine, 35, 422-429. 
Hamric, A. B., Borchers, C. T., \& Epstein, E. G. (2012). Development and testing of an instrument to measure moral distress in healthcare professionals. AJOB Primary Research, 3(2), 1-9.

Hancock, K., Clayton, J. M., Parker, S. M., Walder, S. Butow, P. N., Carrick, S., . . Tattersall, M. H. N. (2007). Truth-telling in discussing prognosis in advanced lifelimiting illnesses: A systematic review. Palliative Medicine, 21, 507-517.

Helft, P. R., Chamness, A., Terry, C., \& Uhrich, M. (2011). Oncology nurses' attitudes toward prognosis-related communication. Oncology Nursing Forum, 38, 468-474.

Hendricks-Ferguson, V. L., Kane, J. R., Pradhan, K. R., Shih, C. S., Gauvain, K. M., Baker, J. N., . . Haase, J. E. (2015). Evaluation of physician and nurse dyad training procedures to deliver a palliative and end-of-life communication intervention to parents of children with a brain tumor. Journal of Pediatric Oncology Nursing, 32(5), 337-347.

Herrmann, L. L., \& Zabramski, J. M. (2005). Tandem practice model: A model for physician $\square$ nurse practitioner collaboration in a specialty practice, neurosurgery. Journal of the American Association of Nurse Practitioners, 17(6), 213-218.

Hjelmfors, L., Stromberg, A., Friedrichsen, M., Martensson, J., \& Jaarsma T. (2014). Communicating prognosis and end-of-life care to heart failure patients: A survey of heart failure nurses' perspectives. European Journal of Cardiovascular Nursing, 13, 152-161.

Huang, S., Tang, F., Liu, C.., Chen, M., Liang, T., \& Sheu, S. (2014). Truth-telling to patients' terminal illness: What makes oncology nurses act individually? European Journal of Oncology Nursing, 18, 492-498.

Hulley, S. B., Cummings, S. R., \& Newman, T. B. (2013). Designing cross-sectional and cohort studies. In S. B. Hulley, S. R. Cummings, W. S. Browner, D. G. Grady, \& T. B. Newman (Eds.), Designing Clinical Research (4 ${ }^{\text {th }}$ ed.) (pp. 85-96). Philadelphia, PA: Lippincott Williams \& Wilkins.

Hulley, S. B., Newman, T. B., \& Cummings, S. R. (2013). Getting started: The anatomy and physiology of clinical research. In S. B. Hulley, S. R. Cummings, W. S. Browner, D. G. Grady, \& T. B. Newman (Eds.), Designing Clinical Research ( $^{\text {th }}$ ed.) (pp. 2-13). Philadelphia, PA: Lippincott Williams \& Wilkins.

Innes, S., \& Payne, S. (2009). Advanced cancer patients' prognostic information preferences: A review. Palliative Medicine, 23, 29-39.

Institute for Healthcare Improvement. (2016). The IHI Triple Aim Initiative: Better care for individuals, better health for populations, and lower per capita costs. Retrieved from http://www.ihi.org/engage/initiatives/tripleaim/Pages/default.aspx 
Institute of Medicine. Crossing the quality chasm. Washington, DC: The National Academies Press, 2001.

Jackson, J. I. (2015, January 26). Nursing paradigms and theories: A primer. Virginia Henderson Global Nursing e-Repository. Retrieved from http://www.nursinglibrary.org/vhl/handle/10755/338888

Jameton, A. (1992). Dilemmas of moral distress: Moral responsibility and nursing practice. AWHONN's Clinical Issues in Perinatal and Women's Health Nursing, $4(4), 542-551$.

Kaiser, H. F. (1991). Coefficient alpha for a principal component and the KaiserGuttman Rule. Psychological Reports, 1991, 68, 855-858

Kaplowitz, S. A., Campo, S., \& Chiu, W. T. (2002). Cancer patients' desires for communication of prognosis information. Health Communication, 14, 221-241.

Kendall, S. (2006). Being asked not to tell: Nurses' experiences of caring for cancer patients not told their diagnosis. Journal of Clinical Nursing, 15, 1149-1157.

Kiely, B. E., Stockler, M. R., \& Tattersall, M. H. N. (2011). Thinking and talking about life expectancy in incurable cancer. Seminars in Oncology, 38, 380-385

King, M. L., \& Lee, J. L. (1994). Perceptions of collaborative practice between Navy nurses and physicians in the ICU setting. American Journal of Critical Care, 3 , 331-336.

Kylma, J., \& Juvakka, T. (2007). Hope in parents of adolescents with cancer - factors endangering and engendering parental hope. European Journal of Oncology Nursing, 11, 262-271.

Lamont, E. B., \& Christakis, N. A. (2003). Complexities in prognostication in advanced cancer: "To help them live their lives the way they want to." JAMA, 290, 98-104.

Lancaster, G., Kolakowsky $\square$ Hayner, S., Kovacich, J., \& Greer $\square$ Williams, N. (2015). Interdisciplinary communication and collaboration among physicians, nurses, and unlicensed assistive personnel. Journal of Nursing Scholarship, 47(3), 275-284.

Larson, E. (1999). The impact of physician-nurse interaction on patient care. Holistic Nursing Practice, 13(2), 38-46.

Lazzarin, M., Biondi, A., \& Di Mauro, S. (2012). Moral distress in nurses in oncology and haematology units. Nursing Ethics, 19(2), 183-195. 
Li, J., Liu, C., Zou, L.Q., Huang, J. J., Yu, C. H., You, G. Y., . . Jiang, Y. (2008). To tell or not to tell: Attitudes of Chinese oncology nurses towards telling of cancer diagnosis. Journal of Clinical Nursing, 17, 2463-2470.

Little, J., \& Bolick, B. N. (2013). Preparing prelicensure and graduate nursing students to systematically communicate bad news to patients and families. Journal of Nursing Education, 53(1), 52-55.

Lynn, M. R., \& McMillen, B. J. (1999). Do nurses know what patients think is important in nursing care? Journal of Nursing Care Quality, 13(5), 65-74.

Lynn, M. R., McMillen, B. J., \& Sidani, S. (2007a). Including the provider in the assessment of quality care. Journal of Nursing Care Quality, 22, 328-336.

Lynn, M. R., McMillen, B. J., \& Sidani, S. (2007b). Understanding and Measuring patients' assessment of the quality of nursing care. Nursing Research, 56(3), 159-166.

MacDonald, S. E., Newburn $\square$ Cook, C. V., Schopflocher, D., \& Richter, S. (2009). Addressing nonresponse bias in postal surveys. Public Health Nursing, 26(1), $95-$ 105.

Mack, J. W., \& Joffe, S. (2014). Communicating about prognosis: Ethical responsibilities of pediatricians and parents. Pediatrics, 133(Supplement 1), S24-S30.

Mack, J. W., Wolfe, J., Cook, F. E., Grier, H. E., Cleary, P. D., \& Weeks, J. C. (2007). Hope and prognostic disclosure. Journal of Clinical Oncology, 25, 5636-5642.

Mack, J. W., Wolfe, J., Grier, H. E., Cleary, P. D., \& Weeks, J. C. (2006). Communication about prognosis between parents and physicians of children with cancer: Parent preferences and the impact of prognostic information. Journal of Clinical Oncology, 24, 5265-5270.

McCaffrey, R. G., Hayes, R., Stuart, W., Cassell, A., Farrell, C., Miller-Reyes, C., . . . Donaldson, A. (2010). A program to improve communication and collaboration between nurses and medical residents. The Journal of Continuing Education in Nursing, 41(4), 172-178.

McLennon, S., M., Lasiter, S., Miller, W. R., Amlin, K., Chamness, A. R., \& Helft, P. R. (2013). Oncology nurses' experiences with prognosis-related communication with patients who have advanced cancer. Nursing Outlook, 61, 427-436.

McLennon, S. M., Uhrich, M., Lasiter, S., Chamness, A. R., \& Helft, P. R. (2013). Oncology nurses' narratives about ethical dilemmas and prognosis-related communication in advanced cancer patients. Cancer Nursing, 36(2), 114-121. 
Messmer, P. R. (2008). Enhancing nurse-physician collaboration using pediatric simulation. The Journal of Continuing Education in Nursing, 39(7), 319-327.

Meyers, L. S., Gamst, G. C., \& Guarino, A. J. (2010). Applied multivariate research: Design \& Interpretation. Thousand Oaks, CA: SAGE Publications, Inc.

Milic, M. M., Puntillo, K., Turner, K., Joseph, D., Peters, N., Ryan, R., . . Anderson, W. G. (2015). Communicating with patients' families and physicians about prognosis and goals of care. American Journal of Critical Care, 24(4), e56-e64.

Millar, C., Reid, J., \& Porter, S. (2013). Refractory cachexia and truth-telling about terminal prognosis: A qualitative study. European Journal of Cancer Care, 22, 326-333.

Miyashita, M., Hashimoto, S., Kawa, M., Shima, Y., Kawagoe, H., Hase, T., . . Shinjo, Y. (2006). Attitudes toward disease and prognosis disclosure and decision making for terminally ill patients in Japan, based on a nationwide random sampling survey of the general population and medical practitioners. Palliative and Supportive Care, 4, 389-398.

Monti, E. J., \& Tingen, M. S. (1999). Multiple paradigms of nursing science. Advances in Nursing Science, 21(4), 64-80.

Muscara, F., McCarthy, M. C., Woolf, C., Hearps, S. J. C., Burke, K., \& Anderson, V. A. (2015). Early psychological reactions in parents of children with a life threatening illness within a pediatric hospital setting. European Psychiatry, 30, 555-561.

Natan, M. B., Shahar, I., \& Garfinkel, D. (2009). Disclosing bad news to patients with life-threatening illness: Differences in attitude between physicians and nurses in Israel. International Journal of Palliative Nursing, 15, 276-281.

Neuman, B. M., \& Fawcett, J. (2011). The Neuman systems model. Boston: Pearson.

Newman, A. R. (2016). Nurses' perceptions of diagnosis and prognosis-related communication: An integrative review. Cancer Nursing, 39(5), E48-E60.

Newman, A. R., \& Helft, P. R. (2015). Reliability and validity of a tool to assess oncology nurses' experiences with prognosis-related communication. Oncology Nursing Forum, 42, 64-73.

Newman, T. B., Browner, W. S., \& Hulley, S. B. (2013). Enhancing causal inference in observational studies. In S. B. Hulley, S. R. Cummings, W. S. Browner, D. G. Grady, \& T. B. Newman (Eds.), Designing Clinical Research (4 ${ }^{\text {th }}$ ed.) (pp. 117136). Philadelphia, PA: Lippincott Williams \& Wilkins. 
Noble, H., Price, J. E., \& Porter, S. (2015). The challenge to health professionals when carers resist truth telling at the end of life: A qualitative secondary analysis. Journal of Clinical Nursing, 24, 927-936.

Nyborn, J. A., Olcese, M., Nickerson, T., \& Mack, J. W. (2016). “Don't try to cover the sky with your hands": Parents' experiences with prognosis communication about their children with advanced cancer. Journal of Palliative Medicine, 19, 626-631.

O'Brien, J. L., Martin, D. R., Heyworth, J. A., \& Meyer, N. R. (2009). A phenomenological perspective on advanced practice nurse-physician collaboration within an interdisciplinary healthcare team. Journal of the American Academy of Nurse Practitioners, 21, 444-453.

Oh, Y., \& Gastmans, C. (2013). Moral distress experienced by nurses: A quantitative literature review. Nursing Ethics. Advance online publication. doi: $10.1177 / 0969733013502803$

Oncology Nursing Society. (2016). The role of the advanced practice registered nurse in oncology care. Retrieved from ons.org/advocacy-policy/positions/education/apn

Onwuegbuzie, A. J. (2000). Expanding the framework of internal and external validity in quantitative research. Retrieved from http://files.eric.ed.gov/fulltext/ ED448205.pdf

Pallant, J. (2010). SPSS survival manual, (4 ${ }^{\text {th }}$ ed.). Berkshire, England: Open University Press.

Park, I., Gupta, A., Mandani, K., Haubner, L., \& Peckler, B. (2010). Breaking bad news education for emergency medicine residents: A novel training module using simulation with the SPIKES protocol. Journal of Emergencies, Trauma, and Shock, 3,385 .

Parse, R. R. (1999). Nursing: The discipline and the profession. Nursing Science Quarterly, 12(4), 275-276.

Petri, L. (2010). Concept analysis of interdisciplinary collaboration. Nursing Forum, $45(2), 73-82$.

Polit, D. (2010). Statistics and data analysis for nursing research, $2^{\text {nd }}$ ed. Upper Saddle River, NJ: Pearson Education Inc.

Polit, D. F., \& Beck, C. T. (2012). Nursing research: Generating and assessing evidence for nursing practice ( $9^{\text {th }}$ ed.). Philadelphia, PA: Lippincott Williams \& Wilkins.

Pontin, D., \& Jordan, N. (2013). Issues in prognostication for hospital specialist palliative care doctors and nurses: A qualitative inquiry. Palliative Medicine, 27(2), 165-171. 
Popp, J. M., Conway, M., \& Pantaleao, A. (2015). Parents' experience with their child's cancer diagnosis: Do hopefulness, family functioning, and perceptions of care matter? Journal of Pediatric Oncology Nursing. Advance online publication. doi: $10.1177 / 1043454214563404$

Pye, K. (2013). Exploring moral distress in pediatric oncology: A sample of registered practitioners. Issues in Comprehensive Pediatric Nursing, 36(4), 248-261.

Racher, F. E., \& Robinson, S. (2003). Are phenomenology and post-positivism strange bedfellows? Western Journal of Nursing Research, 25(5), 464-481.

Radwin, L. (2000). Oncology patients' perceptions of quality nursing care. Research in Nursing \& Health, 23(3), 179-190.

Rassin, M., Levy, O., Schwartz, T., \& Silner, D. (2006). Caregivers' role in breaking bad news: Patients, doctors, and nurses' points of view. Cancer Nursing, 29, 302308.

Reed, P. G. (1997). Nursing: The ontology of the discipline. Nursing Science Quarterly, 10(2), 76-79.

Reinke, L. F., Shannon, S. E., Engelberg, R. A., Young, J. P., \& Curtis, J. R. (2010). Supporting hope and prognostic information. Journal of Pain and Symptom Management, 39, 982-992.

Reitz, O. E., \& Anderson, M. A. (2013). A comparison of survey methods in studies of the nurse workforce. Nurse Researcher, 20(4), 22-27.

Rio-Valle, J. S., Caro, M. P. G., Juarez, R. M., Peña, D. P., Vinuesa, A. M., Pappous, A., ... Quintana, F. C. (2009). Bad news for the patient and the family? The worst part of being a health care professional. Journal of Palliative Care, 25(3), 191.

Robertson, J., \& Bandali, K. (2008). Bridging the gap: Enhancing interprofessional education using simulation. Journal of Interprofessional Care, 22, 499-508.

Robertson, B., Kaplan, B., Atallah, H., Higgins, M., Lewitt, M. J., \& Ander, D. S. (2010). The use of simulation and a modified TeamSTEPPS curriculum for medical and nursing student team training. Simulation in Healthcare, 5, 332-337.

Rose, L. (2011). Interprofessional collaboration in the ICU: How to define? Nursing in Critical Care, 16(1), 5-10.

Ryan, C., Powlesland, J., Phillips, C. Raszewski, R., Johnson, A., Johnson, A., BanksEnorense, K., . . W Welsh, J. (2016). Nurses' perceptions of quality care. Journal of Nursing Care Quality. Advance online publication. doi: 10.1097/NCQ.0000000000000211 
Saylor, J., Vernoony, S., Selekman, J., \& Cowperthwait, A. (2016). Interprofessional education using a palliative care simulation. Nurse Educator, 41(3), 125-129.

Schildmann, J., Härlein, J., Burchardi, N., Schlögl, M., \& Vollmann, J. (2006). Breaking bad news: Evaluation study on self-perceived competences and views of medical and nursing students taking part in a collaborative workshop. Supportive Care in Cancer, 14, 1157-1161.

Schulman-Green, D., McCorkle, R., Cherlin, E., Johnson-Hurzeler, R., \& Bradley, E. H. (2005). Nurses' communication of prognosis and implications for hospice referral: A study of nurses caring for terminally ill hospitalized patients. American Journal of Critical Care, 14, 64-70.

Sellman, D. (2005). Towards an understanding of nursing as a response to human vulnerability. Nursing Philosophy, 6(1), 2-10.

Sheldon, L. K., Barrett, R., \& Ellington, L. (2006). Difficult communication in nursing. Journal of Nursing Scholarship, 38(2), 141-147.

Silver, H., \& Ford, L. (1967). The pediatric nurse practitioner at Colorado. American Journal of Nursing, 67, 1443-1444.

Stichler, J.F. (1989). Development and psychometric testing of a collaborative behavior scale. Unpublished manuscript, University of San Diego, Philip Y. Hahn School of Nursing.

Stichler, J.F. (1990). The effects of collaboration, organizational climate, and job stress on job satisfaction and anticipated turnover in nursing. Ann Arbor, MI: University Microfilms, International.

Sullivan, R. J., Menapace, L. W., \& White, R. M. (2001). Truth-telling and patient diagnoses. Journal of Medical Ethics, 27, 192-197.

Szmuilowicz, E., el-Jawahri, A., Chiappetta, L., Kamdar, M. \& Block, S. (2010).

Improving Residents' End-of-Life Communication Skills with a Short Retreat: A Controlled Trial. Journal of Palliative Medicine, 13, 439-452. doi:

$10.1089=$ jpm. 2009.0262

Tabachnick, B. G., \& Fidell, L. S. (2001). Using multivariate statistics $\left(4^{\text {th }}\right.$ ed.). Needham Heights, MA: Pearson.

Tang, C. J., Chan, S. W., Zhou, W. T., \& Liaw, S. Y. (2013). Collaboration between hospital physicians and nurses: An integrated literature review. International Nursing Review, 60(3), 291-302. 
Tieying. Z., Haishan, H., Meizhen, Z., Yan, L., \& Pengqian F. (2011). Health professionals' attitude towards information disclosure to cancer patients in China. Nursing Ethics, 18, 356-363.

Tobin, G. A. (2012). Breaking bad news: A phenomenological exploration of Irish nurses' experiences of caring for patients when a cancer diagnosis is given in an acute care facility (Part 1). Cancer Nursing, 35(6), E21-29.

Tofil, N. M., Morris, J. L., Peterson, D. T., Watts, P., Epps, C., Harrington, K. F., . . White, M. L. (2014). Interprofessional simulation training improves knowledge and teamwork in nursing and medical students during internal medicine clerkship. Journal of Hospital Medicine, 9(3), 189-192.

Trotochaud, K., Coleman, J. R., Krawiecki, N., \& McCracken, C. (2015). Moral distress in pediatric healthcare providers. Journal of Pediatric Nursing, 30, 908-914.

Valizadeh, L., Zamanzadeh, V., Sayadi, L., Taleghani, F., Howard, A. F., \& Jeddian, A. (2014). Truth-telling and hematopoietic stem cell transplantation: Iranian nurses' experiences. Nursing Ethics, 21, 518-529.

Warnock, C., Tod, A., Foster, J., \& Soreny, C. (2010). Breaking bad news in inpatient clinical settings: Role of the nurse. Journal of Advanced Nursing, 66, 1543-1555.

Watson, J. (1985). Nursing: Human science and human care. Norwalk, CT: AppletonCentury-Crofts.

Weaver, A. C., Callaghan, M., Cooper, A. L., Brandman, J., \& O'Leary, K. J. (2015). Assessing interprofessional teamwork in inpatient medical oncology units. Journal of Oncology Practice, 11(1), 19-22.

Weaver, K., \& Olson, J. K. (2006). Understanding paradigms used for nursing research. Journal of Advanced Nursing, 53, 459-469.

White, J. (1995). Patterns of knowing: Review, critique, and update. Advances in Nursing Science, 17(4), 73-86.

Whitehead, P. B., Herbertson, R. K., Hamric, A. B., Epstein, E. G., \& Fisher, J. M. (2015). Moral distress among healthcare professionals: Report of an Institutionwide survey. Journal of Nursing Scholarship, 47(2), 117-125.

Whittemore, R., \& Knafl, K. (2005). The integrative review: Updated methodology. Journal of Advanced Nursing, 52, 546-553.

Wilkinson, J. M. (1987/88). Moral distress in nursing practice: Experience and effect. Nursing Forum, 23(1): 16-29. 
Williams, A. M. (1998). The delivery of quality nursing care: A grounded theory study of the nurse's perspective. Journal of Advanced Nursing, 27(4), 808-816.

Wittenberg-Lyles, E., Goldsmith, J., \& Ferrell, B. (2013). Oncology nurse communication barriers to patient-centered care. Clinical Journal of Oncology Nursing, 17(2), 152-158.

Wolcott, H. F. (1994). Transforming qualitative data: Description, analysis and interpretation. Thousand Oaks, CA: Sage.

World Health Organization. (2010). Framework for action on interprofessional education \& collaborative practice. Retrieved from http://www.who.int/hrh/resources/ framework_action/en/ 


\section{Appendix A: Manuscript}

Newman, A. R. (2016). Nurses' Perceptions of Diagnosis and Prognosis-Related Communication: An Integrative Review. Cancer Nursing, 39(5), E48-E60. 
Appendix B: Manuscript

Newman, A. R., \& Helft, P. R. (2015). Reliability and validity of a tool to assess oncology nurses' experiences with prognosis-related communication.

Oncology Nursing Forum, 42, 64-73. 
Appendix C

\section{Prognosis-Related Communication in Oncology Nursing}

The following questions are intended to assess your attitudes toward and experiences with prognosis-related communication with parents of children with cancer.

The questions will ask you about your experiences with prognosis-related communication. In the survey, the word "prognosis" incorporates the revelation of whether or not the child will be cured of cancer, how long the child is expected to live, and the kind of life the child is expected to have.

Circle only one response for each question. If any question makes you uncomfortable, please skip it.

When you go through the questions, please think of your experiences with parents of children with cancer.

The scale for the following questions will be as follows:

\section{Strongly Disagree $=1 \quad$ Disagree $=2 \quad$ Agree $=3 \quad$ Strongly Agree $=4$}

\begin{tabular}{|l|c|c|c|c|}
\hline & $\begin{array}{l}\text { Strongly } \\
\text { Disagree }\end{array}$ & Disagree & Agree & $\begin{array}{l}\text { Strongly } \\
\text { Agree }\end{array}$ \\
\hline $\begin{array}{l}\text { Parents can only make good } \\
\text { decisions about their child's care if } \\
\text { they understand their child's } \\
\text { prognosis. }\end{array}$ & 1 & 2 & 3 & 4 \\
\hline $\begin{array}{l}\text { Parents can only make good } \\
\text { decisions about hospice enrollment if } \\
\text { they understand their child's } \\
\text { prognosis. }\end{array}$ & 1 & 2 & 3 & 4 \\
\hline $\begin{array}{l}\text { Parents can only make good } \\
\text { decisions about further anti-cancer } \\
\text { treatments including clinical trials } \\
\text { participation if they understand their } \\
\text { child's prognosis. }\end{array}$ & 1 & 2 & 3 & 4 \\
\hline $\begin{array}{l}\text { I cannot advocate for my patients as } \\
\text { well as I would like to when they don't } \\
\text { understand their prognosis. }\end{array}$ & 1 & 2 & 3 & 4 \\
\hline $\begin{array}{l}\text { When asked questions about life } \\
\text { expectancy by parents, oncology } \\
\text { nurses should provide an estimate. }\end{array}$ & 1 & 2 & 3 & 4 \\
\hline $\begin{array}{l}\text { I feel it Is primarily the physician's } \\
\text { responsibility to discuss the child's } \\
\text { prognosis with the parent. }\end{array}$ & 1 & 2 & 3 & 4 \\
\hline $\begin{array}{l}\text { I feel comfortable telling a child's } \\
\text { parents that the child will probably die } \\
\text { from cancer if they ask me. }\end{array}$ & 1 & 2 & 3 & 4 \\
\hline
\end{tabular}




\begin{tabular}{|c|c|c|c|c|}
\hline $\begin{array}{l}\text { I am willing to initiate a discussion with } \\
\text { parents regarding prognosis-related } \\
\text { information. }\end{array}$ & 1 & 2 & 3 & 4 \\
\hline $\begin{array}{l}\text { I feel that answering questions about } \\
\text { prognosis-related information is within } \\
\text { the scope of nursing practice. }\end{array}$ & 1 & 2 & 3 & 4 \\
\hline $\begin{array}{l}\text { I feel well-equipped to discuss } \\
\text { prognosis-related information with } \\
\text { parents of children with cancer. }\end{array}$ & 1 & 2 & 3 & 4 \\
\hline $\begin{array}{l}\text { Generally, oncology nurses have } \\
\text { enough knowledge to answer parents' } \\
\text { questions about their child's } \\
\text { prognosis. }\end{array}$ & 1 & 2 & 3 & 4 \\
\hline $\begin{array}{l}\text { I am comfortable providing an } \\
\text { estimated life expectancy to parents } \\
\text { who ask. }\end{array}$ & 1 & 2 & 3 & 4 \\
\hline $\begin{array}{l}\text { Physician discomfort with giving bad } \\
\text { news is a major barrier to helping } \\
\text { parents understand their child's } \\
\text { prognosis. }\end{array}$ & 1 & 2 & 3 & 4 \\
\hline $\begin{array}{l}\text { Most of the doctors I work with are } \\
\text { skilled at discussing prognosis-related } \\
\text { information with parents of children } \\
\text { with cancer. }\end{array}$ & 1 & 2 & 3 & 4 \\
\hline $\begin{array}{l}\text { The parents that I work with almost } \\
\text { always understand their child's } \\
\text { prognosis. }\end{array}$ & 1 & 2 & 3 & 4 \\
\hline $\begin{array}{l}\text { The doctors I work with always keep } \\
\text { me informed about what they have } \\
\text { told parents about the child's } \\
\text { prognosis. }\end{array}$ & 1 & 2 & 3 & 4 \\
\hline $\begin{array}{l}\text { I never feel pressure to NOT provide } \\
\text { information about prognosis to parents } \\
\text { who ask because I do not want to } \\
\text { contradict what the doctors have said. }\end{array}$ & 1 & 2 & 3 & 4 \\
\hline $\begin{array}{l}\text { Parents are always given prognostic } \\
\text { information early enough in the illness } \\
\text { process to allow them to make } \\
\text { informed choices about their child's } \\
\text { care. }\end{array}$ & 1 & 2 & 3 & 4 \\
\hline $\begin{array}{l}\text { The doctors I work with always } \\
\text { address end-of-life issues, including } \\
\text { prognosis, with parents of a child with } \\
\text { advanced cancer early in the course } \\
\text { of the child's disease. }\end{array}$ & 1 & 2 & 3 & 4 \\
\hline $\begin{array}{l}\text { When parents do not appear to } \\
\text { understand their child's prognosis, it is } \\
\text { never because the doctors have not } \\
\text { fully discussed it with them. }\end{array}$ & 1 & 2 & 3 & 4 \\
\hline
\end{tabular}


Appendix D

\section{NURSE-PHYSICIAN}

\section{Stichler COLLABORATIVE BEHAVIOR SCALE - PART A}

Directions: The purpose of this scale is to determine the extent of collaboration behaviors that generally exist between you and the physicians with whom you work. (For each statement check $(\sqrt{ })$ the one box that indicates how often you believe that each behavioral statement occurs.) There are no right or wrong answers. Please answer each item as best as you can.

\begin{tabular}{|c|c|c|c|c|}
\hline & $\begin{array}{c}\text { Rarely } \\
1\end{array}$ & $\begin{array}{c}\text { Sometimes } \\
2\end{array}$ & $\begin{array}{l}\text { Offen } \\
3\end{array}$ & $\begin{array}{c}\text { Nearly Always } \\
\qquad 4\end{array}$ \\
\hline $\begin{array}{l}\text { 1. We feel free to share ideas with one } \\
\text { another. }\end{array}$ & & & & \\
\hline $\begin{array}{l}\text { 2. We acknowledge one another's } \\
\text { competence. }\end{array}$ & & & & \\
\hline $\begin{array}{l}\text { We support each other as team } \\
\text { members. }\end{array}$ & & & & \\
\hline 4. We work as partners. & & & & \\
\hline $\begin{array}{l}\text { We are committed to working } \\
\text { together as a team. }\end{array}$ & & & & \\
\hline 6. We trust each one another. & & & & \\
\hline $\begin{array}{l}\text { 7. There is a sharing of expertise and } \\
\text { talents between us. }\end{array}$ & & & & \\
\hline $\begin{array}{l}\text { 8. We work as "equals" or "partners" } \\
\text { for the accomplishment of some } \\
\text { goals. }\end{array}$ & & & & \\
\hline 9. We work together as a team. & & & & \\
\hline 10. My opinions are listened to. & & & & \\
\hline 11. I feel that my input is truly valued. & & & & \\
\hline 12. We work together as associates. & & & & \\
\hline $\begin{array}{l}\text { 13. There is a feeling of mutual regard } \\
\text { and respect. }\end{array}$ & & & & \\
\hline $\begin{array}{l}\text { 14. We make an effort to resolve any } \\
\text { conflicts which arise to our mutual } \\
\text { satisfaction. }\end{array}$ & & & & \\
\hline $\begin{array}{l}\text { 15. We both actively participate in the } \\
\text { relationship in order to meet our } \\
\text { patient care goals. }\end{array}$ & & & & \\
\hline $\begin{array}{l}\text { 16. We share information openly with } \\
\text { one another. }\end{array}$ & & & & \\
\hline
\end{tabular}


17. We problem solve together.

18. We recognize the need to have a sense of "give and take" in the relationship.

19. We recognize our interdependence with one another in order to meet our goals.

20. We are committed to the process of working together to meet our goals.

\section{Used with permission: Stichler} jstichler@aol.com

PO Box 28278, San Diego, CA 92198 
Appendix E

Assessment of Nursing Care Scale

Copyrighted questionnaire

Modified and used with permission from Dr. Mary R. Lynn

Lynn, M. R., McMillen, B. J., \& Sidani, S. (2007a). Including the provider in the assessment of quality care. Journal of Nursing Care Quality, 22, 328-336. 


\section{Appendix F}

Moral Distress Scale - Revised, Pediatric Version

Copyrighted questionnaire

Used with permission from Dr. Ann Baile Hamric

Hamric, A. B., Borchers, C. T., \& Epstein, E. G. (2012). Development and testing of an instrument to measure moral distress

in healthcare professionals. AJOB Primary Research, 3(2), 1-9. 
Appendix G

General Questions About You

1. What is your date of birth (Month/Year)?

2. Are you (Check)

a Female

a Male

3. Ethnicity (Check one)

a Hispanic or Latino

- Not Hispanic or Latino

4. Race (Check all that apply)

- Asian

- Black or African American

- White or Caucasian

- Native Hawaiian or other Pacific Islander

- Native Alaskan/American Indian

5. How many years have you been a registered nurse?

6. How many years have you worked as a pediatric oncology nurse?

7. Are you currently a direct care provider?

a Yes

a No

8. What percentage of your time is spent caring for children with cancer?

口 $0-25 \%$

$26-50 \%$

$51-75 \%$

ㄱ $76-100 \%$

9. What is your highest education level achieved?

- Associate Degree in Nursing

- Bachelor of Science in Nursing

- Master of Science in Nursing

- Doctoral Degree (PhD or DNP)

口 Other 
10. What is your primary position?

a Staff nurse

- Nurse coordinator

- Educator

- Nurse administrator (Director/Supervisor/Manager)

- Clinical Nurse Specialist

- Nurse Practitioner

- Researcher

11. What is your primary practice area?

口 Inpatient hospital setting

- Outpatient setting

- Both inpatient and outpatient

- Other (please describe):

12. What state do you live in?

13. How much formal training or education have you had regarding talking with patients and/or parents about prognosis-related information?

- None or almost none

- A little bit

- A moderate amount

- A great deal 
Appendix H: Manuscript

Newman, A. R., Faut-Callahan, M., Lerret, S. M., Oswald, D. L., \& Weiss, M. E. (2017). Pediatric Oncology Nurses' Experiences with Prognosis-Related Communication. In review.

\begin{abstract}
Purpose: To examine nurses' experiences of prognosis-related communication (PRC) with parents of children with cancer.

Design: Cross-sectional, correlational.

Setting: Online survey.

Sample: 316 pediatric oncology nurses.

Methods: Online survey including study instruments completed by members of the Association of Pediatric Hematology/Oncology Nurses.

Main Research Variables: Individual nurse factors, PRC, interprofessional collaboration, moral distress, perceived quality of care

Findings: Nurses strongly agreed that prognostic disclosure is critical for decision making, but are challenged in determining their role. Nurses who had more years of experience, more training in PRC, worked outpatient or inpatient/outpatient, and indicated higher levels of nurse-physician collaboration reported more positive experiences with PRC. Communication and collaboration were significantly associated with quality of care and nurse moral distress.

Conclusions: Nurses are intimately involved in the process of PRC, but are often unsure of their role and uncomfortable discussing aspects of prognosis. Education in PRC should empower nurses with knowledge and strategies to promote effective collaboration with physician colleagues.

Implications for Nursing: Nurses should work to be active participants in the process of PRC by collaborating with physician colleagues. When nurses sense that prognostic discussions have not occurred or if clarity is needed, nurses should feel confident in approaching physician colleagues to ensure parent understanding and satisfaction around communication.
\end{abstract}

\title{
Knowledge Translation:
}

- While not always acknowledged, pediatric oncology nurses are active participants in the process of prognosis-related communication (PRC).

- Interprofessional education and training are required to articulate and enhance the role of the nurse in PRC.

- An environment which supports nurse-physician collaboration will improve the process of PRC.

- Improved experiences of PRC have the potential to reduce nurse moral distress and enhance the quality of patient care.

Key Words: prognosis-related communication, collaboration, moral distress, quality of care 


\section{Introduction}

Healthcare providers (HCPs) specializing in pediatric oncology are faced with the challenge of communicating with children and their parents the devastating news of a cancer diagnosis and its associated prognosis (Mack, Wolfe, Grier, Cleary, \& Weeks, 2006). Prognostic information incorporates the revelation of likelihood of cure, how long the child is anticipated to live, and the kind of life the child is expected to have (Mack et al., 2006). This type of communication is referred to as prognosis-related communication $(P R C)$.

PRC has been found to enhance decision making by patients and parents, reduce uncertainty, engender hope, and empower patients to live their lives (Butow, Dowsett, Hagerty, \& Tattersall, 2002; Lamont \& Christakis, 2003; Mack \& Joffe, 2014). Lack of prognostic disclosure can result in stress, frustration, and uncertainty among patients and families (Innes \& Payne, 2009). Forgoing prognosis-related discussions can lead to false optimism and significant discrepancies between patient and physician estimates of survival. Such discrepancies may prompt patients and families to pursue futile care that may impact quality of life, delay referral for palliative care services, and limit end-of-life care planning (Hancock et al., 2007; Innes \& Payne, 2009). Finally, lack of disclosure can leave patients and families feeling abandoned by their providers, mistrustful of their healthcare team, and less hopeful (Innes \& Payne, 2009; Mack et al., 2007).

Disclosure of prognosis-related information is a process that involves numerous conversations among patients, families, and HCPs. The initial disclosure of prognostic information is generally considered the purview of the physician (Dewar, 2000). Patients and family members may have limited recall of what was presented during such 
discussions, and then turn to the nursing staff for clarification of the information presented (Dewar, 2000; Rassin et al., 2006). If it is unclear as to what has been communicated, the nurse may limit communication with the patient in an attempt not to convey information different from previous presentations by the physician (Helft, Chamness, Terry, \& Uhrich, 2011). This lack of communication can affect the patient and have a negative impact on the nurse, resulting in the development of moral distress (Tobin, 2012). Moral distress occurs when the nurse is clear about the ethically indicated course of action, but feels constrained in taking such action (Hamric \& Blackhall, 2007). Repeated exposure to experiences of moral distress can increase the risk of burnout, withdrawal from moral dimensions of patient care, and intention to leave the nursing field (Hamric, Borchers, \& Epstein, 2012).

Nurses caring for patients with life-limiting illnesses at times report a lack of collaboration with their physician colleagues in regards to PRC (Reinke, Shannon, Engelberg, Young, \& Curtis, 2010). Interprofessional collaboration is a critical aspect of healthcare teams, and can have a significant impact on patients, families, and members of the healthcare team. Previous research demonstrated that nurse perceptions of nursephysician collaboration are associated with a reduced risk of negative patient outcomes (death or readmission to the ICU) (Baggs et al., 1999), physician and nurse satisfaction with patient care quality, and levels of moral distress (Hamric \& Blackhall, 2007).

Research targeting PRC in the pediatric oncology population is limited, and the nurse's experience with the process is glaringly absent. This study served to address this gap by exploring factors associated with pediatric oncology nurses' experiences with PRC and the potential relationship to the care they provide to patients. Specifically, the 
aims of the study were to 1) examine nurses' experiences with PRC with parents of children with cancer; 2) determine associations among individual nurse factors, nurse perceptions of PRC, and interprofessional collaboration; and 3) determine if individual nurse factors, nurse perceptions of PRC, and interprofessional collaboration are associated with quality of care and moral distress in the context of provider-parent communication regarding prognosis.

\section{Theoretical Framework}

The Quality-Caring Model@ created by Duffy and Hoskins (2003) provided the conceptual foundation for the proposed research. The Quality-Caring Model(C) aims to unveil the impact of caring nursing processes on outcomes within the complex healthcare environment. The three major components of the model are structure/causal past, process/caring relationships, and outcomes/future. Each of these components is represented in the study and operationalized as study variables as presented in Table 1.

\section{Materials and Methods}

\section{Design}

A cross-sectional, correlational design was used to explore pediatric oncology nurses' experiences with PRC with parents of children with cancer. Participants responded to an email request for participation, and completed an online survey that included all of the study instruments.

\section{Hypotheses}

Hypotheses displayed in the study model (Figure 1) include:

- Individual nurse factors (more years of experience in pediatric oncology, a Master's degree or higher, practicing in an outpatient setting, and previous formal 
training in PRC) will be associated with more positive scores on the PrognosisRelated Communication in Oncology Nursing (PRCON) scale (H1) and Collaborative Behavior Scale (CBS)-Part A [RN-MD Communication] (H2); PRCON and CBS will be positively correlated (H3);

- Individual nurse factors as well as more positive scores on the PRCON and CBS will be associated with higher levels of nurse perceived quality of care as measured by the Nurses’ Assessment of Quality Scale - Acute Care Version (NAQS-ACV) (H4) and reduced levels of moral distress as measured by the Moral Distress Scale - Revised (MDS-R) pediatric version (H5); NAQS-ACV and MDS-R will be negatively correlated (H6).

\section{Sample/Participants}

Participants were recruited from the membership roster of the Association of Pediatric Hematology/Oncology Nurses (APHON), a national association of 3,600 nurses and other healthcare professionals.

A priori power analysis using $\mathrm{G}^{*}$ Power software (Faul, Erdfelder, Lang, \& Buchner, 2007) for a regression model with a maximum of 6 predictors with an effect size of 0.15 , significance level of 0.05 , and $80 \%$ power, resulted in a sample size estimate of 98 respondents. In an effort to ensure adequate power and representation from a broad national sample, a goal of 300 respondents was established. A similar study of adult oncology nurses achieved a $29 \%$ response rate with a single postal mailing (Helft et al., 2011).

\section{Measures}


Individual nurse factors. Individual nurse factors identified as possible predictors of process and outcome variables included years of experience in pediatric oncology nursing, level of education, practice setting, and formal training in PRC. For regression analyses, three of the variables were dichotomized: education ( $0=$ diploma, associate, or Bachelor's degree; 1=Master's or doctoral degree); practice setting $(0=$ inpatient; $1=$ outpatient or inpatient/outpatient $)$; and PRC training $(0=$ none or a little bit; 1=moderate amount or great deal).

Prognosis-Related Communication in Oncology Nursing Scale. The PRCON scale (Newman \& Helft, 2015) is designed to characterize nurses' experiences with PRC. Items are rated on a 4-point Likert scale indicating level of agreement, with "1" representing "Strongly Disagree" and "4" representing "Strongly Agree." The instrument contains 3 subscales: MD Communication, RN Role, and Decision Making. Both composite and subscale scores can be generated. A Cronbach's alpha coefficient of 0.75 was previously reported in an adult oncology nurse sample with subscale reliability estimates ranging from 0.76 to 0.84 (Newman \& Helft, 2015).

Collaborative Behavior Scale. The CBS (Stichler, 1989) is designed to determine the extent of collaborative behaviors between nurses and physicians on the respondent's unit. Responses are rated on a 4-point Likert scale, specifying the frequency of listed behaviors from "1" (Rarely) to "4" (Nearly Always). Scores are summed for one composite score with higher totals indicating more collaborative relationships. The instrument has exhibited robust internal reliability with estimates ranging from 0.96 (Stichler, 1990) to 0.98 (Almost \& Laschinger, 2002). 


\section{Nurses' Assessment of Quality Scale - Acute Care Version. The NAQS-ACV}

(Lynn, McMillen, \& Sidani, 2007) documents nurses' evaluations of the process of nursing care. The instrument has three sections: nursing care and relationships between the nurse and the patient, acute care working environments, and intrinsic characteristics of the nurse. The first section was used in this study as recommended when the patient is the unit of analysis rather than the nursing unit. This section contains four subscales, which are labelled as Interaction, Vigilance, Individualization, and Advocate. The scale's wording was modified with permission to apply to the parents of pediatric oncology patients. The 4-point Likert scale was summed for a composite score. Subscale scores were also calculated. Cronbach's alpha has previously been reported as ranging from 0.88 to 0.94 for the subscales (Lynn et al., 2007).

Moral Distress Scale - Revised, Pediatric Version. The MDS-R (Hamric et al., 2012) was developed as a measure of levels of moral distress among healthcare professionals. Parallel versions of the instrument now exist for nurses, physicians, and other HCPs in adult and pediatric settings. Scale items are based on moral dilemmas that present in the healthcare environment. Each of the items is scored in terms of how often the situation arises (frequency) and how disturbing the situation is when it arises (intensity). Composite scores are calculated as the sum of item frequency multiplied by intensity score. Cronbach's alpha estimates have been reported at 0.90 for RNs in a large healthcare system (Whitehead, Herbertson, Hamric, \& Fisher, 2015), and 0.96 in a sample of Italian pediatric oncology nurses (Lazzarin, Biondi, \& Di Mauro, 2012). 


\section{Data Collection}

Prior to data collection, the study protocol was submitted to the university Institutional Review Board of the principal investigator and received an exempt determination. Data collection occurred between April and June of 2016. Emails with an invitation to participate and a weblink to the survey using SurveyMonkey® were sent to all APHON members through the APHON office. Email invitations were repeated two and six weeks later. The survey included the four study instruments and a demographic questionnaire. At the end of the survey, respondents were offered the opportunity to receive a five-dollar gift card to thank them for their time.

\section{Data Analysis}

Data obtained from the web-based survey were exported to SPSS, Version 24. Missing data were analyzed using the Missing Values Analysis (MVA) function in SPSS to assess the extent of missing values for each item as well as the amount of missingness within each case. Case mean substitution, using the participant's scale or subscale mean, was used if less than $25 \%$ of the items were missing in a scale. Specific Aim 1 was analyzed by examining composite and subscale scores from the PRCON. For Specific Aim 2, analyses of Hypotheses 1 through 3 used multiple regression and correlation. For Specific Aim 3, analyses for Hypotheses 4 through 6 employed hierarchical multiple regression and correlation.

\section{Results}

Out of the approximately 3600 emails sent to APHON members, a total of 330 nurses agreed to participate in the survey with 316 completing a minimum of at least one of the survey instruments. Table 2 summarizes demographic characteristics of the 
sample. The vast majority of respondents (98\%) were female with a mean age of 44.1 years. Approximately 50\% of the nurses had a Bachelor's degree, and $41 \%$ had a Master's degree or higher. On average, nurses in the sample had worked as a nurse for 19 years and as a pediatric oncology nurse for 15.7 years. Most respondents worked fulltime as bedside nurses $(43.4 \%)$, providing direct patient care in both the inpatient and outpatient settings. Responses came from throughout the United States. Thirty percent of nurses had received a moderate to great deal of training in PRC.

Instrument composite and subscale scores were calculated (Table 3 ). The mean composite PRCON score was just beyond the midpoint (52.2 on scale of 20-80), indicating both positive and negative experiences with PRC. Nurses scored the highest on the Decision Making subscale with an item mean of 3.2. Scores on the MD Communication subscale fell just above the midpoint with an item mean of 2.6. Lowest scores were found on the RN Role subscale with the item mean falling below the midpoint at 2.3. Mean CBS scores were in the third quartile, signifying frequent collaboration with physician colleagues. Mean total and subscale scores on the NAQS$\mathrm{ACV}$ were at the higher end of the scale with the highest scores reported on the Interaction subscale. Finally, the mean composite score on the MDS-R was in the bottom quartile, indicating low levels of moral distress. Mean score on the MDS-R Frequency scale was also low, but mean score on the MDS-R Intensity scale was high.

The regression model for the association between individual nurse factors with PRCON (H1) explained $17.4 \%$ of the variance in PRCON composite scores, $F(4,294)=$ $15.45, p<.001$. Three individual nurse factors were significant predictors: years of experience in pediatric oncology nursing $(\beta=.18, p=.002)$, outpatient or both inpatient 
and outpatient practice location $(\beta=.26, p<.001)$, and a moderate to great deal of training in $\operatorname{PRC}(\beta=.14, p=.01)$.

The regression model for the association of individual nurse factors with CBS (H2) explained $8.1 \%$ of the variance in CBS composite scores, $F(4,305)=6.73, p=0<$ .001 . Two of the individual nurse factors were significant predictors: outpatient or both inpatient and outpatient practice location $(\beta=.15, p=0.008)$ and a moderate to great deal of previous training in $\operatorname{PRC}(\beta=.12, p=0.04)$.

Composite scores on PRCON and CBS were positively correlated (H3), $r=.48, p$ $<.001$; nurses reporting more positive experiences with PRC also reported more collaborative relationships with physicians. The strongest correlation existed between the MD Communication subscale and the CBS, $r=0.52, p<.001$. The RN Role subscale was also significantly correlated with CBS score, $r=0.25, p<.001$.

In the hierarchical regression analysis assessing the association of PRCON and CBS with NAQS-ACV (H4), individual nurse factors were entered as Step 1 and PRCON and CBS in Step 2 (Table 4). Previous training in PRC was the only individual nurse factor found to be predictive in the initial step of the model $(\beta=.13, p<.05)$. In the final model, the total variance explained by the model was $18.7 \%, F(6,278)=10.69, p<$ .001 . Nurse factors, specifically previous training in PRC, explained only $3 \%$ of the total variance in NAQS-ACV scores. Only two of the predictors were statistically significant in the final model: $\operatorname{PRCON}(\beta=.28, p<.001)$ and $\operatorname{CBS}(\beta=.23, p<.001)$.

The same hierarchical regression approach was used to examine MDS-R as the outcome variable (H5). None of the individual nurse factors entered at Step 1 were found to be significant predictors of MDS-R. The total variance explained by the model as a 
whole was $16.1 \%, F(6,258)=8.24, p<.001$ (Table 5). As with the final model

predicting NAQS-ACV, CBS $(\beta=-.31, p<.001)$ and $\operatorname{PRCON}(\beta=-.19, p=0.01)$ were significant predictors.

Finally, the relationship between NAQS-ACV and MDS-R composite scores was explored (H6). A small, but significant negative correlation was found between the two variables, $r=-.16, \mathrm{n}=266, p=0.01$, indicating an inverse relationship between perceptions of care quality and nurse moral distress. Correlation between MDS-R and NAQS-ACV subscale scores were all similar $(r=-.11$ to -.18$)$.

The summary model of relationships among study variables is presented in Figure 1.

\section{Discussion}

Descriptive analyses of the PRCON and subscale scores point to the importance that nurses place on PRC in decision making, but suggest mixed perceptions of MD communication and challenges in determining the nurse's role in the process. Nurses agreed that PRC is critical to decision making, which is consistent with the sentiments of parents of children with relapsed or refractory cancer (Nyborn, Olcese, Nickerson, \& Mack, 2016). While nurses believe that their physician colleagues are generally skilled at these conversations, they indicated that such discussions often do not occur early enough in the disease process, and that nurses are not always informed when such critical conversations occur.

Nurses scored lowest on the RN Role subscale of the PRCON, indicating lack of comfort and, at times, unwillingness to discuss prognosis-related concerns with parents. Nurses strongly agreed that prognostic disclosure is the responsibility of the physician, 
which is consistent with findings from other studies (Hjelmfors, Stromberg, Friedrichsen, Martensson, \& Jaarsma, 2014; Huang et al., 2014; RioValle et al., 2009). Interestingly, most nurses agreed that answering questions regarding prognosis-related information was within their scope of practice, but despite this, reported feeling uncomfortable providing life expectancy estimates if asked and did not believe that discussing estimated life expectancy was the nurse's role. This discordance has also been documented in adult oncology and critical care nurses (Anderson et al., 2016; Helft et al., 2011).

The second aim of the study explored the relationships among individual nurse factors, nurse perceptions of PRC, and interprofessional collaboration. Individual nurse factors explained a small, but significant portion of the variance in PRCON (17.4\%) and CBS scores (8\%). Formal training in PRC was associated with both, pointing to an opportunity for focused training to improve communication and collaboration. Nurses who had more training reported better experiences and greater comfort with PRC. These findings are echoed by Milic et al. (2015) who implemented an 8-hour workshop for critical care nurses, training them in the skills necessary for engaging patients, families, and physicians in discussions about prognosis and goals of care. Upon completion of the workshop and 3 months later, nurses reported improved understanding of their roles and responsibilities as well as increased skills and confidence in participating in such discussions.

Findings also suggest that collaboration between nurses and physicians is a critical part of PRC. Nurses within this study sample generally viewed relationships with their physician colleagues positively as evidenced by higher scores on the CBS. Such scores were also significantly correlated with higher scores on the PRCON, suggesting 
more collaborative relationships result in more comfort and experience with PRC among nurses. When physicians are more skilled in PRC and are inclusive of the nurse in such conversations, interprofessional collaboration is enhanced. The results are consistent with past research demonstrating an inextricable link between communication and successful nurse-physician collaboration (Tang, Chan, Zhou, \& Liaw, 2013). Unfortunately, perceived hierarchies within the healthcare professions still exist, and physicians often view themselves as singular decision makers without considering the nurse's viewpoint (Lancaster, Kolakowsky-Hayner, Kovacich, \& Greer-Williams, 2015). Such an approach can create a significant barrier to optimal PRC.

The final aim explored factors associated with quality of care and moral distress. Since 2001 when the Institute of Medicine published Crossing the Quality Chasm, an increased emphasis has been placed on healthcare systems and providers to take more responsibility for the quality of their practice (Burhans \& Alligood, 2010). In the current study, nurses reported the provision of high-quality nursing care to pediatric oncology patients and their families. Consistent with reports from Djukic, Kovner, Brewer, Fatehi, and Cline (2013) and Ryan et al. (2016), communication and collaboration were identified as playing key roles in care quality. Identifying modifiable factors that have the potential to improve the quality of patient care is critical as a perceived inability to provide quality care can have a negative impact on both the patient and the nurse (Williams, 1998). Lack of quality nursing care can limit a patient's return to wellness, compromise safety, and reduce satisfaction. In addition, the perception of poor care quality can leave nurses feeling dissatisfied and stressed, which can result in frustration 
and guilt. Such feelings can limit the nurse's ability to provide therapeutically effective care. Repeated inability to provide a desired level of care can result in moral distress.

Overall, nurses reported low levels of moral distress. Nurses infrequently experienced morally distressing situations, but when they did, the situations themselves tended to be moderately to greatly distressing. Nurses were most distressed when they were unable to provide the high level of quality, compassionate care they believed the child and family required, as evidenced by a negative correlation between NAQS-ACV and MDS-R. A negative relationship was also found for MDS-R with PRCON and CBS; improved experiences of PRC and higher levels of nurse-physician collaboration were associated with lower levels of nurse moral distress. Improving communication and collaboration appears to have the ability to minimize moral distress among pediatric oncology nurses. This is crucial as more frequent exposure to distressing situations can result in emotional exhaustion and depersonalizing interactions with patients; both of which are components of burnout syndrome (Allen et al., 2013; Oh \& Gastmans, 2013). Like the perception of poor quality care, moral distress can leave nurses feeling angry and frustrated, limiting their ability to cope with the challenges of oncology nursing practice. This inability to cope leads some nurses to consider leaving their job or the nursing profession altogether.

Future research should aim to develop and test strategies to enhance communication and interprofessional collaboration. First steps include examining the views of physicians and parents regarding the nurse's role in the process of PRC, and how through this process, the nurse can improve targeted patient and family outcomes. The impact of interprofessional education focused on PRC should be explored in an 
effort to improve collaboration, enhance quality of care, and reduce distress among staff. Empowering nurses to engage more fully and confidently in the process of PRC as well as nurse-physician collaboration has the potential to contribute to improved healthcare team performance resulting in improved quality of care and patient and family outcomes.

\section{Implications for Nursing}

Study findings suggest that nurses should work to be more actively involved in PRC, seeking out their physician and advanced practice colleagues to identify when critical conversations will take place. Nurses can request clarification of prognostic information when needed, and indicate an interest in participating in prognostic-related discussions. Following such discussions, nurses can aim to support patients and families by determining their understanding of the information presented and recognizing when confusion or conflict may be present.

\section{Limitations}

Generalizability is limited because of the homogeneity of the sample. Although the large sample is representative of nurses from across the United States, respondents were members of a professional organization, and 30\% had previous training in PRC. Also, the response rate was less than that of a similar study with adult oncology nurses (Helft et al., 2011). The reason for the low response rate in this study is unknown.

While the instruments used had prior evidence supporting reliability and validity, several of them, particularly the PRCON and the NAQS-ACV, have been used in a limited fashion and not with pediatric oncology nurses. Instructions and items on the NAQS-ACV were revised to be consistent with the population under investigation. In addition, generation of a composite score on the first section of the NAQS-ACV has not 
been previously reported. Despite this, both instruments demonstrated good reliability with the current sample.

All of the instruments captured the perceptions of nurses' experiences, and therefore may not be reflective of observable behaviors. PRC is a process experienced by patients, family members, physicians, and other healthcare team members. This study represents only one perspective. Further, the study does not link directly to patient/parent outcomes, but uses the nurse's perception of quality as a surrogate. Finally, as a crosssectional design, the results of this study do not infer causality.

\section{Conclusion}

As front-line caregivers, nurses are intimately involved with PRC. Nurses are often unsure of their role and uncomfortable with some of the questions asked during these conversations with patients and families. More years of experience in pediatric oncology, training in PRC, outpatient practice setting, and strong interprofessional collaboration with physician colleagues are all associated with better experiences with the process. When interprofessional collaboration is poor or past experiences with PRC are viewed negatively, quality of care can be compromised, and moral distress may develop. Pediatric oncology nurses should aim to be more active and proactive participants in the process and engage their physician colleagues to collaborate. Nurses with more years of experience can serve as mentors and role models to novice nurses in regards to nursephysician collaboration and PRC. As the providers who spend the most time with patients and families, pediatric oncology nurses must be empowered to participate in PRC in a meaningful way to ensure optimal patient and family outcomes and team functioning. 
Table 1. Linkages between Quality-Caring Model $\mathbb{C}$ Components, Study Variables, and Study Measures

\begin{tabular}{|c|c|c|c|}
\hline $\begin{array}{l}\text { Quality-Caring } \\
\text { Model }\end{array}$ & $\begin{array}{c}\text { Structure/Causal } \\
\text { Past }\end{array}$ & $\begin{array}{c}\text { Process/Caring } \\
\text { Relationships }\end{array}$ & Outcomes/Future \\
\hline Study concepts & $\begin{array}{l}\text { Individual nurse } \\
\text { factors }\end{array}$ & $\begin{array}{l}\text { Nurse Perceptions of } \\
\text { PRC } \\
\text { Interprofessional } \\
\text { Collaboration }\end{array}$ & $\begin{array}{l}\text { RN: Moral Distress } \\
\text { Patient/Family: } \\
\text { Perceived Quality of } \\
\text { Patient Care }\end{array}$ \\
\hline $\begin{array}{l}\text { Study } \\
\text { variables }\end{array}$ & $\begin{array}{l}\text { Demographic } \\
\text { information } \\
\text { (experience, level of } \\
\text { education, practice } \\
\text { setting, formal } \\
\text { training in PRC) }\end{array}$ & $\begin{array}{l}\text { PRCON } \\
\text { CBS }\end{array}$ & $\begin{array}{l}\text { MDS-R } \\
\text { NAQS-ACV }\end{array}$ \\
\hline
\end{tabular}

Note. PRCON = PRC in Oncology Nursing; CBS = Collaborative Behavior Scale; MDS-R = Moral Distress Scale-Revised; NAQS-ACV = Nurses' Assessment of Quality Scale-Acute Care Version. 
Figure 1. Model of Relationships Among Study Variables

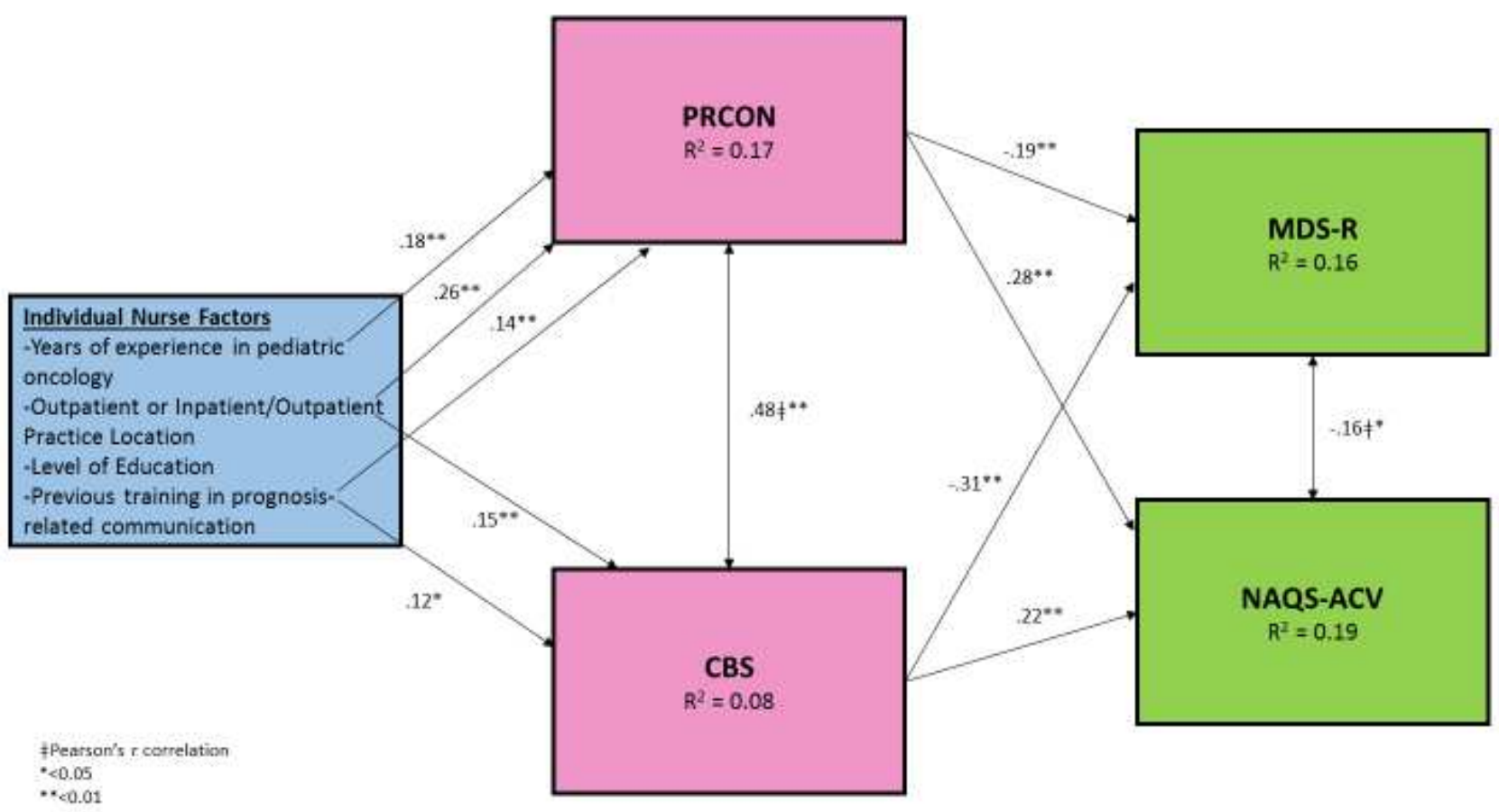


Table 2. Nurse Characteristics

\begin{tabular}{|c|c|c|c|c|c|}
\hline & & Mean & SD & $\mathbf{n}$ & $\%$ \\
\hline Age (years) & & 44.1 & 10.4 & & \\
\hline Years as an RN & & 19.4 & 11.0 & & \\
\hline Years as pediatric oncology nurse & & 15.7 & 9.7 & & \\
\hline \multirow[t]{2}{*}{ Gender $(N=314)$} & Female & & & 306 & 98 \\
\hline & Male & & & 8 & 3 \\
\hline \multirow[t]{5}{*}{ Race $(N=314)$} & White or Caucasian & & & 289 & 92 \\
\hline & Asian & & & 8 & 3 \\
\hline & Black or African American & & & 3 & 1 \\
\hline & Hispanic & & & 1 & 0.3 \\
\hline & Other & & & 13 & 4 \\
\hline \multirow{5}{*}{$\begin{array}{l}\text { Highest Educational Level }(\mathrm{N}= \\
\text { 314) }\end{array}$} & Associate's Degree & & & 22 & 7 \\
\hline & Bachelor's Degree & & & 156 & 49 \\
\hline & Master's Degree & & & 117 & 37 \\
\hline & Doctoral Degree & & & 12 & 4 \\
\hline & Other & & & 7 & 2 \\
\hline \multirow[t]{8}{*}{ Primary Position $(\mathrm{N}=316)$} & Staff nurse & & & 137 & 43 \\
\hline & Nurse practitioner & & & 52 & 17 \\
\hline & Nurse coordinator & & & 45 & 14 \\
\hline & $\begin{array}{l}\text { Nurse administrator } \\
\text { (director/supervisor/manager) }\end{array}$ & & & 22 & 7 \\
\hline & Educator & & & 21 & 7 \\
\hline & Clinical nurse specialist & & & 17 & 5 \\
\hline & Research nurse & & & 16 & 5 \\
\hline & Researcher & & & 6 & 2 \\
\hline \multirow[t]{3}{*}{ Practice Setting $(\mathrm{N}=312)$} & Inpatient & & & 104 & 33 \\
\hline & Outpatient & & & 130 & 42 \\
\hline & Both inpatient and outpatient & & & 78 & 25 \\
\hline \multirow[t]{4}{*}{ Employment Status $(\mathrm{N}=315)$} & Full time & & & 271 & 86 \\
\hline & Part time & & & 39 & 12 \\
\hline & Casual or per diem & & & 4 & 1 \\
\hline & Other & & & 1 & 0.3 \\
\hline \multirow[t]{6}{*}{ Region of practice $(N=303)$} & Midwest & & & 75 & 25 \\
\hline & Southeast & & & 69 & 23 \\
\hline & Northeast & & & 59 & 19 \\
\hline & West & & & 50 & 17 \\
\hline & Southwest & & & 43 & 14 \\
\hline & Alaska/Hawaii & & & 7 & 2 \\
\hline \multirow{4}{*}{$\begin{array}{l}\text { Formal Training in PRC }(\mathrm{N}= \\
\text { 316) }\end{array}$} & A great deal & & & 24 & 8 \\
\hline & A moderate amount & & & 68 & 22 \\
\hline & A little bit & & & 116 & 37 \\
\hline & None or almost none & & & 108 & 34 \\
\hline
\end{tabular}


Table 3. Summary of Scale Statistics

\begin{tabular}{|c|c|c|c|c|c|c|c|}
\hline Scale & $\begin{array}{l}\text { Number } \\
\text { of Items }\end{array}$ & $\begin{array}{c}\text { Possible } \\
\text { Min/Max Scores }\end{array}$ & $\mathbf{N}$ & Scale Mean (SD) & $\begin{array}{c}\text { Range } \\
\text { (Min-Max) }\end{array}$ & Item Mean & $\begin{array}{c}\text { Cronbach's } \\
\text { Alpha }\end{array}$ \\
\hline PRCON & & & & & & Scale $=1-4$ & \\
\hline - $\quad$ Total scale & 20 & $20 / 80$ & 302 & $52.2(6.2)$ & $29-69$ & 2.6 & .75 \\
\hline - $\quad$ RN Role & 8 & $8 / 32$ & 290 & $18.3(4.1)$ & $8-31$ & 2.3 & .84 \\
\hline - MD Communication & 8 & $8 / 32$ & 285 & $21.0(3.9)$ & $8-30$ & 2.6 & .80 \\
\hline - Decision Making & 4 & $4 / 16$ & 299 & $13.0(2.1)$ & $4-16$ & 3.2 & .79 \\
\hline CBS & & & & & & Scale $=1-4$ & \\
\hline & 20 & $20 / 80$ & 316 & $64.7(13.3)$ & $24-80$ & 3.2 & .98 \\
\hline NAQS-ACV & & & & & & Scale $=1-4$ & \\
\hline - Total Scale & 45 & $45 / 180$ & 291 & $153.4(16.8)$ & $124-180$ & 3.4 & .98 \\
\hline - Interaction & 19 & $19 / 76$ & 291 & $66.8(7.5)$ & $55-76$ & 3.5 & .96 \\
\hline - Vigilance & 10 & $10 / 40$ & 291 & $32.4(4.2)$ & $19-140$ & 3.2 & .91 \\
\hline - Individualization & 6 & $6 / 24$ & 291 & $19.9(2.5)$ & $14-24$ & 3.3 & .85 \\
\hline - $\quad$ Advocate & 10 & $10 / 40$ & 291 & $34.3(4.2)$ & $24-40$ & 3.4 & .94 \\
\hline MDS-R & & & & & & Scale $=0-4$ & \\
\hline - Summed Scale Score & 21 & $0 / 336$ & 268 & $63.9(37.8)$ & $0-222$ & 3.0 & .89 \\
\hline - $\quad$ Frequency & 21 & $0-84$ & 279 & $20.5(10.3)$ & $1-60$ & 1.0 & .87 \\
\hline - Intensity & 21 & $0-84$ & 269 & $67.4(13.6)$ & $0-84$ & 3.2 & .94 \\
\hline
\end{tabular}


Table 4. Summary of Hierarchical Regression Analysis for Variables Predicting Scores on NAQS-ACV \& MDS-R

\begin{tabular}{|c|c|c|c|c|}
\hline \multicolumn{5}{|c|}{ NAQS-ACV } \\
\hline Variable & $\beta$ & $\mathbf{F}$ & $\mathbf{R 2}$ & $\Delta \mathbf{R} 2$ \\
\hline Step 1 & & 2.2 & .03 & .03 \\
\hline Education level & .08 & & & \\
\hline Practice location & -.02 & & & \\
\hline Previous training in PRC & $.13^{*}$ & & & \\
\hline $\begin{array}{l}\text { Years of experience in } \\
\text { pediatric oncology }\end{array}$ & .05 & & & \\
\hline Step 2 & & $10.7 * *$ & .19 & .16 \\
\hline Education level & .04 & & & \\
\hline Practice location & -.11 & & & \\
\hline Previous training in PRC & .08 & & & \\
\hline $\begin{array}{l}\text { Years of experience in } \\
\text { pediatric oncology }\end{array}$ & -.02 & & & \\
\hline CBS Scale Score & $.23^{* *}$ & & & \\
\hline PRCON Scale Score & $.28 * *$ & & & \\
\hline \multicolumn{5}{|c|}{ MDS-R } \\
\hline Variable & $\boldsymbol{\beta}$ & $\mathbf{F}$ & $\mathbf{R 2}$ & $\Delta \mathbf{R 2}$ \\
\hline Step 1 & & .43 & .01 & .01 \\
\hline Education level & -.02 & & & \\
\hline Practice location & -.08 & & & \\
\hline Previous training in PRC & .08 & & & \\
\hline $\begin{array}{l}\text { Years of experience in } \\
\text { pediatric oncology }\end{array}$ & .10 & & & \\
\hline Step 2 & & $8.2^{* *}$ & .16 & .16 \\
\hline Education level & .04 & & & \\
\hline Practice location & .02 & & & \\
\hline Previous training in PRC & .08 & & & \\
\hline $\begin{array}{l}\text { Years of experience in } \\
\text { pediatric oncology }\end{array}$ & .10 & & & \\
\hline CBS Scale Score & $-.31 * *$ & & & \\
\hline PRCON Scale Score & $-.18^{*}$ & & & \\
\hline
\end{tabular}




\section{References}

Allen, R., Judkins-Cohn, T., deVelasco, R., Forges, E., Lee, R., Clark, L., \& Procunier, M. (2013). Moral distress among healthcare professionals at a health system. JONA'S Healthcare Law, Ethics and Regulation, 15(3), 111-118.

Almost, J., \& Laschinger, H. J. S. (2002). Workplace empowerment, collaborative work relationships, and job strain in nurse practitioners. Journal of the American Academy of Nurse Practitioners, 14, 408-420.

Anderson, W. G., Puntillo, K., Boyle, D., Barbour, S., Turner, K., Cimino, J., . . . Grywalski, M. (2016). ICU bedside nurses' involvement in palliative care communication: A multicenter survey. Journal of Pain and Symptom Management, 51, 589-596.

Baggs, J. G., Schmitt, M. H., Mushlin, A. I., Mitchell, P. H., Eldredge, D. H., Oakes, D., \& Hutson, A. D. (1999). Association between nurse-physician collaboration and patient outcomes in three intensive care units. Critical Care Medicine, 27, 19911998.

Burhans, L. M. \& Alligood, M. R. (2010). Quality nursing care in the words of nurses. Journal of Advanced Nursing, 66(8), 1689-1697. doi: 10.1111/j.13652648.2010.05344.x

Butow, P. N., Dowsett, S., Hagerty, R., \& Tattersall, M. H. N. (2002). Communicating prognosis to patients with metastatic disease: What do they really want to know? Supportive Care in Cancer, 10, 161-168.

Dewar, A. (2000). Nurses' experiences in giving bad news to patients with spinal cord injuries. Journal of Neuroscience Nursing, 32, 324-330. 
Djukic, M., Kovner, C. T., Brewer, C. S., Fatehi, F. K., \& Cline, D. D. (2013). Work environment factors other than staffing associated with nurses' ratings of patient care quality. Health Care Management Review, 38(2), 105-114.

Duffy, J. R., \& Hoskins, L. M. (2003). The Quality-Caring ModelC: Blending dual paradigms. Advances in Nursing Science, 26(1), 77-88.

Faul, F., Erdfelder, E., Lang, A. G., \& Buchner, A. (2007). G*Power 3: A flexible statistical power analysis program for the social, behavioral, and biomedical sciences. Behavior Research Methods, 39, 175-191.

Hamric, A. B., \& Blackhall, L J. (2007). Nurse-physician perspectives on the care of dying patients in intensive care units: Collaboration, moral distress, and ethical climate. Critical Care Medicine, 35, 422-429.

Hamric, A. B., Borchers, C. T., \& Epstein, E. G. (2012). Development and testing of an instrument to measure moral distress in healthcare professionals. AJOB Primary Research, 3(2), 1-9.

Hancock, K., Clayton, J. M., Parker, S. M., Walder, S. Butow, P. N., Carrick, S., . . . Tattersall, M. H. N. (2007). Truth-telling in discussing prognosis in advanced lifelimiting illnesses: A systematic review. Palliative Medicine, 21, 507-517.

Helft, P. R., Chamness, A., Terry, C., \& Uhrich, M. (2011). Oncology nurses' attitudes toward PRC. Oncology Nursing Forum, 38, 468-474.

Hjelmfors, L., Stromberg, A., Friedrichsen, M., Martensson, J., \& Jaarsma T. (2014). Communicating prognosis and end-of-life care to heart failure patients: A survey of heart failure nurses' perspectives. European Journal of Cardiovascular Nursing, 13, 152-161. 
Huang, S., Tang, F., Liu, C.., Chen, M., Liang, T., \& Sheu, S. (2014). Truth-telling to patients' terminal illness: What makes oncology nurses act individually? European Journal of Oncology Nursing, 18, 492-498.

Innes, S., \& Payne, S. (2009). Advanced cancer patients' prognostic information preferences: A review. Palliative Medicine, 23, 29-39.

Institute of Medicine. Crossing the quality chasm. Washington, DC: The National Academies Press, 2001.

Lamont, E. B., \& Christakis, N. A. (2003). Complexities in prognostication in advanced cancer: "To help them live their lives the way they want to." JAMA, 290, 98-104.

Lancaster, G., Kolakowsky-Hayner, S., Kovacich, J., \& Greer-Williams, N. (2015). Interdisciplinary communication and collaboration among physicians, nurses, and unlicensed assistive personnel. Journal of Nursing Scholarship, 47(3), 275-284.

Lazzarin, M., Biondi, A., \& Di Mauro, S. (2012). Moral distress in nurses in oncology and haematology units. Nursing Ethics, 19(2), 183-195.

Lynn, M. R., McMillen, B. J., \& Sidani, S. (2007). Including the provider in the assessment of quality care. Journal of Nursing Care Quality, 22, 328-336.

Mack, J. W., \& Joffe, S. (2014). Communicating about prognosis: Ethical responsibilities of pediatricians and parents. Pediatrics, 133(Supplement 1), S24-S30.

Mack, J. W., Wolfe, J., Cook, F. E., Grier, H. E., Cleary, P. D., \& Weeks, J. C. (2007). Hope and prognostic disclosure. Journal of Clinical Oncology, 25, 5636-5642.

Mack, J. W., Wolfe, J., Grier, H. E., Cleary, P. D., \& Weeks, J. C. (2006) Communication about prognosis between parents and physicians of 
children with cancer: Parent preferences and the impact of prognostic information. Journal of Clinical Oncology, 24, 5265-5270.

Milic, M. M., Puntillo, K., Turner, K., Joseph, D., Peters, N., Ryan, R., . . Anderson, W. G. (2015). Communicating with patients' families and physicians about prognosis and goals of care. American Journal of Critical Care, 24(4), e56-e64.

Newman, A. R., \& Helft, P. R. (2015). Reliability and validity of a tool to assess oncology nurses' experiences with PRC. Oncology Nursing Forum, 42, 64-73.

Nyborn, J. A., Olcese, M., Nickerson, T., \& Mack, J. W. (2016). “Don't try to cover the sky with your hands": Parents' experiences with prognosis communication about their children with advanced cancer. Journal of Palliative Medicine, 19, 626-631.

Oh, Y., \& Gastmans, C. (2013). Moral distress experienced by nurses: A quantitative literature review. Nursing Ethics. Advance online publication. doi: $10.1177 / 0969733013502803$

Rassin, M., Levy, O., Schwartz, T., \& Silner, D. (2006). Caregivers' role in breaking bad news: Patients, doctors, and nurses' points of view. Cancer Nursing, 29, 302-308.

Reinke, L. F., Shannon, S. E., Engelberg, R. A., Young, J. P., \& Curtis, J. R. (2010). Supporting hope and prognostic information. Journal of Pain and Symptom Management, 39, 982-992.

Rio-Valle, J. S., Caro, M. P. G., Juarez, R. M., Peña, D. P., Vinuesa, A. M., Pappous, A., ... Quintana, F. C. (2009). Bad news for the patient and the family? The worst part of being a health care professional. Journal of Palliative Care, 25(3), 191. 
Ryan, C., Powlesland, J., Phillips, C. Raszewski, R., Johnson, A., Johnson, A., BanksEnorense, K., . . W Welsh, J. (2016). Nurses' perceptions of quality care. Journal of Nursing Care Quality. Advance online publication. doi:

10.1097/NCQ.0000000000000211

Stichler, J.F. (1989). Development and psychometric testing of a collaborative behavior scale. Unpublished manuscript, University of San Diego, Philip Y. Hahn School of Nursing.

Stichler, J.F. (1990). The effects of collaboration, organizational climate, and job stress on job satisfaction and anticipated turnover in nursing. Ann Arbor, MI: University Microfilms, International.

Tang, C. J., Chan, S. W., Zhou, W. T., \& Liaw, S. Y. (2013). Collaboration between hospital physicians and nurses: An integrated literature review. International Nursing Review, 60(3), 291-302.

Tobin, G. A. (2012). Breaking bad news: A phenomenological exploration of Irish nurses' experiences of caring for patients when a cancer diagnosis is given in an acute care facility (Part 1). Cancer Nursing, 35(6), E21-29.

Whitehead, P. B., Herbertson, R. K., Hamric, A. B., Epstein, E. G., \& Fisher, J. M. (2015). Moral distress among healthcare professionals: Report of an institutionwide survey. Journal of Nursing Scholarship, 47(2), 117-125.

Williams, A. M. (1998). The delivery of quality nursing care: A grounded theory study of the nurse's perspective. Journal of Advanced Nursing, 27(4), 808-816. 